\title{
ESTUDIANTES DE CONDICIÓN NOBILIARIA EN LA UNIVERSIDAD DE SANTIAGO DE COMPOSTELA (SIGLOS XVII y XVIII):
} APROXIMACIÓN A SU PERFIL SOCIOLÓGICO*

por

\section{ANTONIO PRESEDO GARAZO}

Instituto de Estudios Gallegos «Padre Sarmiento» (CSIC)

RESUMEN: Durante la Época Moderna, las aulas de la Universidad de Santiago de Compostela estuvieron concurridas por vástagos de casas nobiliarias cuya educación universitaria fue financiada con la intención de que accediesen posteriormente a un cargo en la administración, tanto eclesiástica como civil. En las siguientes páginas se pretende delimitar el perfil sociológico de este sector elitista en el conjunto del colectivo estudiantil. Su reducida presencia entre el estudiantado, aunque más destacada entre los colegiales, se ve compensada por un acercamiento a sus compañeros procedentes de otras familias que se ballan inmersas en procesos de ascenso social. Con ello cobra más fuerza la bipótesis de que la ideología nobiliaria era la imperante entre las clases dominantes en la Galicia del Antiguo Régimen.

PALABRAS Clave: Universidad. Estudiantes. Hidalguía-hidalgos. Nobleza provincial. Reproducción social.

ABSTRACT: The lecture balls of the University of Santiago de Compostela were in part filled with the scions of noble families during the Early Modern period. Their academic education was financed in the bope of subsequently gaining an office in the Church or civil government. What this article tries to address in the following pages is the sociology of this privileged sector in relation to the larger student body. The fact that they were numerically limited among university students -although more numerous among students in the schools - is balanced by their close relations with

* Relación de abreviaturas archivísticas citadas a lo largo del texto: Archivo Histórico Universitario de Santiago (A.H.U.S.), Expedientes Personales (E.P.), Fondo de la Universidad (F.U.), Serie Histórica (S.H.). 
classmates from upwardly mobile families. This gives weight to the bypothesis that noble ideology prevailed within the elites of Galicia during the Ancien Régime.

KeY WORDS: University. Students. Hidalguía. Hidalgos. Provincial nobility. Social reproduction.

\section{Planteamiento inicial y OBjetivos ${ }^{1}$}

La incrustación progresiva de la nobleza provincial gallega en los órganos de gobierno locales durante la Época Moderna, es un tema que todavía no cuenta con una nutrida producción científica, si bien ha sido afrontada de manera parcial e indirecta a través de investigaciones no necesariamente centradas en la temática nobiliaria ${ }^{2}$.

Es un hecho constatado que en las sociedades europeas de Antiguo Régimen, el estamento nobiliario, en su amplio espectro de realidades sociales que alberga, ha funcionado como un referente para el resto de los grupos sociales que aspiran a alcanzar un ascenso socio-político ${ }^{3}$. El ideario socio-cultural de raíz excluyente, la estructura patrimonial que tiende a primar los ingresos en concepto de renta territorial, y la difusión de un modelo de reproducción social que revaloriza a la casa como centro neurálgico, parecen haber sido aceptados por los distintos especialistas en la materia como tres elementos básicos de la idiosincrasia nobiliaria, en absoluto exenta de controversia y crítica ${ }^{4}$, que funciona en la práctica como máximo referente de ascenso social.

La consolidación de la nobleza provincial gallega en los siglos modernos fue posible, precisamente, en gran medida, merced a la asimilación de estos tres

\footnotetext{
1 Trabajo realizado en el marco del proyecto de investigación «Los pazos de Galicia: Hidalgos y señores en el Antiguo Régimen» (XGPS 2002.09).

${ }_{2}$ Vid. en relación con la presencia de la hidalguía local en el control de la Junta del Reino de Galicia la obra de ARTAZA, M.M. de: A Xunta do Reino de Galicia no final do Antigo Réxime (17751834), A Coruña, 1993, p.42. En lo que se refiere a la progresiva aristocratización de los concejos gallegos durante los siglos XVI y XVII, han profundizado en dicho proceso CEBREIROS ÁlvaREZ, E.: El municipio de Santiago de Compostela a finales del Antiguo Régimen (1759-1812), Santiago, 1999, p.113; LÓPEZ DíAZ, M.a: Gobierno y Hacienda Municipales. Los concejos dé Santiago y Lugo en los siglos XVI y XVII, Lugo, 1994, p. 97; SAAVEDRA FERNÁNDEZ, P.: Economía, Política y Sociedad en Galicia. La provincia de Mondoñedo, 1480-1830, Madrid, 1985, p. 475; y SAAVEdra VÁzQUEZ, Ma .C.: La Coruña durante el reinado de Felipe II, A Coruña, 1989, p. 48.

3 Dew ALD, J.: The European Nobility, 1400-1800, Cambridge, 1996; GouberT, P.: El Antiguo Régimen. 1. La sociedad, Madrid, 1984 (París, 1969), caps.VII y VIII; y MEYER, J.: Noblesses et pouvoirs dans L'Europe d'Ancien Régime, París, 1973.

${ }^{4}$ ATIENZA HernÁNDEZ, I.: «La nobleza en el Antiguo Régimen: clase dominante, grupo dirigente», en Estudios de Historia Social (Madrid), $36-37$ (1986), p. 467; y KAMEN, H.: La sociedad europea (1500-1700), Madrid, 1986 ( $1^{\text {a }}$ ed. en inglés de 1984), pp. 101-103.
}

Hispania, LXIII/3, núm. 215 (2003) 907-968 
principios básicos ${ }^{5}$ que podemos ver reflejados en otros dominios de la Monarquía Hispánica ${ }^{6}$, por demás extensibles a buena parte de la geografía europea ${ }^{7}$. No obstante, el hecho de que la ubicación geográfica de sus patrimonios, cuya dispersión es sobradamente conocida ${ }^{8}$, y sus propias residencias privadas se hallasen en una zona que debemos considerar periférica respecto a los principales centros neurálgicos del entramado del poder monárquico, fue decisivo para que el grueso de la nobleza gallega moderna se hubiese decantado por supeditar sus principales intereses al marco regional. Algunos de los casos sobradamente conocidos de exitosa promoción política, como por ejemplo la Secretaría del Consejo de Guerra para los asuntos de tierra con que fue distinguido el hidalgo valdeorrés Andrés de Prada y Gómez de Santalla - I Señor de Outarelo- en 1586, como asimismo la Secretaría del Consejo de Estado un poco más tarde en $1600^{9}$, o la Presidencia del Consejo de Indias y el Virreinato de Nápoles desempeñados por el VII conde de Lemos, don Pedro Fernández de Castro, en 1601-10 y 161016 respectivamente ${ }^{10}$, e incluso las sucesivas embajadas en Londres de 1613-18 y 1620-22 a cargo del I conde de Gondomar, don Diego Sarmiento de Acuña ${ }^{11}$, no hacen sino confirmar una norma: los nobles gallegos que contaban con más posibilidades de acceder al servicio real en empresas e instituciones importantes de gobierno eran aquellos cuya genealogía familiar se podía remontar hasta los últimos siglos bajomedievales, y que además habían accedido al poder señorial ${ }^{12}$.

5 Presedo Garazo, A.: Dueños y señores de casas, torres y pazos, 1500-1900 (Contribución al estudio de la bidalguía gallega), 2 vols., Santiago, 2001, tesis doctoral inédita.

6 IGLESIAS, C. (dir.): Nobleza y Sociedad en la España Moderna. III, Las noblezas españolas, reinos y señoríos en la Edad Moderna, Oviedo, 1999.

7 Sobre todo en aquellos estados en los que la nobleza había optado por un modelo sucesorio desigualitario en el que se prima al varón primogénito con la jefatura de la casa, tal como sucede en los reinos de Portugal y Nápoles. Vid. MONTEIRO, N.G.: O crepúsculo dos grandes. A casa e o património da aristocracia em Portugal (1750-1832), Lisboa, 1998; y VISCEGLIA, M.A.: Il bisogno di eternità. I comportamenti aristocratici a Napoli in Età Moderna, Nápoles, 1988. En el caso gallego, el mayorazgo, y sobre todo las mejoras vinculares con gravamen de mayorazgo difundidas a partir de las Leyes de Toro de 1505, procedentes de la legislación castellana, serán las que permitan la definitiva consolidación patrimonial de la nobleza provincial. Nos remitimos para esta cuestión al ensayo clásico de Clavero, B.: Mayorazgo. Propiedad feudal en Castilla (1369-1836), Madrid, 1974.

8 Villares PAZ, R.: La propiedad de la tierra en Galicia, 1500-1936, Madrid, 1982, pp. 104106; y también PreSEDo Garazo, A.: Dueños y señores de casas, torres y pazos ..., pp. 403-410.

9 García Tato, I.: Vilanova, Outarelo y San Francisco Blanco. Monografía histórica de una parroquia gallega, Barco de Valdeorras, 1999, pp. 97-98.

10 Pardo de Guevara y Valdés, E.: Don Pedro Fernández de Castro, VII Conde de Lemos (15761622), Santiago, 1997, 2 vols.

${ }^{11}$ Manso Porto, C.: Don Diego Sarmiento de Acuña, Conde de Gondomar (1567-1626). Erudito, mecenas y bibliófilo, Santiago, 1996; y García ORO, J.: Don Diego Sarmiento de Acuña, Conde de Gondomar y embajador de España (1567-1626). Estudio biográfico, Santiago, 1997.

12 Así, pese a que el estamento noble en su conjunto se identificó -en teoría- con las empresas políticas de la monarquía a través del «servicio público», en la práctica, durante el siglo XVII, tan sólo accedieron a puestos importantes en el aparato administrativo de la Corona ciertos nobles que 
De hecho, tan sólo un $2 \%$ de los súbditos que accedieron al hábito de cualquiera de las distintas órdenes militares en el tramo central del siglo XVII, coincidiendo con el reinado de Felipe IV, eran de origen galaico ${ }^{13}$.

Para la mayor parte del contingente nobiliario oriundo, que representaba en torno al $5 \%$ de la población del antiguo reino a fines del siglo $\mathrm{XVI}^{14}$, y que todavía seguía suponiendo este mismo porcentaje a mediados del XVIII ${ }^{15}$, las prebendas eclesiásticas, el complejo entramado señorial, e incluso las propias instituciones de la monarquía asentadas en territorio gallego representaban, pues, un preciado «botín» con que saciar sus particulares ansias por consolidarse como grupo dirigente en el ámbito local ${ }^{16}$.

En este contexto, la Universidad de Santiago de Compostela desempeñó un papel fundamental para que algunos de los hidalgos oriundos más enriquecidos y/o mejor situados pudiesen alcanzar una excelente promoción social. Al igual que otras de tamaño mediano, como las andaluzas de Granada y Sevilla, ejerció una notable influencia en el espacio regional, permaneciendo subordinada en jerarquía a las poderosas universidades castellanas de Salamanca, Valladolid y Alcalá de Henares, cuando menos hasta la segunda mitad del siglo XVIII ${ }^{17}$.

disponían de un título y de una trayectoria colaboracionista reconocida con los intereses regios. Vid. ATIENZA HeRnÁNDEZ, I.: A ristocracia, poder y riqueza en la España moderna. La Casa de Osuna, siglos XVXIX, Madrid, 1987, pp. 50-60. En relación con las poderosas casas nobiliarias gallegas de los siglos XIV y XV, vid. GARCíA ORO, J.: Señorío y nobleza. Galicia en la Baja Edad Media, Santiago, 1977, y La nobleza gallega en la Baja Edad Media. Las casas nobles y sus relaciones estamentales, Santiago, 1982.

13 Postigo Castellanos, L.: Honor y privilegio en la Corona de Castilla. El Consejo de las Órdenes $y$ los Caballeros de Hábito en el siglo XVII, Soria, 1988, pp. 202-203. Y más adelante, ya entre 1771 y 1808 , sólo un 2,77\% de los caballeros que vistieron el hábito de la Orden de Carlos III eran de origen gallego, tal como ha demostrado MORETA I MUNUJOS, J.: «Los caballeros de Carlos III: Aproximación social», en Hispania (Madrid), 148 (1981), p. 417.

14 Molinie-Bertrand, A.: «Les hidalgos dans le Royaume de Castille a la fin du XVI siècle», en Revue d'Histoire économique et sociale (París), 52 (1974).

15 Gasalla Regueiro, P.L. y SAavedra Fernandez, P.: "Alumnos, bachilleres y catedráticos en el siglo XVIII", en X.R. Barreiro Fernández (coord.): Historia de la Universidad de Santiago de Compostela, vol.I, De los orígenes al siglo XIX, Santiago, 2000, p. 511.

${ }^{16}$ SAAVEDRA FERNÁNDEZ, P.: «Formación, consolidación e influencia social e cultural da fidalguía, ss.XVI-XVIII", en VV.AA.: Galicia fai dous mil anos. O feito diferencial galego, I. Historia, Santiago, 1997, pp. 134-138; y también PRESEDo GARAZO, A.: Dueños y señores de casas, torres y pazos ..., pp. 461-467. Un ejemplo monográfico muy acertado en este sentido es el estudio que hizo en su día X. Ferro Couselo referido a la familia hidalga orensana de los Boán. Vid. Ferro COUSELO, X.: "Gente llana con ventura. Los Boanes", en Boletín Auriense (Ourense), II (1972).

17 Gasalla Regueiro, P.L. y SAAVedra Fernández, P.: «Alumnos, bachilleres y catedráticos ...», p. 492. Es preciso incidir en el carácter periférico de la universidad compostelana en este momento, ya que tal como ha aclarado A. Domínguez Ortiz, en contraste con estos centros universitarios distantes de las importantes instituciones académicas castellanas, los licenciados en Salamanca, Valladolid, Alcalá y Bolonia "gozaron de ciertos privilegios nobiliarios». Vid. DOMÍNGUEz OrTIZ, A.: Las clases privilegiadas en el Antiguo Régimen, Madrid, 1985, $3^{\text {a }}$ ed. ( $1^{a}$ ed., 1973), p.55. Vid. además FERNÁNDEZ TERRICABRAS, I.: «Universidad y episcopado en el siglo XVI. Las universidades 
Luego de las constituciones de Cuesta de 1555, así como de las aprobadas en 1588 poco después de la visita de don Pedro Portocarrero acometida en 1577, la universidad compostelana había conseguido convertirse en una institución académica perfectamente consolidada, dejando atrás los intentos fallidos de 1495 y $1501^{18}$. La obra de mecenazgo de don Alonso de Fonseca III había resultado decisiva, y el cumplimiento de su testamento otorgado en 1534 en que dejaba fundado un colegio mayor en la sede arzobispal, en cuya tarea destacó su sobrino el conde de Monterrey, permitió culminar con éxito el proceso organizativo de dicha incipiente institución universitaria gallega ${ }^{19}$.

La universidad compostelana pasó a ofrecer entonces, sobre todo a partir de la segunda mitad del siglo XVI en adelante, la posibilidad de obtener titulaciones en un momento de clara demanda de las mismas, en el cual los letrados comenzaron a perfilarse como un nuevo horizonte social de poderosa «fuerza

donde estudiaron los obispos de las Coronas de Castilla y Aragón (1556-1598)", en Revista de Historia Moderna (Alicante), 20 (2002), pp.75-96.

${ }_{18}$ En relación con el primer colegio de Lope Gómez de Marzoa de 1496 y el Estudio General Compostelano de 1501, son de obligada consulta los trabajos de X.R. Barreiro Fernández titulados «El primer colegio de Lope Gómez de Marzoa» y «La fundación del estudio General (1501)», contenidos en la obra ya citada de BARREIro FernándeZ, X.R. (coord.): Historia de la Universidad de Santiago de Compostela ..., pp. 23-36 y 37-54 respectivamente; así como la obra de GARCía ORO, J.: Diego de Muros III y la cultura gallega del siglo XV, Vigo, 1976, pp. 81-99. En cuanto a las Constituciones de Cuesta, puede verse un estudio exhaustivo y una transcripción paleográfica de las mismas en RODRíGueZ SuÁREZ, Ma. P.: As constitucións do Dr. Cuesta para a Universidade de Santiago de Compostela (1550-1555), Santiago, 1997, del mismo modo que su trabajo titulado «El proceso organizativo de la Universidad» en BARREIRO FERNÁNDEZ, X.R. (coord.): Opus cit., pp. 103-117. El contenido de la visita del licenciado don Pedro Portocarrero ha sido transcrito y estudiado por ROMANí, M. y RODRíGUEZ SuÁrez, Ma . P.: A Real Universidade de Santiago de Compostela. Actas da visita do licenciado D. Pedro Portocarrero, Gobernador de Galicia (1577), Santiago, 1992, y asimismo merece ser consultada la visión de conjunto elaborada por RODRíGUEZ SUÁREZ, $\mathrm{M}^{\mathrm{a}}$.P.: «El proceso organizativo de la Universidad», en BARREIRO FERNÁNDEZ, X.R. (coord.): Opus cit., pp.123-155, donde se detallan las nuevas constituciones aprobadas en 1588 que suscitó dicha visita. Igualmente, es preciso destacar la síntesis sobre la consolidación de la universidad compostelana durante el siglo XVI elaborada por GARCíA ORO, J.: «A Universidade de Santiago de Compostela no século XVI", Introducción a ROMANí, M. y RoDRíGUEZ SUÁREZ, $\mathrm{M}^{\mathrm{a}}$. P.: A Real Universidade de Santiago ..., pp. XV-LXXIV; además de la panorámica general de la historia de la Universidad Compostelana desde la Reforma de Cuesta hasta la llegada de los ilustrados que debemos a ReY CASTELAO, O.: A Galicia clásica e barroca, Vigo, 1998, pp. 120-129.

19 Puede verse una transcripción de dicho testamento en García Oro, J. y PORTELA SILVA, $\mathrm{M}^{\mathrm{a}}$. J.: Os Fonseca na Galicia do Renacemento. Da guerra ó mecenado, Noia, 2000, pp. 202-288, y para la fundación de dicho colegio mayor las pp.232-237. En relación con este Colegio Nuevo de Fonseca (1522), y la bula del Papa Clemente VII de 1526, vid. GARCía Oro, J.: "A Universidade de Santiago de Compostela no século XVI», art. cit., pp.XXI-XXII; y BARREIRO FERNÁNDEZ, X.R. "La obra de Fonseca», en Historia de la Universidad de Santiago de Compostela ..., pp. 60-70. Vid. una completa aproximación a los principales valores transmitidos en los diferentes sistemas educativos desarrollados en los territorios de la Monarquía Hispánica durante la Época Moderna, en el reciente trabajo de MORGADO GARCÍA, A.: «Teología moral y pensamiento educativo en la España Moderna», en Revista de Historia Moderna (Alicante), 20 (2002), pp. 97-115. 
emergente» ${ }^{20}$, cuando menos en ciudades muy burocratizadas como de hecho lo eran Santiago y A Coruña ${ }^{21}$. Una de las pruebas más visibles de dicha demanda la tenemos en la nutrida serie de preceptorías públicas que se fundaron en el siglo que transcurre entre 1520 y 1620 , auspiciadas por concejos de algunas ciudades y villas, y que contaron con el apoyo económico de nobles locales ${ }^{22}$. No obstante, tal como han señalado acertadamente Pegerto Saavedra y P.L. Gasalla:

«El interés por estos estudios [de cánones y leyes] provenía no sólo de aquellos que deseaban seguir una carrera de letrados o ejercer otro empleo en la administración civil, sino también de la necesidad de unos conocimientos mínimos por parte de quienes percibían rentas por variados - y disputados - derechos de propiedad, de los que tenían relaciones con el mundo comercial y de los que desempeñaban diversos cargos en el ámbito local, en una sociedad marcadamente legalista, en la que el derecho era el verdadero «soberano». Por otra parte, a través del estudio de cánones se podía acceder a la mayoría de las prebendas eclesiásticas»23.

A finales de dicho siglo, la incrustación de las casas hidalgas en el entorno rural era ya una realidad consumada, incluso mucho antes del auge fundacional de vínculos y mayorazgos que veremos materializarse todavía entre 1650 y $1750^{24}$. La consolidación patrimonial, que había tenido como objeto principal acumular una considerable cantidad de rentas agrícolas a costa del campesinado, había conseguido convertirles en poderosos centros rentistas ${ }^{25}$; pero a la

\footnotetext{
${ }^{20}$ Una visión de conjunto en este sentido para la Corona de Castilla en KAGAN, RL.: Universidad y Sociedad en la España Moderna, Madrid, 1981 ( $1^{2}$ ed. en inglés de 1974); y asimismo en ATIENZA HERNÁNDEZ, I.: Aristocracia, poder y riqueza ..., pp.52-53; y YUN CASALILLA, B.: Sobre la transición al capitalismo en Castilla. Economía y sociedad en Tierra de Campos (1500-1830), Salamanca, 1987, pp. 321-337.

${ }^{21}$ Gelabert GonZález, J.E.: Santiago y la Tierra de Santiago de 1500 a 1640, Sada, 1982, pp.289-293; y SAAVEDRA VÁzQUEZ, $\mathbf{M}^{2}$. C.: La Coruña durante el reinado ..., pp.111-117.

${ }^{22}$ Entre ellas, merecen ser destacadas la preceptoría de Pontevedra, fundada en 1533 por el clérigo Alonso Gómez, y ampliada en 1593 gracias a un legado del testamento de doña Ana Álvarez de Montaos, mujer del regidor Payo de Rivera; la de A Coruña, fundada en 1549 por un acuerdo entre el concejo de la ciudad y el cabildo de la colegiata; la de Noia, que se remonta cuando menos hasta 1544, y que dispuso de una dotación de 100 ducados anuales que otorgó en su testamento el hidalgo don Rodrigo de Mendoza y Soutomaior en 1566; la de Vilagarcía de Arousa, que también fue dotada con 40 ducados anuales por el mismo don Rodrigo de Mendoza; la de Pontedeume, fundada por el regidor de dicha villa Juan Beltrán de Anido, esposo de doña Isabel de Jaspe, en su testamento otorgado en 1580; y la de Viveiro, fundada por doña María Sarmiento de Ribadeneira en su testamento de 1563, y ratificada por su marido el hidalgo Gómez Pérez das Mariñas en 1592. A esta serie, debemos añadir las preceptorías de Ourense (entre 1521 y 1565), Ribadeo (1542), Baiona (1591), Ferrol (ca.1613) y Betanzos (1614). Vid. BARREIRo FERNÁNDEZ, X.R.: La Galicia del Antiguo Régimen. Enseñanza, ilustración y política, A Coruña, 1991, pp. 43-63.

23 Gasalia Regueiro, P.L. y SAAVEDRA FernÁNDEZ, P.: «Alumnos, bachilleres y catedráticos ...», p. 495.

24 Presedo Garazo, A.: Dueños y señores de casas, torres y pazos ..., pp. 195-198.

25 Vid. para el conjunto de la antigua provincia de Mondoñedo, SAAvedra FERNÁNDEZ, P.: Economía, Política y Sociedad ..., pp. 442-451.
} 
hora de reforzar su poderío socio-político, aquéllas que contaban con una capacidad adquisitiva mayor habían decidido dirigir parte de sus esfuerzos a situar a algunos de sus vástagos al frente de escribanías, curatos y cargos en la milicia. Al monopolizar el control sobre algunas de las distintas instituciones de poder que coincidían en el ámbito local, habían conseguido garantizar su futura reproducción social ${ }^{26}$, y a la vez disponer de una inmunidad casi intransferible, máxime si tenemos en cuenta que algunos de estos pequeños nobles habían adquirido cotos coincidiendo con las desmembraciones eclesiásticas acontecidas en 1529,1551 y $1574^{27}$. Dentro de este control ejercido sobre las diferentes instituciones de poder en el marco regional por parte de las casas más enriquecidas, también entraron en sus planes, sobre todo para aquéllas que habían tomado contacto con el entorno urbano, las regidurías de ciudades y villas, algunos cargos de la Real Audiencia, y las canonjías catedralicias.

Ahora bien, es evidente que una parte de dicho colectivo procedente de la nobleza provincial más acomodada que se había incrustado en las filas de la jerarquía de eclesiásticos y letrados, pasó por las aulas de la universidad compostelana, ya de por sí un buen «trampolín» en el seno de una sociedad mayoritariamente no escolarizada, como de hecho lo era la de la Galicia del Antiguo Régimen ${ }^{28}$.

En la presente reflexión nos hemos propuesto valorar el alcance de esta presencia atendiendo a una serie de parámetros. En primer lugar, trataremos de delimitar hasta dónde llegaba el contingente de alumnos de origen nobiliario, para comprobar si realmente las aulas universitarias eran o no un punto de partida para alcanzar, a continuación, una promoción socio-política más beneficiosa. Inicialmente, el elevado $65 \%$ calculado en su día por Barreiro Fernández para el período 1685-1707 parece indicar que la universidad compostelana habría estado saturada de vástagos de familias linajudas ${ }^{29}$. No obstante, los resultados obtenidos por el profesor Pérez García para la antigua Jurisdicción de A Lanzada a mediados del siglo XVIII apuntan en otra dirección: los hidalgos apenas supondrían el $34 \%$ entre los alumnos universitarios procedentes de esta comarca ${ }^{30}$. Tal como tendremos ocasión de comprobar, los libros de matrí-

26 Vid. comparativamente, la similitud con el modelo de elites locales portuguesas estructurado por MONTEIRO, N.G.: «Elites locais e mobilidade social em Portugal nos finais do Antigo Regime», en Análise Social (Lisboa), 141 (1997), pp. 335-368.

27 BuRgo LóPEZ, $M^{a}$.C.: «El señorío monástico gallego en la Edad Moderna», en Obradoiro de Historia Moderna (Santiago), 1 (1992), pp. 101-107; LÓPEZ DÍAZ, $\mathbf{M}^{\mathrm{a}} .:$ «Alteraciones en el mapa jurisdiccional gallego durante la edad moderna: las desmembraciones eclesiásticas del siglo XVI», en Estudios Mindonienses (Ferrol), 7 (1991), p. 581; y SAAvedra FERNÁNDEZ, P.: «Contribución al estudio del régimen señorial gallego», en Anuario de Historia del Derecho Español (Madrid), LIX (1990), pp. 114 y ss.

28 SaAvedra Fernández, P.: La vida cotidiana en la Galicia del Antiguo Régimen, Barcelona, 1994 , pp. 368 y ss.

29 BARREIRO FERNÁNDEZ, X.R.: Enseñanza, ilustración y política ..., p. 180

30 PÉrez García, J.M.: Un modelo de sociedad rural de Antiguo Régimen en la Galicia costera: la península del Salnés (Jurisdicción de La Lanzada), Santiago, 1979, p. 387. 
culas de mediados del XVII verifican nuevamente los resultados obtenidos por Pérez García, y ponen en entredicho la hipótesis de que la universidad santiaguesa estuvo a disposición exclusiva de la hidalguía local, hipótesis también cuestionada recientemente por P.L. Gasalla y Pegerto Saavedra ${ }^{31}$. A partir de dos catas efectuadas en los años centrales de los siglos XVII y XVIII, tomando de base los libros de asientos de matrículas y los expedientes personales ${ }^{32}$, se pretende delimitar $1^{\circ}$. su presencia porcentual entre el alumnado medio, $2^{\circ}$. los estudios por los cuales se decantaron, y $3^{\circ}$. cuál era su procedencia geográfica ${ }^{33}$.

Luego, centraremos nuestro interés en comprobar si dicha presencia era o no mayor entre el colectivo de los colegiales, tomando de referencia a los individuos que consiguieron una beca en el Colegio de Fonseca entre 1580 y 1800. Los datos elaborados por Antonio Fraguas Fraguas en $1958^{34}$, junto con los expedientes de limpieza de sangre conservados ${ }^{35}$, nos presentan a un colectivo con un perfil sociológico complejo, en absoluto homogéneo, en el que, por cierto, los colegiales de ascendencia hidalga tampoco resultan ser mayoritarios.

Lógicamente, no todos los súbditos que componían el contingente hidalgo del reino gallego disponían de los medios económicos suficientes como para financiar los estudios universitarios de algún vástago en la sede compostelana. Y por lo tanto, sólo podían estudiar los hijos varones procedentes de aquellas casas linajudas cuyos ingresos permitían hacer frente a la manutención de los mismos mientras durase su estancia en Santiago ${ }^{36}$. Es decir, la universidad podía servir de lanzadera para la nobleza provincial más enriquecida, pero no po-

\footnotetext{
31 GaSAlla RegUeIRO, P.L. y SAAVEDRA FERNÁNDEZ, P.: «Alumnos, bachilleres y catedráticos ...», p. 511.

32 Concretamente, para el período 1647-55, hemos elaborado la muestra a partir de A.H.U.S., F.U., S.H., lib.A.229, y para 1751-54, A.H.U.S., F.U., S.H., leg.211. Asimismo, la serie de expedientes personales cotejados proceden de A.H.U.S., F.U., E.P., legs.1310-1312, 1329-1332, 1349$1352,1373,1374,1378-1380,1408-1412$, y 1434-1441.

33 Hemos de tener en cuenta que, tal como advierten P.L. Gasalla y Pegerto Saavedra, es difícil averiguar con precisión el número exacto de alumnos matriculados que estudiaron en la universidad compostelana antes de 1750 , pues el registro no se comenzó a concretar de manera continua hasta mediados del siglo XVII, y todavía en la primera mitad del XVIII «La práctica de la matrícula se hallaba convertida (...) en una actividad irregular. Unas veces los alumnos se apuntaban en el primer año y se olvidaban del trámite para los sucesivos. Otras, lo hacían en el último y probaban haber asistido al resto con informaciones, con acuerdos del claustro o certificaciones de los catedráticos». GASALLA REgueIro, P.L. y SAAvedRA FERnÁNDeZ, P.: «Alumnos, bachilleres y catedráticos ...», pp. 492497 y Apéndice 1 en pp. 568-572.

34 Fraguas Fraguas, A.: O Colexio de Fonseca, Santiago, 1995 (reedición conjunta de las obras Historia del Colegio de Fonseca, Madrid, 1956, y Los colegiales de Fonseca, Santiago, 1958).

35 A.H.U.S., F.U., S.H., Pruebas de limpieza de sangre, legs. 202-209 y 365-373.

36 De hecho, en un contexto más general, P.L. Gasalla y P. Saavedra han demostrado, para el siglo XVIII, que «A largo plazo, la evolución de la coyuntura socioeconómica motivó un aumento de los costos de manutención, desplazamiento y graduación, y también reducción de las expectativas profesionales». Vid. «Alumnos, bachilleres y catedráticos ...», p. 495.
} 
demos aplicar este razonamiento en igual medida al referirnos al grupo en su conjunto ${ }^{37}$.

\section{ESTUDIANTES DE ORIGEN HIDALGO EN LA UNIVERSIDAD DE SANTIAGO DE COMPOSTELA}

Para aproximarnos al porcentaje que representan los alumnos procedentes de casas hidalgas a mediados de los siglos XVII y XVIII, hemos partido de la hipótesis comúnmente aceptada de que si un individuo o alguno de sus ascendientes en primer grado eran merecedores de ser distinguidos con el timbre «Don», ello podía ser indicativo de hidalguía. Tal como tendremos ocasión de comprobar en las páginas siguientes, la progresiva desvirtualización de esta costumbre a medida que avance la centuria dieciochesca, que coincide con su generalización entre individuos no procedentes de dicha extracción social, nos ha situado en la tesitura de cuestionarnos hasta qué punto resulta totalmente válida esta correlación para momentos avanzados de la Edad Moderna, y a ponderar, por tanto, los datos que ofrecen los libros de registro de matrículas.

\subsection{Estudiantes de origen hidalgo a mediados del siglo XVII (1647-55)}

El registro de matrículas de alumnos de la Universidad de Santiago comienza a normalizarse a mediados del XVII, si bien es cierto que todavía habrá que esperar, cuando menos hasta bien avanzado el siglo siguiente, para disponer de series lo suficientemente completas ${ }^{38}$. Este hecho no supone, sin embargo, un obstáculo insalvable, a la hora de delimitar la presencia porcentual de matriculados de origen hidalgo, entre el alumnado que cursó estudios universitarios en dicha institución en el momento en que se comenzó a regularizar la operación de asiento de matrículas, pues únicamente se pretende calcular una tendencia general.

Conviene advertir además que, si bien es cierto que esta primera muestra ha sido confeccionada teniendo en cuenta dicha característica intrínseca a la fuente histórica empleada, y que, por lo tanto, se basa en cifras reales infravaloradas de antemano, hay dos argumentos de peso que nos han animado a decantarnos por estos años centrales de la centuria y no por otros. El primero de ellos también tiene que ver con las propias limitaciones que presenta el registro de matrículas, pues tal como han señalado P.L. Gasalla y Pegerto Saavedra

37 Vid. sino desde el campo del conocimiento de la Sociología, el razonamiento de FrEEMAN, L.C.: «The Sociological Concept of «Group»: An Empirical Test of Two Models», en American Journal of Sociology (Chicago), 98-1 (1992), pp.152-166.

38 GASALla REgueIRO, P.L. y SAAVEDRA FERNÁNDEZ, P.: «Alumnos, bachilleres y catedráticos ...», pp. 492 y ss.

Hispania, LXIII/3, núm. 215 (2003) 907-968 
tiende a ser más irregular y discontinuo antes de dicho momento ${ }^{39}$. El segundo se halla muy relacionado con el proceso histórico de consolidación socioeconómica de la nobleza provincial, ya que es un hecho demostrado que las casas hidalgas más poderosas del reino habían comenzado a consolidar sus patrimonios amayorazgados bastante antes de $1650^{40}$, y que habrían estado en condiciones de comenzar a enviar a estudiar a parte de la prole a Santiago, con la intención de obtener algún grado que le permitiese acceder posteriormente a la jerarquía de letrados y eclesiásticos, o simplemente disponer de unos conocimientos mínimos para llevar a cabo la contabilidad de sus ingresos anuales ${ }^{41}$, compuestos principalmente de rentas agrícolas abonadas en diferentes productos.

Por lo tanto, los datos de mediados del XVII ${ }^{42}$ van a permitirnos localizar, en primer término, a estudiantes de origen hidalgo que han nacido en casas cuyas fundaciones vinculares han sido otorgadas mucho antes ${ }^{43}$; en segundo, a estudiantes hidalgos cuyos padres, y por extensión demás familiares involucrados en la expansión hacendística de sus casas, aún habiendo fundado algún vínculo, todavía están en condiciones de agregar más bienes ${ }^{44}$; y en tercero, a estudiantes cuyos padres están en proceso de ennoblecimiento, ya que su capacidad adquisitiva les ha permitido acumular un destacado capital fundacional, susceptible de experimentar próximas ampliaciones, y de aspirar, en un tiempo no lejano, a ser borrados de las listas de pecheros y reconocidos como hidalgos ${ }^{45}$.

El recuento del número total de alumnos matriculados en las carreras de cánones, artes, teología y medicina, por cursos, durante el tramo central del siglo XVII (1647-55) ${ }^{46}$, nos ha permitido comprobar que de un total de 2.733 matrículas, sólo 902 corresponden a individuos cuyos asientos aparecen precedidos del timbre «Dón»; es decir, un 33\% del conjunto, o lo que es lo mismo un tercio (Tabla 1.a). Aunque hay años en los que este porcentaje experimenta un cierto incremento hasta situarse en el $35 \%$, tal como sucede en los años 1648 y 1651 , lo habitual es que, por el contrario, ni tan siquiera se alcance

\footnotetext{
39 Ibidem.

40 VILLARES PAZ, R.: La propiedad de la tierra en Galicia ..., pp. 80 y ss.

${ }^{41}$ BurÓN, T.: «El aprendizaje de la escritura: De oficio a necesidad», en Estudios humanísticos. Geografia, Historia, Arte (León), 15 (1993), p. 63.

42 A.H.U.S., F.U., S.H., lib. A. 229.

${ }^{43}$ Es el caso de don José de Taibo, procedente de la parroquia de Sta. María de Dexo, que se matricula en tercero de cánones en 1649. A.H.U.S., F.U., S.H., lib. A. 229, s.f. Pues bien, procede de la Casa de Dexo fundada por el escudero Fernán López de Taibo y su mujer Teresa González en 1537. Libro becerro de la Casa-Nova de Golán, conservado en el Archivo de la Casa da Fraga, ff. 269v. y ss.

${ }_{44} \mathrm{Tal}$ como sucede con los Boán del Pazo de San Damián, en Amoeiro, estudiados por Ferro COUSELO, X.: "Gente llana con ventura ...», art. cit.

${ }^{45}$ Como de hecho sucede con don Gregorio de Vilamarín, quien cursa primero de cánones en 1649, y procede de la Pousa de Souto de Rei, sita en la feligresía de S. Pedro de Cudeiro. A.H.U.S., F.U., S.H., lib.A.229, s.f. Vid. PRESEDO GARAZO, A.: Dueños y señores de casas, torres y pazos ..., p. 158.

46 Pueden verse estos datos desglosados por carreras y cursos en el Apéndice 1.
} 
TABLA 1: ESTUDIANTES DE ORIGEN HIDALGO EN LA UNIVERSIDAD DE SANTIAGO DE COMPOSTELA EN 1647-55.

a. Según el número de alumnos que portan «Don» respecto al total de individuos matriculados ${ }^{47}$.

\begin{tabular}{|l|c|c|c|}
\hline \multirow{2}{*}{ AÑO } & \multirow{2}{*}{ N $^{\circ}$ TOTAL DE MATRÍCULAS } & \multicolumn{2}{|c|}{ MATRICULADOS QUE PORTAN «DON» } \\
\cline { 3 - 4 } & & $\mathrm{n}^{\mathbf{0}}$ & $\%$ \\
\hline 1647 & 215 & 69 & 32,09 \\
\hline 1648 & 250 & 88 & 35,20 \\
\hline 1649 & 268 & 87 & 32,46 \\
\hline 1650 & 348 & 116 & 33,33 \\
\hline 1651 & 337 & 121 & 35,90 \\
\hline 1652 & 339 & 112 & 33,03 \\
\hline 1653 & 342 & 108 & 31,57 \\
\hline 1654 & 331 & 106 & 32,02 \\
\hline 1655 & 303 & 95 & 31,35 \\
\hline Total & 2.733 & 902 & 33,00 \\
\hline
\end{tabular}

b. Según el número de alumnos que portan «Don» matriculados en las distintas carreras.

\begin{tabular}{|l|c|c|c|c|c|c|c|c|c|}
\hline CARRERAS & \multicolumn{3}{|c|}{ ARTES } & \multicolumn{3}{c|}{ TEOLOGÍA } & \multicolumn{3}{c|}{ CÁNONES } \\
\hline \multirow{3}{*}{ Años } & $\begin{array}{c}\text { Matricu- } \\
\text { lados }\end{array}$ & $\begin{array}{c}\text { Matriculados } \\
\text { que portan } \\
\text { «Don» }\end{array}$ & $\begin{array}{c}\text { Matricu- } \\
\text { lados }\end{array}$ & $\begin{array}{c}\text { Matriculados } \\
\text { que portan } \\
\text { «Don» }\end{array}$ & $\begin{array}{c}\text { Matricu- } \\
\text { lados }\end{array}$ & $\begin{array}{c}\text { Matriculados } \\
\text { que portan } \\
\text { «Don» }\end{array}$ \\
\cline { 2 - 11 } & $\mathrm{n}^{\circ}$ & $\mathrm{n}^{\circ}$ & $\%$ & $\mathrm{n}^{\circ}$ & $\mathrm{n}^{\circ}$ & $\%$ & $\mathrm{n}^{\circ}$ & $\mathrm{n}^{\circ}$ & $\%$ \\
\hline 1650 & 85 & 27 & 31,76 & 26 & 6 & 23,07 & 237 & 83 & 35,02 \\
\hline 1651 & 93 & 24 & 25,80 & 22 & 5 & 22,27 & 222 & 92 & 41,44 \\
\hline 1652 & 95 & 18 & 18,94 & 21 & 5 & 23,80 & 223 & 89 & 39,91 \\
\hline 1653 & 72 & 14 & 19,44 & 22 & 5 & 22,72 & 248 & 89 & 35,88 \\
\hline 1654 & 76 & 16 & 21,05 & 16 & 3 & 18,75 & 239 & 87 & 36,40 \\
\hline 1655 & 70 & 8 & 11,42 & 14 & 3 & 21,42 & 219 & 80 & 36,51 \\
\hline Total & 491 & 107 & 21,79 & 121 & 27 & 22,31 & 1.388 & 520 & 37,46 \\
\hline
\end{tabular}

Fuente: Elaboración propia a partir de A.H.U.S., F.U., S.H., lib. A.229, Libro de matrículas de 1647-61.

${ }_{47}$ Los datos de la evolución de la matrícula del alumnado, a excepción del año 1648, han sido tomados de Gasalla Regueiro, P.L. y SAavedra Fernández, P.: «Alumnos, bachilleres y catedráticos ...», pp. 568-572. 
dicha media, situándose ésta entre el 31 y el $32 \%$. La presencia de alumnos de origen hidalgo en las aulas compostelanas se aleja considerablemente, luego, del elevado $65 \%$ calculado por Barreiro Fernández para fines de siglo ${ }^{48}$, y parece incidir en el hecho de que a esta universidad tan sólo concurren selectivamente algunos miembros de casas linajudas con suficiente capacidad económica como para hacer frente al pago de su manutención, por demás, un lastre bastante pesado para aquéllas que se hallan inmersas en plena expansión patrimonial ${ }^{49}$.

Algunos ejemplos concretos pueden servir para ilustrar el esfuerzo económico que debía suponer para estas casas el costear la educación académica de sus hijos. Así, el hidalgo lugués Fernán Sanxurxo de Montenegro, fundador de los vínculos de las casas de Padroelo y Corbelle, había destinado 17.600 rs. a la educación de dos de sus hijos antes de $1594^{50}$. Para un poco más adelante, coincidiendo con la cronología de nuestra muestra, disponemos de los datos procedentes de la familia Boán del Pazo de San Damián, sito en el ángulo noroccidental de la actual provincia de Ourense: un desembolso de 3.500 rs. entre 1642 y 1644 para costear los estudios de su hijo primogénito en Compostela, permite deducir un gasto medio anual igual o superior a los 1.750 reales $^{51}$. Y es que la simple adquisición de los útiles y enseres cotidianos imprescindibles, así como los complementos del estudio, ya hacía preciso un desembolso notable, tal como atestigua el recuento de los bienes pertenecientes al colegial don Pedro Alonso de Ulloa, fallecido en 1618:

«Una sotanilla y una capa de veinte y dos senos de luto.

Dos almoadas ya viejas.

Dos colchones viejos.

Un cofre grande.

Un bufete y una carpeta de cuero.

Un scritorio con sus pies y llave.

Cuatro sillas.

Tres cuadros: uno de Nuestra Señora, otro del Salvador, otro en que se contienen los pasos de la Pasión.

Cinco camisas viejas.

Dos paños de clavo labrados.

Unos gregüiesquillos de roan ya viejos.

Un candelabro.

Un tintero y su salvera» ${ }^{52}$.

48 BARREIRo FERNÁNDEZ, X.R: Enseñanza, ilustración y política, p. 180.

49 En relación con la expansión económica de la nobleza provincial gallega en este preciso momento, vid. Presedo Garazo, A.: Os devanceiros dos pazos, Santiago, 1997, pp. 41 y ss.; y además MiguÉs RoDRíGUEZ, V.M.: A fidalguía galega: un breve enxergar bistórico através da Casa de San Fiz de Asma e agregadas no Antigo Réxime, Santiago, 1997, pp. 77 y ss.

50 Archivo de la Casa de Mirapeixe, Sección Pardo Montenegro, caja 1, mazo III.

51 FERro COUSELO, X.: «Gente llana con ventura ...», p. 68.

52 Cit. por Fraguas Fraguas, A.: O Colexio de Fonseca, p. 274. 
Esta limitada presencia, directamente relacionada con los elevados gastos de manutención, nos está indicando que también llegan a las aulas compostelanas estudiantes cuyo origen social se halla en sectores no emparentados con la nobleza, como de hecho lo son ciertos comerciantes asentados en núcleos urbanos, e incluso familias de burócratas que han comenzado a sentir la necesidad de «ennoblecer su sangre»" 33 .

El análisis de las carreras elegidas por estos individuos asimilables a la hidalguía nos indica una clara predilección por cursar Derecho, y especialmente Cánones (Tabla 1.b). Tal es así, que los alumnos de origen hidalgo que se matricularon en alguno de los cinco cursos comprendidos por la carrera de cánones entre 1650 y 1655 llegaron a suponer de media un $37,46 \%$ del alumnado total que asistió a las lecciones canónicas, habiendo años en los que incluso representaron un porcentaje mayor, en torno al $40 \%$ - para ser más exactos en el bienio 1651-52 — ${ }^{54}$. Dicha vocación por los Cánones se halla muy relacionada con el acceso de algunos de estos futuros canonistas a las prebendas catedralicias en alguna de las cinco sedes diocesanas gallegas, de las cuales la de Santiago es un ejemplo bien significativo, tal como se desprende de las pruebas de limpieza de sangre conservadas en el archivo catedralicio ${ }^{55}$. Del mismo modo, el aprendizaje de los rudimentos elementales del derecho podía permitirles ejercer algún oficio jurisdiccional tras finalizar sus estudios universitarios, y escalar en la carrera de cargos, bien empleándose en instituciones monárquicas asentadas en el reino, o bien poniéndose al servicio de algún señor ${ }^{56}$.

Sea lo que fuere, la mayor expectativa laboral en el campo de la jurisprudencia $^{57}$, muy condicionada por el carácter legalista en que se desarrolla el

53 En este sentido, puede verse una descripción de la sociología de los grupos dominantes en la ciudad de Santiago, para el período 1588-1635, en GELABERT GonZÁL.EZ, J.E.: Santiago y la Tierra de Santiago..., pp.313-317. Y asimismo una completa visión de conjunto sobre los cauces que facilitaron el ascenso social en la Castilla del siglo XVII en SANZ Y AYÁN, C.: "Poderosos y privilegiados», en J.N. Alcalá-Zamora (dir.): La vida cotidiana en la España de Velázquez, Madrid, 1999, $2^{\mathrm{a}}$ ed., pp. 162-167.

${ }_{54}$ Este hecho viene a confirmar la conclusión de R.L. Kagan para la elite universitaria castellana en la Época Moderna, pues los colegiales de las universidades de Salamanca, Valladolid y Alcalá de Henares, mostraron una clara preferencia, a partir de 1550 en adelante, por encauzar sus estudios hacia el derecho canónico. Vid. KAGAN, R.L.: Universidad y sociedad ..., cuadro 9 en p. 178.

55 Archivo Catedralicio de Santiago, Informaciones de limpieza de sangre, legs. 728 a 776 . Vid. además IGLESIAS CASTELAO, A.: «Análisis sociológico del cabildo compostelano a través de los expedientes de limpieza de sangre», en Compostellanum (Santiago), XII (1996).

56 Siguiendo, por lo tanto, aunque a menor escala, el modelo de promoción practicado por los colegiales, en el caso compostelano los procedentes del Colegio de Fonseca, tal como tendremos ocasión de comprobar un poco más adelante. Vid. una visión de conjunto para las universidades castellanas en KAGAN, R.L.: Universidad y sociedad ..., p.153. A su vez, la relación cada vez mayor que existe en el marco de la Corona de Castilla entre la nobleza y la elite de letrados, sobre todo en el siglo XVII, ya ha sido objeto de análisis por parte de FAYARD, J.: Los miembros del Consejo de Castilla (1621-1746), Madrid, 1982 (Ginebra, París, 1979), pp. 171 y ss.

57 GonZÁlez FernáNDEZ, J.M.: «La justicia local y territorial en la Galicia del Antiguo Régimen», en Obradoiro de Historia Moderna (Santiago), 4 (1995), pp. 238-247. 
marco de convivencia cotidiana en la sociedad gallega de Antiguo Régimen ${ }^{58}$, debió de ser decisiva a la hora de elegir la formación académica propicia para el hijo que habría de pasar algún tiempo cursando sus estudios universitarios en la Ciudad del Apóstols?. De ello da cuenta don Juan Antonio de Boán y Landecho, hijo primogénito de don Pedro Fernández de Boán y su mujer doña Josefa, señores de la Casa de San Damián, quien cursó artes y cánones durante los años académicos $1642-43$ y $1643-44$, tal como se puede observar en el libro tumbo redactado por su padre:

«En domingo, veinte y tres de nouienbre del año de 1642, se partió don Juan Antonio de Boán y Landecho con Juan de Barcia de Araujo, su ayo (y con Hernando de Boán, hijo de mi hermano el Licenciado Juan Fernández de Boán de Temes y Araujo, abbad de Villarrubín) al estudio de la Universidad de Santiago a oyr artes y cánones y estubo el curso asta fin de abril de 1643 , y estubo malo, curándose de unos humores, en que hubo de tomar sudores y gastó en este curso y estada más de 1.500 Rs., sin los vestidos.

Asimismo voluió en 29 de outubre de 1643 a Santiago al estudio con dicho su ayo y paje y estubo hasta (...) de (...) dicho año y gastó en este curso más de dos mil Rs»60.

Esta preferencia por los cánones entre los alumnos socialmente distinguidos, no es incompatible, en modo alguno, con que haya unos cuantos que opten por dirigir sus pasos hacia las Artes y la Teología (Tabla 1.b y Gráfica 1).

De estas dos últimas opciones señaladas - que debemos considerar secundarias si tenemos en cuenta la carrera de Derecho-, la Teología ocupa el segundo puesto, representando los estudiantes hidalgos el 22,31\% del total de matriculados en dicha carrera durante el quinquenio 1650-55. Las Artes ocupan el tercer puesto con un también considerable $21,79 \%$ sobre el total de matrículas en esta carrera a lo largo de dicho período. Mientras que los valores máximo y mínimo de representatividad oscilan entre el 18,75 y el $23,80 \%$ en el caso de la Teología, es decir, con una diferencia de cinco puntos entre ambos extremos, que nos está indicando una constante, o lo que es lo mismo una preferencia normalizada hacia los estudios teológicos; por el contrario, en Artes, dicha relación es cuatro veces mayor, al suponer entre el 11,42 y el $31,76 \%$. Y

58 Vid. unas interesantes reflexiones en relación con el caso italiano en MAZZACANE, A.: «Law and Jurists in the Formation of the Modern State in Italy", en The Journal of Modern History (Chicago), 67, suplemento (1995), pp. 62-73.

59 En relación con la ocupación de cargos en la administración regia y urbana por parte de la hidalguía y la pequeña nobleza durante los siglos XVI y XVII, vid. para el caso riojano BURGOS ESTEVAN, F.M.: «Las bases sociales del poder de la élite del estamento hidalgo. El linaje de los Barrón (Logroño. Siglos XVI y XVIII)", en Cuadernos de Investigación Histórica. BROCAR (Logroño), 15 (1989), p. 93; y asimismo para el caso andaluz Calvo POYATO, J.: Del siglo XVII al XVIII en los señoríos del sur de Córdoba, Córdoba, 1986, p. 519.

60 Cit. por Ferro Couselo, X.: «Gente llana con ventura ...», p. 68.

Hispania, LXIII/3, núm. 215 (2003) 907-968 
GRÁfICA 1: CARRERAS PREFERIDAS POR LOS ALUMNOS QUE PORTAN «DON» AL MATRICULARSE EN LA UNIVERSIDAD DE SANTIAGO DE COMPOSTELA EN 1647-55.

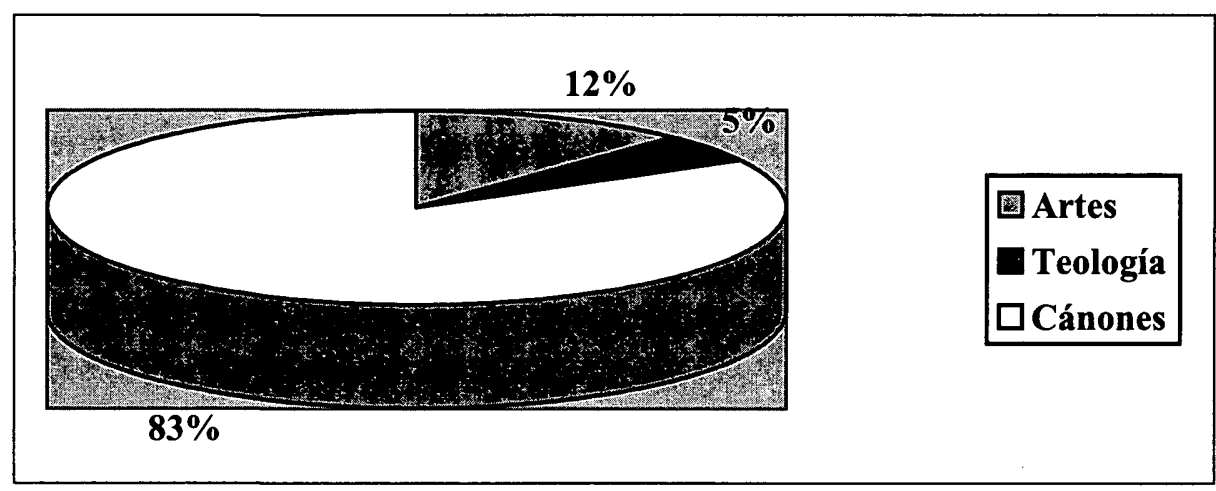

aunque el porcentaje de alumnos que portan «Don» matriculados en Artes es superior en tres ocasiones al de aquellos que coinciden en un mismo año académico estudiando Teología, y viceversa, sólo en el curso de $1650-51$ se traduce en una amplia ventaja, en tanto que en 1651-52 y 1654-55 ésta no alcanza a superar un intervalo de tres puntos de diferencia.

\section{GRÁFICA 2: NÚMERO DE ESTUDIANTES DE ORIGEN HIDALGO MATRICULADOS EN 1647-55 EN LAS CARRERAS DE ARTES Y CÁNONES (POR CURSOS).}

\section{2.a. Artes}

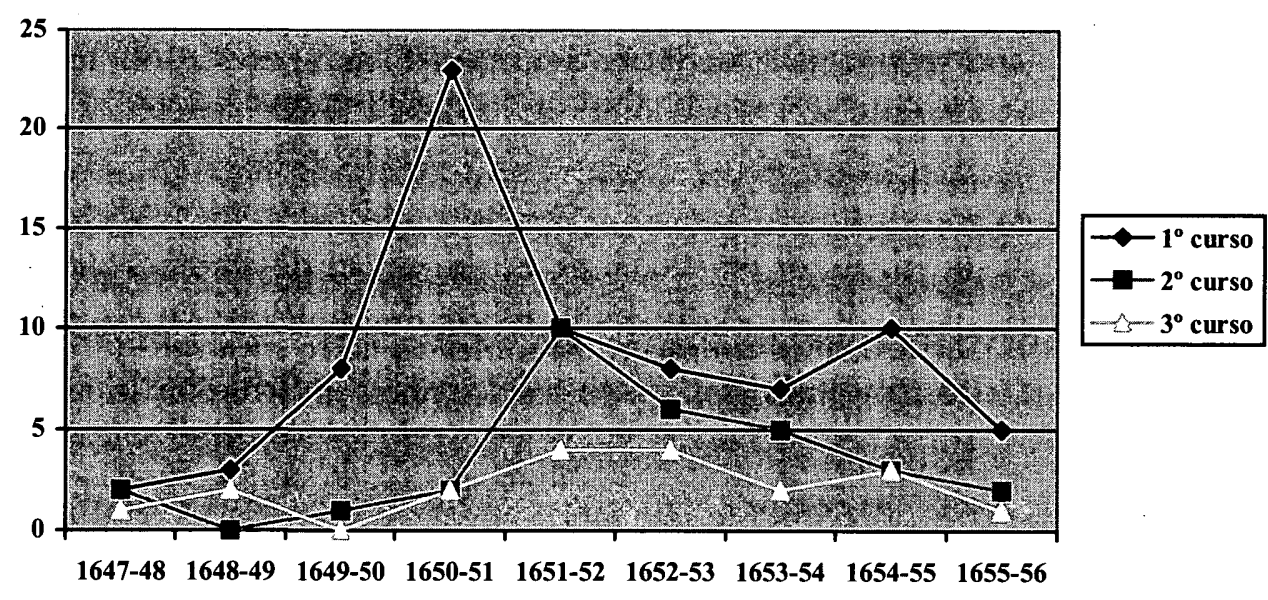




\section{2.b. Cánones}

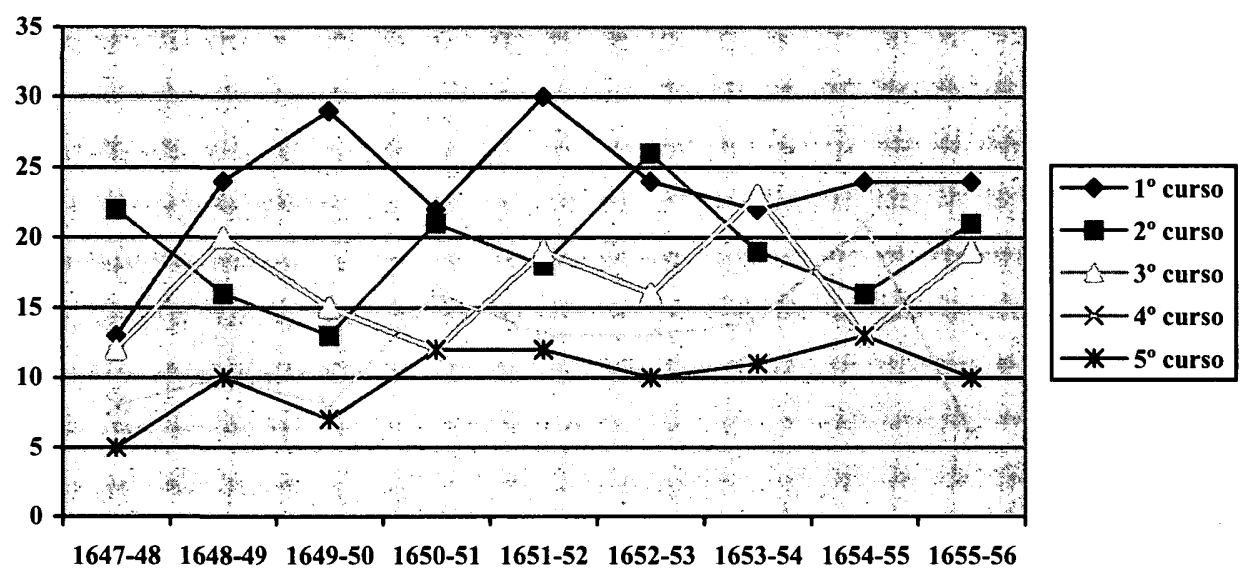

Por norma, la presencia de alumnos procedentes de casas linajudas experimenta una caída gradual según avanzamos en los distintos cursos que componen las carreras en las que se han ido matriculando. Así, por ejemplo, la matrícula en primero de Cánones es mucho mayor que en el quinto y último curso; o en primero de Artes que en tercero (Gráfica 2). Ello quiere decir que, al igual que sucede con el resto de sus compañeros, no todos acaban sus estudios, lo cual viene a reforzar la hipótesis de que la finalidad de su presencia en las aulas compostelanas no siempre consiste en acceder al grado de bachiller, licenciado o doctor, sino en acercarse a la cultura letrada por diversos motivos.

La estancia en la universidad es, pues, un período intermedio, casi diríamos que transitorio, para el vástago hidalgo a quien sus padres han financiado los estudios universitarios pensando en una recolocación futura que reinvierta positivamente en beneficio de la propia casa. De hecho, si han llegado a Compostela con el ánimo de asistir a las lecciones de alguno de los distintos cursos de estas carreras, es por imposición de la lógica y la estrategia de reproducción social inherentes a la casa.

La procedencia geográfica de este privilegiado tercio de estudiantes matriculados a mediados del siglo XVII reitera, todavía un poco más, este último aspecto señalado.

De las 902 matrículas correspondientes a la totalidad de alumnos que se hallan precedidos del timbre "Don», y una vez descontados los 113 que o bien son foráneos (97), o bien cuya diócesis de procedencia no se menciona (16), la mayor parte de ellos acostumbran a proceder de distintos núcleos poblacionales rurales y/o urbanos diseminados por la archidiócesis compostelana (Tabla 2.a y Mapa 1). El casi $40 \%$ sobre el total de alumnos asimilables a la hidalguía matriculados entre 1647 y $1655^{61}$, no sólo está poniendo de manifiesto la influen-

${ }^{61}$ El total asciende a 789, una vez descontados los 113 por los argumentos expuestos. 
TABLA 2: PROCEDENCIA GEOGRÁFICA DE LOS ESTUDIANTES DE ORIGEN HIDALGO MATRICULADOS EN LA UNIVERSIDAD DE SANTIAGO DE COMPOSTELA EN 1647-55 (SEGÚN EL TOTAL DE MATRICULADOS QUE PORTAN «DON»).

\begin{tabular}{|l|r|r|r|r|r|r|r|r|r|}
\hline \multicolumn{10}{|c|}{ a. Según la diócesis } \\
\hline AÑos & 1647 & 1648 & 1649 & 1650 & 1651 & 1652 & 1653 & 1654 & 1655 \\
\hline Astorga & 2 & 2 & 4 & 0 & 0 & 2 & 1 & 1 & 0 \\
\hline Lugo & 14 & 17 & 13 & 18 & 21 & 22 & 23 & 15 & 12 \\
\hline Mondoñedo & 3 & 2 & 6 & 1 & 6 & 5 & 7 & 6 & 5 \\
\hline Ourense & 14 & 17 & 17 & 21 & 23 & 22 & 19 & 18 & 12 \\
\hline Santiago & 26 & 30 & 22 & 45 & 38 & 35 & 36 & 38 & 38 \\
\hline Tui & 7 & 9 & 17 & 17 & 16 & 14 & 11 & 9 & 8 \\
\hline No gallegos & 2 & 7 & 4 & 11 & 14 & 11 & 11 & 19 & 19 \\
\hline Sin especificar & 1 & 4 & 3 & 3 & 3 & 1 & 0 & 0 & 1 \\
\hline Total & 69 & 88 & 87 & 116 & 121 & 112 & 108 & 106 & 95 \\
\hline & \multicolumn{7}{|c|}{ b. Según se trate de ámbito rural o urbano } & & \\
\hline AÑos & 1647 & 1648 & 1649 & 1650 & 1651 & 1652 & 1653 & 1654 & 1655 \\
\hline $\begin{array}{l}\text { Parroquias } \\
\text { rurales }\end{array}$ & 4 & 8 & 13 & 15 & 6 & 10 & 9 & 7 & 4 \\
\hline $\begin{array}{l}\text { Villas y } \\
\text { ciudades }\end{array}$ & 15 & 27 & 31 & 48 & 54 & 40 & 22 & 20 & 26 \\
\hline No gallegos & 2 & 7 & 4 & 11 & 14 & 11 & 11 & 19 & 19 \\
\hline Sin especificar & 48 & 46 & 39 & 42 & 47 & 51 & 66 & 60 & 46 \\
\hline Total & 69 & 88 & 87 & 116 & 121 & 112 & 108 & 106 & 95 \\
\hline
\end{tabular}

Fuente: Elaboración propia a partir de A.H.U.S., F.U., S.H., lib. A.229, Libro de matrículas de 1647-61.

cia que ejerce dicha institución sobre las áreas más cercanas a la ciudad, sino también una concentración mayor de posibles alumnos en la Galicia occidental, a estas alturas más dinámica que las comarcas interiores y orientales como consecuencia de la progresiva introducción del maíz en las rotaciones de culti$\operatorname{vos}^{62}$. De hecho, los procedentes de la diócesis de Tui ocupan el cuarto puesto con un $13,56 \%$ sobre el total. Si sumamos ambos contingentes, el casi $54 \%$

62 Vid. unas buenas visiones de conjunto en DUBERT GARCÍA, I.: «Espacio y comportamientos sociales en la Galicia de la época moderna", en VV.AA.: Concepcións espaciais e estratexias territoriais na Historia de Galicia, Santiago, 1993; y SAAvedra VÁzQUEZ, Mª.C.: Galicia na Idade Moderna, Oleiros, 1995, pp.33 y ss. En relación con la introducción del maíz en las tierras de cultivo, nos remitimos a PÉREZ GARCÍA, J.M.: «Aproximación al estudio de la penetración del maíz en Galicia», en A. Eiras Roel et al.: La historia de Galicia en sus fuentes de protocolos, Santiago, 1981. 
resultante es lo bastante significativo como para atrevernos a sostener la hipótesis de que las casas hidalgas asentadas en la franja atlántica son las que han protagonizado un esfuerzo mayor por enviar a sus hijos a las aulas universitarias compostelanas.

\section{MAPA 1: PROCEDENCIA GEOGRÁFICA DE LOS ESTUDIANTES DE ORIGEN HIDALGO MATRICULADOS EN LA UNIVERSIDAD DE SANTIAGO DE COMPOSTELA EN 1647-55, SEGÚN LAS DISTINTAS PROVINCIAS ECLESIÁSTICAS.}

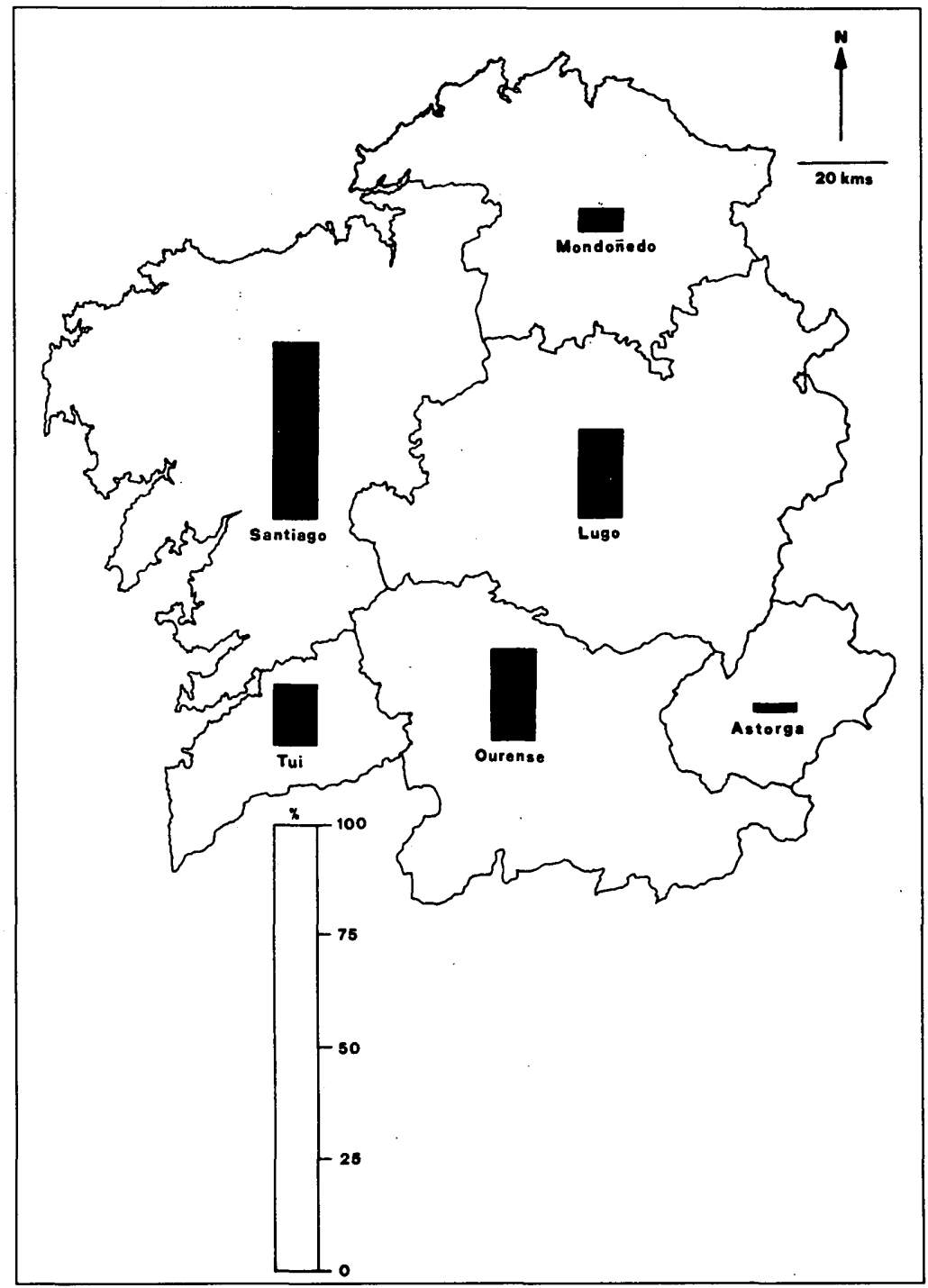

Hispania, LXIII/3, núm. 215 (2003) 907-968 
MAPA 2: PROCEDENCIA GEOGRÁFICA DE LOS ESTUDIANTES DE ORIGEN HIDALGO MATRICULADOS EN LA UNIVERSIDAD DE SANTIAGO DE COMPOSTELA EN 1647-55, SEGÚN SE TRATE DE ÁMBITO RURAL O URBANO.

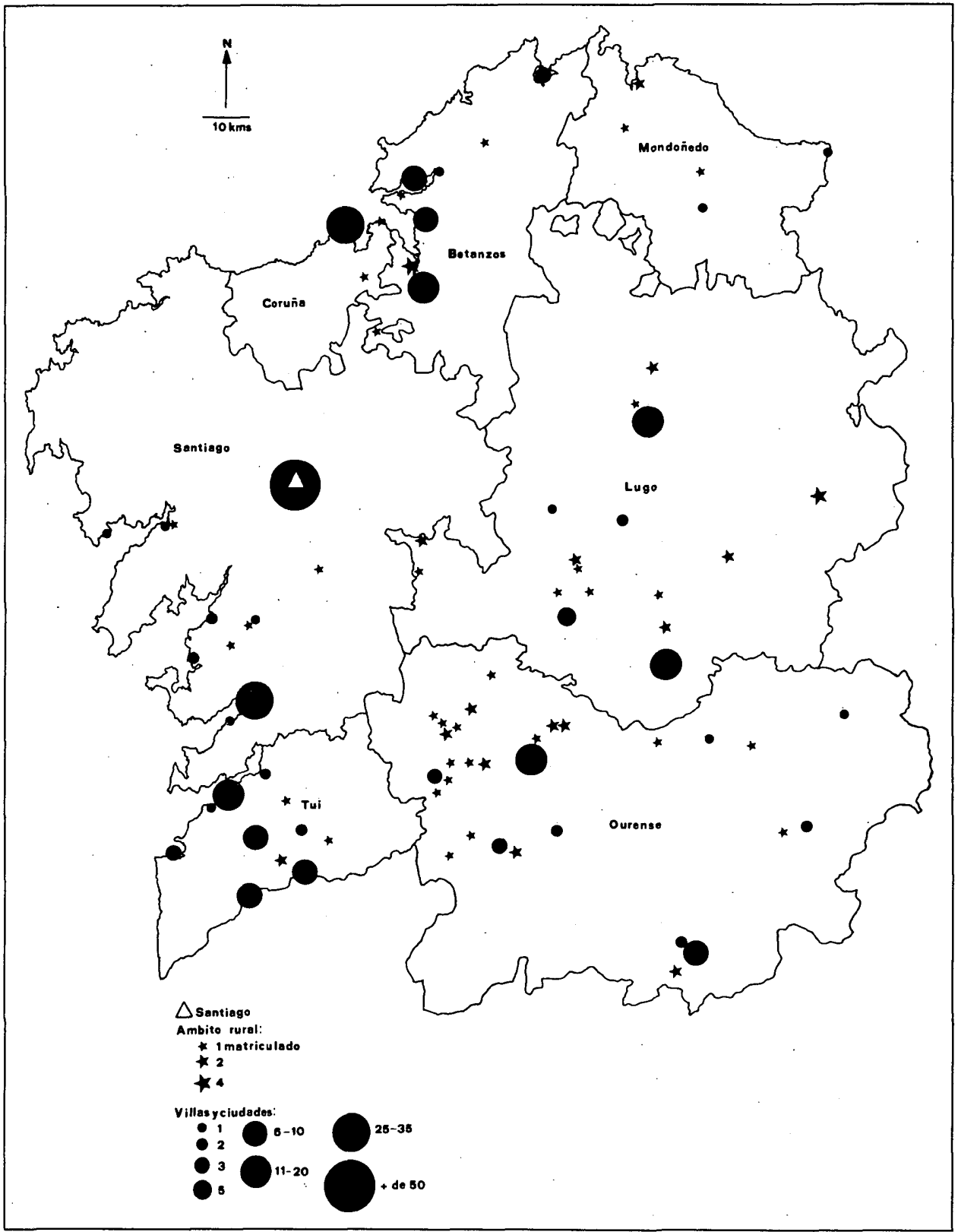

Hispania, LXIII/3, núm. 215 (2003) 907-968 
No obstante, conviene no perder de vista a los estudiantes hidalgos procedentes de las diócesis de Ourense y Lugo. Por separado representan respectivamente el $20,65 \%$-es decir, el segundo puesto- y el $19,64 \%$-el tercero- del total, pero en conjunto llegan a superar el $40 \%$. La gran concentración de casas-grandes y pazos en las comarcas vitivinícolas próximas a la capital orensana ${ }^{63}$, así como la progresiva asimilación de un modelo sucesorio no igualitario en las tierras lucenses, en el que se prima a la mejora vincular ${ }^{64}$, ambos factores ya presentes a comienzos del siglo XVII, parece que ha permitido que algunos de estos hidalgos rurales - muchos de ellos en vías de convertirse en poderosos rentistas - también se hayan animado a enviar a alguno de sus hijos temporalmente a Santiago, con la intención de que tomen contacto con el conocimiento de la cultura letrada y de la contabilidad.

Mucho menor resulta, en cambio, el porcentaje procedente de las diócesis de Mondoñedo - un 5,19\%-y Astorga - 1,52\%-, que se ven superadas incluso por los foráneos, que suponen un elevado $10,75 \%$ de todas las matrículas revisadas. El colectivo que nos ocupa se nutre, luego, ora principalmente de la Galicia atlántica, ora en segundo término de la Galicia interior en donde se han ido consolidando las poderosas casas-grandes hidalgas.

Conviene tener en cuenta, sin embargo, una advertencia relacionada con el método empleado a la hora de valorar el progresivo asentamiento en villas y ciudades que han protagonizado los ascendientes de estos alumnos, y que tiene su origen en el propio sistema de anotación empleado por los distintos individuos encargados de acometer el registro del pago de las matrículas. A mediados del siglo XVII era costumbre que se anotase con regularidad la diócesis de procedencia del alumno matriculado, aunque tal como hemos podido comprobar fue objeto de omisión, en este sentido, una cantidad mínima de 16 sujetos que apenas supone un $1,77 \%$ de la muestra; ahora bien, esto mismo no sucedía a la hora de anotar el punto exacto de origen, y las omisiones sí alcanzan a afectar aquí, en cambio, a un importante $49,33 \%$ del conjunto. Eso quiere decir que desconocemos la procedencia exacta de la mitad de estos estudiantes, y que, en consecuencia, no estamos en condiciones de valorar si procedían de parroquias rurales, $\mathrm{o}$, por el contrario, de ciudades y villas. Si nos atenemos a los resultados obtenidos por P.L. Gasalla y Pegerto Saavedra para un momento posterior al que nos ocupa, exactamente entre 1751 y 1805 , a partir de series más completas y fiables que las utilizadas en el presente trabajo, no cabe la menor duda de que el principal contingente de matriculados en la universidad compostelana - incluyendo a todo el alumnado, y no sólo al de origen hidalgo - habría procedido del ámbito

63 DOMíNGUez CASTRO, L.: «Las tierras vinculares orensanas a finales del Antigupo Régimen: origen y formas de explotación», en L. Fernández Prieto y X. Balbóa López (eds.): La sociedad rural en la España contemporánea. Mercado y patrimonio, Sada, 1996, p. 125.

${ }^{64}$ SOBRAdo CoRreA, H.: Las Tierras de Lugo en la Edad Moderna. Economía campesina, familia y berencia, 1550-1860, A Coruña, 2001, pp.400 y ss. 
rural $^{65}$. Así, todo parece indicar que las apreciaciones que podamos hacer al respecto se hallan muy mediatizadas, creemos, por una importante omisión de alumnos hidalgos de origen rural, sobre todo en lo referido a los residentes en las antiguas provincias de Lugo y Ourense ${ }^{66}$.

En todo caso, con los datos de que disponemos, sí parece posible demostrar una mayor procedencia urbana en el caso de la Galicia atlántica, y asimismo un equilibrio rural-urbano en el interior (Tabla 2.b y Mapa 2) ${ }^{67}$. Tal es así, que la mayor parte de los puntos de procedencia localizados para las antiguas provincias occidentales de Betanzos, A Coruña, Santiago y Tui siempre nos indican un claro predominio urbano ${ }^{68}$. Estos núcleos se extienden a lo largo de un eje longitudinal que arranca en las villas costeras de la antigua provincia de Betanzos, se desplaza en dirección sur hasta llegar a Santiago, y desde allí sigue por las Rías Baixas hasta alcanzar los enclaves fronterizos del Valle de O Rosal.

Los datos procedentes de algunos cursos concretos pueden servir para ilustrar mejor esta tendencia. Fijémonos, por ejemplo, en 1647. De las 6 villas o ciudades en las que reside/n algún/os de el/los alumno/s cotejado/s, tan sólo aparece destacado un núcleo urbano de la Galicia interior: la villa de Castro Caldelas (1). Por el contrario, los otros enclaves se hallan en dicho eje occidental: Neda (1) y Betanzos (2) al norte, Santiago (7) en el centro, Pontevedra hacia el sur en las Rías Baixas (2), y la villa de O Porriño más al sur (1), próxima a la frontera lusitana.

En 1650 nos encontramos con una imagen más equilibrada, cuando menos inicialmente: de las 16 villas y ciudades localizadas, corresponden 8 a cada zona; sin embargo, los núcleos occidentales vuelven a concentrar un número mayor de estudiantes que portan «Don». Así, desde Coruña (8) y Pontedeume (4) en el norte, el eje atlántico se vuelve a desplazar hacia el sur para llegar primero hasta Santiago (7), continuar por las Rías Baixas abarcando Pontevedra (3), Vigo (3) y Baiona (2), hasta alcanzar nuevamente la frontera con Portugal: Tui (3) y Salvaterra (2). Mientras tanto, en el interior, las villas y ciudades comprendidas entre las capitales provinciales de Lugo y Ourense arrojan una imagen bastante más modesta: Lugo (2), Portomarín (1), Chantada (1), Monforte

65 Gasalla Regueiro, P.L. y SaAvedra Fernández, P.: «Alumnos, bachilleres y catedráticos ...», p. 513.

${ }^{66}$ Máxime si tenemos en cuenta que a fines del siglo XVI, los súbditos hidalgos suponían el $7,8 \%$ de la población de la provincia de Lugo, y el $6,5 \%$ de la de Ourense. Vid. MolinieBERTRAND, A.: «Les «hidalgos» dans le Royaume de Castilla ...», art. cit.

${ }^{67}$ Para una mejor comprensión de la ideología de la hidalguía urbana de la Corona de Castilla en la transición del siglo XVI al XVII, vid. GUTIÉRREZ NiETO, J.I.: «Valores nobiliarios en España en la transición del Siglo XVI al XVII», en Torre de los Lujanes (Madrid), 28 (1994), pp. 35-43.

${ }_{68}$ Tal como han señalado P.L. Gasalla y Pegerto Saavedra, para el decenio 1691-1700, entre la totalidad de los alumnos matriculados en los primeros cursos de artes y cánones-leyes, los procedentes de villas y ciudades representaban un elevado 29,69\%, a los que debemos añadir el 5,38\% de la propia ciudad de Santiago. Vid. «Alumnos, bachilleres y catedráticos ...», p. 515.

Hispania, LXIII/3, núm. 215 (2003) 907-968 
(3) y Ourense (4). Otras villas orensanas tampoco ofrecen una imagen mejor: Ribadavia (1), Celanova (2) y Verín (2).

Finalmente, en tercer lugar, de los 13 núcleos urbanos localizados para 1655, sólo tres se hallan ubicados en la Galicia interior, y para ser más exactos en la provincia de Ourense: Ourense (1), Monterrei (1) y Verín (1). Es decir, nuevamente nos encontramos con un panorama similar al descrito para 1647. Las diez restantes encajan a la perfección en lo que ya sabemos: aparecen concentradas en una franja longitudinal de villas y ciudades próximas a la costa que se desplaza desde las Rías Altas - Ortigueira (1), Ferrol (1), Coruña (2) - hacia el sur, pasando por la Mariña Betanceira - Betanzos (2) - y Santiago (10), para difuminarse por las Rías Baixas - Noia (1), Cambados (1), Vilagarcía de Arousa (1) y Pontevedra (2) —, hasta parar en la frontera portuguesa — Tui (2) -

El principal contingente de estudiantes pertenecientes a la nobleza provincial asentada en la Galicia atlántica, durante el período 1647-55, residía en núcleos poblacionales urbanos. Santiago ocupaba, de hecho, el primer puesto, con un total de 59 matriculados que portan «Don», y Coruña - también capital provincial- el segundo, con 35 . Es más que probable que esta notable procedencia se halle condicionada por la progresiva irrupción de letrados en dichos núcleos urbanos durante el siglo $\mathrm{XVI}^{69}$, así como por la tradicional presencia de familias linajudas residiendo en ellas, situación que propició, en ocasiones, casamientos promovidos por intereses en común - para ambos grupos- muy relacionados con la noción de prestigio social ${ }^{70}$. No en vano, Hernando de Ojea

69 Vid. bibliografía citada en la nota 21 del presente trabajo.

${ }^{70}$ Aunque para la ciudad de Betanzos, puede verse el ejemplo del pacto matrimonial entre los Pardo, poseedores de una regiduría urbana, y los Taibo de las Casas de Mesoiro y Dexo, a comienzos del siglo XVII, en Presedo Garazo, A.: Dueños y señores de casas, torres y pazos ..., p. 462. Vid. en este mismo sentido los diversos trabajos incluidos en BERNARDo ARES, J.M. (de) y GONZÁLEZ BELTRÁN, J.M. (eds.): La Administración Municipal en la Edad Moderna, Cádiz, 1999, correspondientes a la Sección D. de la V Reunión Científica de la Fundación Española de Historia Moderna, concretamente pp. 471 y ss.; y también el volumen titulado Oligarquías y Municipio en la España de los Austrias, correspondiente a la Revista de Historia Moderna (Alicante), 19 (2001). Asimismo, vid. las revisiones de gran utilidad sobre el alcance de la organización social dentro del ámbito de la historia de la familia, y de la historia política en relación con el poder ejercido por ciertas familias calificables de notables, en el ámbito del modernismo español, en CHACón JiMÉNEZ, F.: «Hacia una nueva definición de la estructura social en la España del Antiguo Régimen», en Historia Social (Valencia), 21 (1995), pp. 71-104, y «Propuestas teóricas y organización social desde la Historia de la Familia en la España Moderna», en Stvdia Historica. Historia Moderna (Salamanca), 18 (1998), pp. 17-26; y HeRNÁDEZ FRANCO, J.: «El reencuentro entre historia social e historia política en torno a las familias de poder. Notas y seguimiento a través de la historiografía sobre la Castilla moderna», en Stvdia Historica. Historia Moderna (Salamanca), 18 (1998), pp. 179-199. Además de las obras colectivas de CHACóN Jiménez, F. y HeRnández Franco, J. (eds.): Poder, familia y consanguinidad en la España del Antiguo Régimen, Barcelona, 1992; HeRnÁNDEZ FRANCO, J. (ed.): Familia y poder. Sistemas de reproducción social en España (siglos XVI-XVIII), Murcia, 1995; CASEY, J. y HernándeZ FranCO, J. (eds.): Familia, Parentesco, Linaje, Murcia, 1997; e IMízcoz BEUnZA, J.M. ${ }^{\text {a }}$. (dir.): Elites, poder y red social. Las elites del País Vasco y Navarra en la Edad Moderna (Estado de la cuestión y perspectivas), Bilbao, 1996. 
dejó constancia en 1615 de los abundantes «Mayorazgos, y caualleros principales» que residían en Santiago ${ }^{71}$.

Las otras dos capitales provinciales occidentales, aunque también fueron cuna de algunos de estos estudiantes privilegiados, se encontraban ciertamente a un nivel inferior: Betanzos (12) y Tui (8), siendo incluso superadas por las villas marineras de Pontevedra (28) y Vigo (14). En todo caso, las cifras totales para el período vuelven a confirmar una concentración mayor en las villas costeras atlánticas, agrupadas en torno a un eje longitudinal que se desplaza hacia el sur desde las Rías Altas - Ortigueira (3), Neda (1) y Ferrol (10)-, pasando por la Mariña de Betanzos - Pontedeume (10)_, y tras recalar en la sede compostelana continuar por las villas asentadas en las inmediaciones de las Rías Baixas -Muros (1), Noia (1), Caldas de Reis (1), Vilagarcía de Arousa (2), Cambados (2), Marín (1), Redondela (2), Bouzas (1) y Baiona (3) - , hasta llegar a la comarca de O Rosal y a la frontera con el reino de Portugal - Ponteareas (2), Porriño (6) y Salvaterra (6)-.

La procedencia urbana resulta algo menor, sin embargo, en las provincias de Lugo y Ourense ${ }^{72}$. En la primera de ellas, la capital —esto es, Lugo (11) se ve incluso superada por la villa de Monforte (17), y el resto de núcleos localizados no llegan a sumar diez individuos en conjunto durante los nueve años comprendidos por la muestra: villas de Chantada (5), Monterroso (1) y Portomarín (2). Ahora bien, la procedencia rural sí aparece perfectamente reflejada en las proximidades de dichos enclaves, a diferencia de lo que sucede en la Galicia occidental. Por su parte, Ourense ofrece una imagen similar, aunque algo más compleja. Los 17 alumnos que portan «Don» procedentes de la capital hacen indiscutible su supremacía entre los núcleos urbanos de la Galicia interior. Las villas que la circunvalan también merecen ser tenidas en cuenta: Ribadavia (3), Allariz (2) y Celanova (3), del mismo modo que las ubicadas en la franja más oriental: villas de Castro Caldelas (1), Viana do Bolo (2), Barco de Valdeorras (1), Monterrei (3) y Verín (6). Pero es preciso destacar la alta presencia, entre el alumnado hidalgo orensano, de vástagos procedentes de casas grandes asentadas en los Ribeiros del Miño y del Avia, así como en la jurisdicción de A Peroxa, que todavía se hallan inmersas en plena consolidación patrimonial ${ }^{73}$, lo cual no hace sino subrayar su enorme poderío económico.

71 OJEA, H.: Historia del Glorioso Apóstol Santiago, Madrid, 1615, ff.362v.-363r.

${ }_{72} \mathrm{Y}$ eso aún dando por supuesto que Lugo fue la ciudad gallega que contó con la mayor presencia de hidalgos entre sus vecinos durante toda la Edad Moderna, tal como ha demostrado recientemente BURGo LóPEZ, $\mathrm{M}^{\mathrm{a}}$.C.: «Lugo na Idade Moderna», en F. Arias Vilas et al.: Historia de Lugo, A Coruña, 2001, p. 134.

$73 \mathrm{Tal}$ como se puede comprobar a partir de los ejemplos de las casas de Casaldereito (en el Ribeiro del Avia) y Fontefiz (en A Peroxa). Vid. Domínguez CASTro, L.: Viños, viñas e xentes do Ribeiro. Economía e patrimonio familiar, 1810-1952, Vigo, 1992, pp. 40 y ss.; y LEIRÓS DE LA PEÑA, P.: «La casa de Fontefiz», en Boletín Avriense (Ourense), XXIII (1993), pp. 200-204. 


\subsection{Pervivencias y cambios a mediados del siglo XVIII}

El registro de matrículas que hemos consultado para los años 1751-54 presenta un obstáculo de consideración que nos ha alertado sobre los riesgos que supondría identificar, en estos momentos ya avanzados de la Época Moderna, a los estudiantes de hipotético origen hidalgo, basándonos exclusivamente en el hecho de si portan, o no, el timbre ${ }^{2}$ Don» ${ }^{74}$. Tal como acabamos de comprobar, éstos suponían de media un $33 \%$ sobre el total de matrículas a mediados del siglo XVII; es decir, un destacado tercio que no alcanzaba a copar las aulas universitarias, y que, por lo tanto, estaba obligado a convivir con otros alumnos procedentes de otros grupos sociales igualmente dominantes en el seno de la sociedad gallega. Pues bien, a mediados del XVIII, todos los alumnos matriculados en la Universidad de Santiago, sin ninguna excepción - cuando menos los revisados para dicho quinquenio-, han sido asentados precedidos del «Don»; o lo que es lo mismo, el $100 \%$ responde a esta norma. No obstante, creemos que resulta difícil que se pueda sostener la idea de que todos los estudiantes que asistieron por entonces a las lecciones de los tres cursos de Artes, a los dos de Teología y a los cinco de Leyes y Cánones hubiesen procedido en su integridad de las filas de la nobleza provincial.

El simple seguimiento de los apellidos de los matriculados puede servirnos para confirmar, rudimentaria pero efectivamente, que muchos de ellos no se han criado en el seno de familias hidalgas. Tomemos de referencia, por ejemplo, los matriculados en primero de Leyes en el año académico 1753-54: individuos como don Ángel Díaz Carrillo, don Juan Rodríguez, don Joaquín García, don Jacobo Sánchez, don Miguel Correa, don José Medelo, don Marcos Costas, don Benito Casal, etc., no encajan precisamente -que digamos- en la onomástica compleja, a base de nombre y apellido compuestos tan habituales en la hidalguía gallega de estos momentos. Pero lo cierto es que si nos fijamos en el mismo curso y misma carrera un año más tarde, esto es 1754-55, vemos repetirse nuevamente esta rutina: don Pedro Antonio Botana, don José Méndez, don Tomás Sotelo, don José Benito Santos, don Andrés Vázquez, etc. A su lado aparecen individuos con apellidos tales como Vaamonde, Ribadeneira, Ocampo, Somoza, Osorio, Cadórniga, Varela, Seixas, etc., a los cuales podría atribuírseles, muy tímidamente, cierta filiación hidalga sólo verificable a través de un seguimiento individualizado de todos y cada uno de ellos, tarea en la actualidad inabarcable si tenemos en cuenta que todavía no existe un inventario genealógico-nobiliario completo y exhaustivo para el conjunto de la Galicia moderna.

Todo parece indicar, luego, que el empleo del timbre «Don» se había diversificado y vulgarizado en tal medida en el ideario social gallego a mediados del siglo XVIII, que a la hora de proceder a matricular a un alumno en una de las

${ }_{74}$ A.H.U.S., F.U., S.H., leg. 211, Libro de matrículas de 1751-54. 
cuatro carreras existentes entonces en la universidad compostelana, se optó simplemente por asentarle precedido del «Don» fuese o no hidalgo. Los resultados obtenidos por J.M. Pérez García para la comarca de O Salnés —en las Rías Baixas - en este preciso momento vienen a reforzar esta hipótesis; ya que tan sólo un $34 \%$ de los alumnos universitarios por él localizados en esta comarca eran de extracción hidalga ${ }^{75}$. En consecuencia, todo parece indicar que el registro de matrículas por sí solo, a mediados de la centuria dieciochesca, no sirve para determinar con exactitud, ni siquiera para elaborar estimaciones aproximadas, si un alumno procede o no de una casa hidalga.

Esta rutina puesta en práctica por dicha institución, no hace sino confirmar la hipótesis de que los roles sociales tradicionalmente aceptados hasta entonces en el reino gallego están siendo objeto de una mutación que afecta a su contenido; un proceso que también podremos ver reflejado en la dinámica por la que se rigen las relaciones entre los distintos grupos sociales dominantes, para los cuales los valores simbólicos ocupan un lugar preferente y destacado ${ }^{76}$. Sin salir de la misma ciudad de Santiago, el profesor Antonio Eiras Roel, basándose en el Catastro de Ensenada, ha demostrado que había hidalgos cuyos ingresos económicos eran inferiores a los de algunos artesanos urbanos a la altura de 1752, así como mujeres de evidente condición hidalga que se dedicaban a hacer labores de encaje y costura ${ }^{77}$. Él mismo nos aclara que:

«La pertenencia a la élite exige reunir a la vez fortuna, prestigio, poder y respetabilidad social y no necesariamente linaje noble, aunque la mayor parte de sus individuos vivan noblemente y un elevado porcentaje posea patentes de hidalguía o nobleza, casi siempre reciente. En esta época de transición de mediados del XVIII, vivir noblemente parece ya más importante que el hecho de ser efectivamente noble» 78 .

Pero lejos de tratarse de una característica estructural exclusiva de la sociedad compostelana urbana del tramo central del siglo, nos hallamos ante una realidad social trasladable cuando menos a las otras tres capitales de provincia de la Galicia occidental, para las cuales disponemos hoy en día de datos ${ }^{79}$. Así,

75 Pérez García, J.M.: Opus cit., p. 387.

76 Resultan muy oportunas en relación con esta cuestión las apreciaciones de GOUBERT, P.: "Observaciones sobre el vocabulario social del Antiguo Régimen», en C.E. Labrousse et al.: Órdenes, estamentos y clases, Madrid, 1978 (París, 1973), pp. 163 y ss.; y de LENSKI, G.E.: Poder y privilegio. Teoría de la estratificación social, Barcelona, 1993 ( $1^{\text {a }}$ ed. en inglés de 1966).

77 EIRAS ROEL, A.: «Las élites urbanas de una ciudad tradicional: Santiago de Compostela a mediados del siglo XVIII", en VV.AA.: La Documentación Notarial y la Historia, Santiago, 1984, vol.I, p. 120 .

78 EIRAS Roel, A. (ed. e introd.): Santiago de Compostela, 1752, Según las Respuestas Generales del Catastro de Ensenada, Madrid, 1990, pp. 23-24.

79 Y no sólo en Galicia, sino también en el contexto general de la Corona de Castilla, tal como ha demostrado ÁlvareZ-OSSORIO AlVARIÑo, A.: «Rango y apariencia. El decoro y la quiebra de la

Hispania, LXIII/3, núm. 215 (2003) 907-968 
en la ciudad de Tui es posible distinguir en 1753 a mujeres hidalgas que, según Ofelia Rey, llevarían «una muy mediocre existencia» al carecer de servicio doméstico y además aparecer clasificadas como «solteras», «viudas» y «sin oficio» ${ }^{80}$. En Coruña, había incluso dos hidalgos ejerciendo de maestros de peluquería en 1752. Tanto don Pedro Antonio Pereiro y Saavedra como don Juan Pardo Ribadeneira no alcanzan a ingresar anualmente ni 2.000 rs., bastante menos que algún maestro herrero o algún tratante de sardina y bacalao en salazón ${ }^{81}$. Y en Betanzos, también en este mismo momento, la elite hidalga no suponía más de un tercio sobre dicho colectivo nobiliario ${ }^{82}$.

Por tanto, parece poco probable que todos/as los/as individuos/as que aparecen como hidalgos/as y con el timbre «Don» en los distintos padrones catastrales de estas cuatro ciudades, hubiesen podido costearse un ritmo de vida ostentoso acorde con su evidente condición nobiliaria, únicamente verificable a partir del propio trato de que son merecedores por parte de quienes estaban encargados de asentarlos/as en los distintos padrones ${ }^{83}$. A su vez, estos hidalgos incapaces de costearse un gasto regular y considerable en lujo conviven con otros individuos que, sin serlo, sí están en condiciones de hacerlo - tratantes, cargos de la milicia, burócratas empleados en distintas administraciones ...-; y todos ellos comparten un mismo espacio social y un mismo universo mental, en los cuales la riqueza y el estilo de vida parecen haberse sobrepuesto a las tradicionales barreras estamentales ${ }^{84}$.

Visto este cambio que se está produciendo y que afecta seriamente a ciertos hábitos relacionados con el capital simbólico, es lógico deducir que, sin tener en cuenta otro tipo de fuentes históricas complementarias, el simple manejo de los libros de matrículas de alumnos por sí solo no sirva para determinar qué cantidad exacta de estudiantes podrían ser asimilables o no al entorno de la nobleza provincial. A lo sumo, nos pueden ofrecer una orientación aproximada, pero nunca del todo precisa, sobre su procedencia geográfica, dando por supuesto que éstos responden a las pautas generales afines al colectivo estudiantil.

distinción en Castilla (siglos XVI-XVIII)», en Revista de Historia Moderna (Alicante), 17 (199899), pp. 263-278.

${ }^{80}$ Rey CASTELAO, O. (ed. e introd.): Tuy, 1753, Según las Respuestas Generales del Catastro de Ensenada, Madrid, 1990, p. 28.

${ }^{81}$ Barreiro Mallón, B. (ed. e introd.): La Coruña, 1752, Según las Respuestas Generales del Catastro de Ensenada, Madrid, 1990, p. 169.

82 VAQuero Lastres, B.: «La hidalguía en Betanzos en el siglo XVIII: La familia y la vivienda», en Anuario Brigantino (Betanzos), 9 (1986), p. 55.

${ }_{83}$ Cuestión que, además, podemos ver reflejada en el entorno rural. Vid. Presedo Garazo, A.: Dueños y señores de casas, torres y pazos ..., pp. 330-341.

${ }^{84}$ Aunque en el plano teórico, la crítica ilustrada sigue sosteniendo «una tradición de hostil desconfianza hacia los plebeyos ennoblecidos», tal como ha señalado ARAGÓN MATEOS, S.: «Nobleza y opinión pública en tiempos de Carlos III. Los límites de la crítica social ilustrada», en Pedralbes. Revista d'Historia Moderna (Barcelona), 8-I (1988), p. 20.

Hispania, LXIII/3, núm. 215 (2003) 907-968 
TABLA 3: PROCEDENCIA GEOGRÁFICA DE LOS ESTUDIANTES MATRICULADOS EN PRIMERO DE LEYES EN EL AÑO ACADÉMICO 1754-55.

\begin{tabular}{|l|c|}
\hline \multicolumn{2}{|c|}{ a. Según la diócesis } \\
\hline Astorga & 2 \\
\hline Lugo & 5 \\
\hline Mondoñedo & 5 \\
\hline Ourense & 7 \\
\hline Santiago & 14 \\
\hline Tui & 8 \\
\hline No gallegos & 7 \\
\hline Sin especificar & 1 \\
\hline Total & 49 \\
\hline & 14 \\
\hline Parroquias rurales & 16 \\
\hline Villas y ciudades & 7 \\
\hline No gallegos & 49 \\
\hline Sin especificar & 12 \\
\hline Total & urbano de ámbito rural o urbano \\
\hline
\end{tabular}

Fuente: Elaboración propia a partir de A.H.U.S., F.U., S.H., leg.211, Libro de matrículas de 1751-54.

A tenor de los datos procedentes de la matrícula del primer curso de leyes correspondiente al año académico 1754-55 (Tabla 3), es posible establecer cierto grado de continuidad con lo que hemos apreciado cien años atrás ${ }^{85}$ : el grueso estudiantil sigue procediendo en su mayoría de las dos diócesis occidentales (Santiago y Tui), suponiendo el $44,89 \%$ del total, mientras que las de Lugo y Ourense aportan un nada desdeñable $24,48 \%$ que irá en aumento hasta comienzos del siglo XIX ${ }^{86}$. Sí se confirma, en cambio, una mayor procedencia de parroquias rurales en comparación a lo que sucedía a mediados del XVII, posiblemente debido a que, tal como han demostrado P.L. Gasalla y Pegerto Saavedra, desde las últimas décadas de dicho siglo «parecen haberse incrementado las posibilidades de acceso de los hijos de campesinos de cierto acomodo a los estudios universitarios, en muchas ocasiones con la mira puesta en la carrera clerical ${ }^{87}$.

Para intentar solventar esta deficiencia informativa que presentan los libros de matrículas en este momento, hemos dirigido nuestro interés hacia los expe-

\footnotetext{
${ }^{85} \mathrm{La}$ edad media para este reducido grupo de matriculados es de 18,48 años.

${ }^{86}$ Gasalla Regueiro, P.L. y SAavedra Fernández, P.: "Alumnos, bachilleres y catedráticos ...», pp. 516-519.

87 Ibidem, p. 515.
} 
dientes personales de alumnos con la intención de encontrar información complementaria. En total, han sido supervisados 360 expedientes correspondientes a estudiantes cuyo primer apellido comienza por la letra $« S » 88$.

En estos expedientes académicos acostumbra a hacerse mención al lugar de procedencia del alumno en cuestión, junto con el seguimiento de los estudios cursados, y en menor medida aparecen referencias a su ascendencia familiar, frecuentes a partir de 1815 - ya coincidiendo con la crisis del Antiguo Régimen-. Es esta última circunstancia la que nos indujo a adentrarnos en dicha fuente, para la cual no se conservan series homogéneas y completas durante el período histórico que nos ocupa. Así, lejos de las expectativas que nos habíamos propuesto inicialmente, los resultados finales tampoco arrojan demasiada luz para el tramo central del siglo XVIII, y aunque sí lo hacen para comienzos del XIX, hemos de tomar estos datos con cierta precaución, pues, tal como hemos tenido ocasión de señalar un poco más arriba, coincide con un momento en el que se están produciendo cambios relevantes en la evolución de la matrícula en la Universidad de Santiago. Dos argumentos de suficiente peso nos alertan acerca de estos límites informativos que presenta la base de datos que hemos elaborado (Tabla 4).

En primer lugar, de los 358 expedientes personales consultados, tan sólo un único caso ofrece información concisa sobre la ascendencia familiar de un individuo para antes de 1800, algo después de mediados del XVIII ${ }^{89}$. Esta otra muestra tampoco soluciona, por tanto, el problema que plantean los libros de matrículas para momentos ya avanzados de la Época Moderna. La relación de expedientes que se conservan para el XVIII/2 es superior a los que nos han llegado del XIX (215 frente a 143), por lo que incluso los primeros disponen de una representatividad mayor en la serie; sin embargo, al no incluir información complementaria alguna sobre la ascendencia familiar, su utilidad resulta lamentablemente infructuosa para resolver el problema que plantean los asientos de matrículas.

88. La elección de dicha letra para acometer la elaboración de la serie responde a un criterio arbitrario, fundamentado en el hecho de que existe una nutrida serie de apellidos hidalgos gallegos que comienzan por «S», tales como Saavedra, Sanxurxo, Sarmiento, Sánchez Fraguío, Somoza, Soutomaior...; hemos añadido además todos los expedientes de los alumnos que se hayan apellidado Taboada. La muestra ha sido confeccionada a partir de A.H.U.S., F.U., E.P., legs.1310 a 1312, 1329 a 1332,1349 a $1352,1373,1374,1378$ a 1380,1408 a 1412, y 1434 a 1441 . De estos 360 expedientes supervisados, hemos prescindido de dos: el de don Jacinto Taboada (leg.1434), que estaba estudiando Teología en 1700 , por tratarse de una fecha lejana a la realidad histórica que pretendemos reconstruir para mediados de siglo; y el de don José Esteban Somoza de Lobera (leg.1410), que cursaba leyes en 1750 y que consiguió una beca en el Colegio de Fonseca, motivo por el cual hemos decidido incluirlo en el análisis de los colegiales.

89 Nos referimos al expediente personal de don Vicente Taboada Gil, quien cursó leyes y cánones en 1771-79 y procedía de la feligresía de S. Martiño de Prado, en la diócesis de Lugo, en el cual se incluye su partida de bautismo fechada en 1754, en la que se hace referencia al hecho de que sus padres don José Taboada y doña Rosa Gil Teixeiro habían sido "Dueños de la Casa de Liñares». A.H.U.S., F.U., E.P., leg. 1436.

Hispania, LXIII/3, núm. 215 (2003) 907-968 
TABLA 4: RELACIÓN PORMENORIZADA DE LOS EXPEDIENTES PERSONALES COTEJADOS, ORDENADOS CRONOLÓGICAMENTE.

\begin{tabular}{|l|c|c|c|c|c|}
\hline \multirow{3}{*}{ PERÍODO } & \multicolumn{2}{|c|}{$\begin{array}{c}\text { TOTAL DE EXPEDIENTES } \\
\text { COTEJADOS }\end{array}$} & \multicolumn{3}{|c|}{$\begin{array}{c}\text { EXPEDIENTES CON REFERENCIAS A } \\
\text { LA ASCENDENCIA FAMILIAR }\end{array}$} \\
\cline { 2 - 6 } & $\mathrm{n}^{\circ}$ & \% sobre el total & $\begin{array}{c}\text { Alumnos con } \\
\text { ascendientes que } \\
\text { portan «Don» }\end{array}$ & $\begin{array}{c}\text { Alumnos sin } \\
\text { ascendientes que } \\
\text { portan «Don» }\end{array}$ & Total \\
\hline $1741-50$ & 9 & 2,51 & 0 & 0 & 0 \\
\hline $1751-55$ & 6 & 1,67 & 0 & 0 & 0 \\
\hline $1756-60$ & 9 & 2,51 & 0 & 0 & 0 \\
\hline $1761-65$ & 12 & 3,35 & 0 & 0 & 0 \\
\hline $1766-70$ & 12 & 3,35 & 0 & 0 & 0 \\
\hline $1771-75$ & 14 & 3,91 & 1 & 0 & 1 \\
\hline $1776-80$ & 20 & 5,58 & 0 & 0 & 0 \\
\hline $1781-85$ & 26 & 7,26 & 0 & 0 & 0 \\
\hline $1786-90$ & 17 & 4,74 & 0 & 0 & 0 \\
\hline $1791-95$ & 19 & 5,30 & 0 & 0 & 0 \\
\hline $1796-1800$ & 17 & 4,74 & 0 & 0 & 0 \\
\hline $1801-05$ & 10 & 2,79 & 0 & 0 & 0 \\
\hline $1806-10$ & 7 & 1,95 & 0 & 0 & 0 \\
\hline $1811-15$ & 11 & 3,07 & 0 & 0 & 0 \\
\hline $1816-20$ & 15 & 4,18 & 2 & 0 & 2 \\
\hline $1821-25$ & 20 & 5,58 & 5 & 1 & 6 \\
\hline $1826-30$ & 38 & 10,61 & 13 & 2 & 15 \\
\hline $1831-35$ & 29 & 8,10 & 8 & 0 & 8 \\
\hline $1836-40$ & 11 & 3,07 & 4 & 1 & 5 \\
\hline $1841-45$ & 19 & 5,30 & 7 & 3 & 10 \\
\hline $1846-50$ & 19 & 5,30 & 7 & 2 & 9 \\
\hline $1851-60$ & 18 & 5,02 & 4 & 2 & 6 \\
\hline Total & 358 & 100,00 & 50 & 11 & 61 \\
\hline & & & & & 0 \\
\hline
\end{tabular}

Fuente: Elaboración propia a partir de A.H.U.S., F.U., E.P., legs.1310 a 1312, 1329 a 1332, 1349 a $1352,1373,1374,1378$ a 1380,1408 a 1412, y 1434 a 1441 .

Hemos de añadir todavía un segundo obstáculo igualmente importante. Los 61 expedientes personales comprendidos entre 1816 y 1860 que contienen información genealógica, tan sólo representan un 36,09\% de todos los que se redactaron en dicho intervalo de tiempo, y apenas llegan a suponer un modesto $17,03 \%$ sobre los 358 totales. Las estimaciones que podamos obtener resultan, pues, parciales e incompletas, y a lo sumo sirven para establecer una tendencia genérica, pero nunca para dar una visión exhaustiva y completa. Es más, se 
refieren a distintos estudiantes cuya ascendencia en primer y segundo grado podemos retrotraer hasta momentos muy avanzados del Antiguo Régimen, pero que, a diferencia de aquellos, tendrán que asistir a la difusión de ciertos cambios que intentarán limitar algunos privilegios de los que se había venido beneficiando la nobleza provincial gallega durante los siglos modernos ${ }^{90}$.

El principal contingente de este reducido grupo de alumnos para los cuales disponemos de información genealógica o bien nacieron entre 1811 y 1830 —un $40 \%$ - o bien comenzaron sus estudios en dicho intervalo de tiempo - un $22 \%$ - 91 . Sea lo que fuere, sus antepasados inmediatos, o lo que es lo mismo sus padres y distintos abuelos, vivieron en pleno Antiguo Régimen, por lo que la información que ofrecen puede resultar indicativa de pervivencias y/o cambios sociológicos respecto a lo que sucede en momentos anteriores.

La distribución de las principales áreas geográficas de procedencia sigue coincidiendo con lo que ya sabemos ${ }^{92}$ : por provincias, las occidentales acumulan un número mayor de alumnos (en este caso concreto Betanzos y Santiago), si bien es cierto que Lugo es merecedora de un segundo destacado puesto; y por diócesis, vemos repetirse este mismo esquema ya que Santiago ocupa el primer puesto y Lugo nuevamente el segundo. Al igual que los libros de matrículas, los expedientes personales indican que la Galicia occidental sigue siendo la principal área de procedencia, mientras que en la Galicia interior, y para ser más exactos en la provincia de Lugo, comienza a percibirse un interés por los estudios universitarios que irá in crescendo a medida que avance el siglo XIX. Por su parte, el equilibrio entre el origen rural y el urbano responde más a la propia casuística de los expedientes cotejados a la hora de elaborar la muestra, que a la tendencia general, en la cual, como hemos visto, prima el alumnado nacido en las parroquias rurales.

La información sociológica sí ofrece, en cambio, algunas pistas que creemos más relevantes ${ }^{93}$. Un $38 \%$ de este reducido grupo están emparentados entre sí a través de lazos fraternales, por lo que están coincidiendo en las aulas universitarias compostelanas alumnos con algún hermano, y que el gasto a que debe de hacer frente su familia de procedencia se multiplica por el número de hijos que se hallan cursando sus respectivos estudios; es decir, proceden de familias económicamente acomodadas ${ }^{94}$. No en vano, el $98 \%$ de los padres de todos ellos aparecen precedidos del timbre "Don", aunque responden a grupos sociales aparentemente distintos: un $10 \%$ de los mismos pueden ser asimilados a la

90 Presedo Garazo, A.: Dueños $y$ señores de casas, torres $y$ pazos ..., pp. 551 y ss.

91 Vid. Apéndice 2.1.

92 Vid. Apéndice 2.2

93 Vid. Apéndice 2.3

${ }_{94}$ Sirvan de ejemplo los tres hermanos Félix María, Juan Crisóstomo, y Patricio Antonio Taboada Loureiro, nacidos en la misma ciudad de Santiago a comienzos del siglo XIX, quienes pasaron por las aulas universitarias compostelanas en 1827-34, 1825-29 y 1822-32 respectivamente. A.H.U.S., F.U., E.P., leg.1437.

Hispania, LXIII/3, núm. 215 (2003) 907-968 
nobleza provincial 95 , un $8 \%$ a individuos que desempeñan profesiones libera$l^{1 e s}{ }^{96}$, y un destacadísimo $82 \%$ a situaciones posiblemente intermedias entre ambos grupos, a los cuales habría que añadir incluso cargos políticos y militares, y también comerciantes y algún que otro campesino acomodado.

En lo que se refiere a los abuelos, la mayoría porta el «Don», si bien es cierto que con un matiz considerable: mientras que en un 58\% de los casos ambos cónyuges aparecen precedidos de dicha fórmula, tan sólo en un $8 \%$ lo hace uno de los dos miembros de la pareja marital. Estos últimos nos están indicando que incluso en momentos tardíos del Antiguo Régimen los pactos matrimoniales sirven para culminar procesos de ascenso social. De hecho, sólo un reducido $2 \%$ es asimilable, con toda certeza, a las filas de la nobleza local, por lo que es muy probable que algunos miembros de esta generación aún hayan podido fundar alguna mejora vincular durante el transcurso de sus vidas. El $12 \%$ de abuelos ejerciendo profesiones liberales no hace sino incidir nuevamente en ello ${ }^{97}$.

El origen hidalgo de los alumnos cuyos expedientes personales ofrecen información genealógica se diluye, luego, entre una densa bruma de realidades sociales indeterminadas, en las cuales el hecho de portar "Don» no tiene porque ser significativo de hidalguía, aunque sí de amplia capacidad adquisitiva. Tal es así, que si nos limitásemos en exclusividad a la información que se deriva de esta fuente, los alumnos con antepasados directos identificados como hidalgos jamás habrían llegado a exceder del $10 \%$. Un reducido porcentaje, sin lugar a dudas, que seguramente pueda experimentar un incremento considerable en caso de disponer de información complementaria para el sector mayoritario con ascendientes indeterminados merecedores de este distintivo. En todo caso, la presencia de alumnos con padres y abuelos ejerciendo profesiones liberales también nos está indicando que sus progenitores han tenido muy en cuenta su futura recolocación en dicho entorno laboral una vez finalizados sus estudios universitarios, así que, llegado el caso, incluso hubiesen sido capaces de hacerle sombra a los estudiantes procedentes de familias nobiliarias. De un modo o de

95 Tal como se puede ver en el Apéndice 2.3, los individuos cuyos padres aparecen asociados a la hidalguía tan sólo representan el $8 \%$; el incremento hasta el $10 \%$ es debido a que hemos tenido en cuenta a mayores a don Juan María Saavedra, quien cursando leyes en 1820-23 y procediendo de la parroquia de Santiago de Xubial, en la diócesis de Lugo, aparece reconocido en su expediente personal como "caballero maestrante de la Real de Ronda» (A.H.U.S., F.U., E.P., leg. 1310). Entre los estudiantes cuyos padres forman parte de la hidalguía, podemos citar a modo de ejemplo a don Benito Sánchez Barallobre y Freire, nacido en 1823, quien cursa jurisprudencia en 1841-47, y cuyo padre era "dueño de la casa y antiguo pazo del mismo nombre [Roade], tambien llamado de Golmar», sito en S. Andrés de Roade, en la diócesis de Santiago (A.H.U.S., F.U., E. P., leg. 1329).

${ }_{96}$ Podemos verlo perfectamente reflejado en los hermanos Benito y Gregorio Sánchez Coucieiro, ambos hijos del escribano de Pontedeume don Ramón Sánchez Coucieiro. El primero de ambos, nacido en 1810 , cursa filosofía en 1828 , y el segundo, cuya fecha exacta de nacimiento desconocemos, estudia leyes en 1820-28. A.H.U.S., F.U., E.P., leg. 1331.

97 Vid. algunos ejemplos en A.H.U.S., F.U., E.P., leg. 1331 (Ibidem), y leg. 1350 (expediente de don José Sanxurxo Barbié). 
otro, las distintas pistas siempre apuntan en la dirección de que estos últimos siguieron siendo minoritarios entre 1811 y 1830.

TABLA 5: ESTUDIOS CURSADOS POR LOS 163 ALUMNOS CUYOS EXPEDIENTES PERSONALES SE REDACTARON ENTRE 1751 Y $1804^{98}$.

\begin{tabular}{|l|c|c|c|c|c|}
\hline QUINQUENIO & LEYES Y CÁNONES & ARTES & TEOLOGÍA & MEDICINA & LATINIDAD \\
\hline $1751-55$ & 2 & 2 & 1 & 0 & 0 \\
\hline $1756-60$ & 3 & 5 & 2 & 0 & 0 \\
\hline $1761-65$ & 5 & 7 & 1 & 0 & 0 \\
\hline $1766-70$ & 3 & 8 & 1 & 0 & 0 \\
\hline $1771-75$ & 7 & 7 & 2 & 0 & 0 \\
\hline $1776-80$ & 12 & 6 & 2 & 0 & 0 \\
\hline $1781-85$ & 10 & 12 & 4 & 0 & 1 \\
\hline $1786-90$ & 7 & 6 & 3 & 1 & 0 \\
\hline $1791-95$ & 10 & 7 & 3 & 1 & 0 \\
\hline $1796-1800$ & 9 & 7 & 1 & 0 & 0 \\
\hline $1801-04$ & 2 & 6 & 2 & 0 & 0 \\
\hline Total & 70 & 73 & 22 & 2 & 1 \\
$\%$ & 41,46 & 43,45 & 13,09 & 1,19 & 0,59 \\
\hline
\end{tabular}

Fuente: Elaboración propia a partir de A.H.U.S., F.U., E.P., legs.1310 a 1312, 1329 a 1332, 1349 a $1352,1373,1374,1378$ a 1380,1408 a 1412 , y 1434 a 1441.

En lo que se refiere a las carreras universitarias preferidas por los estudiantes cuyos expedientes personales hemos incluido en la muestra (Tabla 5), éstas coinciden con los datos obtenidos por P.L. Gasalla y Pegerto Saavedra al estudiar la evolución de la matrícula en la universidad compostelana durante la Época Moderna. Las series confeccionadas por ambos autores confirman un incremento de la matrícula en Artes a partir de mediados del siglo XVIII frente a las otras carreras ${ }^{99}$, muy relacionado con el aumento de las posibilidades que se le presentan al campesinado acomodado desde fines del XVII a la hora de enviar a sus hijos a la Universidad de Santiago, frecuentemente motivados por una futura recolocación en el estamento eclesiástico ${ }^{100}$. Dicha supremacía

\footnotetext{
98 Los 5 alumnos que cursaron a la vez cánones y teología han sido registrados en ambas carreras, por lo que la cifra total resultante que hemos tomado de base para efectuar los cálculos porcentuales es de 168. Asimismo, tampoco han sido tenidos en cuenta los 10 alumnos cuyos expedientes comenzaron a redactarse antes de 1751.

99 Gasalla Regueiro, P.L. y SAAvedra FernáNDeZ, P.: «Alumnos, bachilleres y catedráticos ...», pp. 570-572.

100 Ibidem, p. 515.
}

Hispania, LXIII/3, núm. 215 (2003) 907-968 
también se deja notar en nuestra serie para el período 1751-1804, pues el $43,45 \%$ de los encuestados se decantan por tal carrera; si bien es cierto que conviene no perder de vista al destacado segundo sector compuesto por quienes han optado por el Derecho. Es entre éstos donde, con más probabilidad, nos hemos de encontrar con vástagos de casas hidalgas, para quienes, todavía en momentos tardíos del Antiguo Régimen, las prebendas eclesiásticas siguen siendo un buen reclamo para una futura colocación ${ }^{101}$, del mismo modo que el servicio en la administración, tanto pública como privada.

TABLA 6: PROCEDENCIA GEOGRÁFICA DE 173 ALUMNOS CUYOS EXPEDIENTES PERSONALES SE REDACTARON ENTRE 1741 Y 1804.

\begin{tabular}{|l|c|}
\hline \multicolumn{2}{|c|}{ a. Según la diócesis } \\
\hline Lugo & 39 \\
\hline Mondoñedo & 4 \\
\hline Ourense & 20 \\
\hline Santiago & 59 \\
\hline Tui & 11 \\
\hline No gallegos & 3 \\
\hline Sin especificar & 37 \\
\hline Total b. Según se trate de ámbito rural o urbano \\
\hline \multicolumn{2}{|c|}{173} \\
\hline Parroquias rurales & 93 \\
\hline Villas y ciudades & 37 \\
\hline No gallegos & 3 \\
\hline Sin especificar & 40 \\
\hline Total & 173 \\
\hline
\end{tabular}

Fuente: Elaboración propia a partir de A.H.U.S., F.U., E.P., legs. 1310 a 1312,1329 a 1332,1349 a $1352,1373,1374,1378$ a 1380,1408 a $1412, y$ 1434 a 1441.

El monto principal de estudiantes localizados han nacido en la Galicia atlántica, y se concentran en las diócesis de Santiago y Tui. No obstante, también destaca suficientemente el segundo puesto que ocupan las provincias eclesiásticas de Lugo y Ourense, esto es, en la Galicia interior, donde está constatada una mayor presencia porcentual de hidalgos en el contexto del reino

101 Tal como demostró en su día PÉrez Costantr, P.: Linajes galicianos, en Boletín de la Real Academia Gallega (A Coruña), 1911-1924 (ed. completa y ampliada a cargo de E. Pardo de Guevara y Valdés, Santiago, 1998), pp. 209 y ss. 
gallego ${ }^{102}$. Nos hallamos, pues, ante una característica que podemos retrotraer hasta mediados del siglo anterior, y que parece haberse incrementado a medida que se fueron generalizando las fundaciones vinculares entre 1650 y $1750^{103}$. La supremacía de los alumnos procedentes de parroquias rurales sobre los de villas y ciudades, además de incidir en esta idea, también confirma la hipótesis planteada conjuntamente por P.L. Gasalla y Pegerto Saavedra en relación con la llegada a las aulas compostelanas de alumnos cuyo origen social encontramos entre el campesinado acomodado.

\section{El Caso especial de los Colegiales: el ejemplo del Colegio de Fon- SECA O DE SANTIAGO EL MAYOR}

Al igual que sucedía con las grandes universidades castellanas, la de Santiago también contó con colegios en los cuales residían aquellos alumnos socialmente más aventajados que habían conseguido una beca en ellos, y de donde habrían de salir preparados para comenzar, en un futuro no muy lejano, su carrera de cargos en el ámbito eclesiástico o seglar ${ }^{104}$. Concretamente, la institución compostelana disponía de cinco colegios: el de Fonseca o Santiago el Mayor, fundado y dotado por el arzobispo don Alonso de Fonseca III en su testamento de $1534^{105}$; el de San Xerome, consolidado en 1555 tras las constituciones del Doctor Cuesta ${ }^{106}$; el de San Clemente de Pasantes, que habrá de comenzar su andadura en $1630^{107}$; el de San Salvador, ya desaparecido en 1681; y el de San Patricio de los Irlandeses, extinguido en 1767-70 ${ }^{108}$.

El hecho de que para acceder a estos centros fuese preciso elaborar informaciones de limpieza de sangre, fue decisivo para que, desde pronto, se configurasen como principales destinos para los vástagos de la nobleza provincial gallega más encumbrada que se hubiesen decantado por los estudios universitarios ${ }^{109}$.

\footnotetext{
${ }^{102}$ BURGo López, $M^{\text {a }}$.C.: «Lugo na Idade Moderna», p. 134.

103 Presedo Garazo, A.: Dueños y señores de casas, torres y pazos ..., pp. 195-197.

104 KAGAN, R.: Universidad y sociedad ..., p. 153.

105 Vid. nota 19 del presente trabajo.

${ }^{106}$ Rodríguez SuÁreZ, Ma ${ }^{\mathrm{a}}$.P.: As constitucións do Dr. Cuesta ..., pp. 119-127.

${ }_{107}$ GonZÁlezz García-Paz, S.: O Colexio de San Clemente de Pasantes de Compostela, Santiago, 1934 (reed. en Santiago, 1993), pp. 67-77.

108 Vid. dos visiones de conjunto sobre los colegios universitarios compostelanos durante la Época Moderna en BARREIRo FERNÁNDEZ, X.R.: Enseñanza, ilustración y política, pp. 164-175; y en Gasalla Regueiro, P.L. y SAAVEdRa Fernández, P.: «La Universidad en la primera mitad del siglo XVIII. Los grupos de poder», en X.R. Barreiro Fernández (coord.): Historia de la Universidad de Santiago ..., pp. 259-272.

${ }^{109}$ En el artículo I de las constituciones elaboradas por el Doctor Cuesta en 1555 para el Colegio de Fonseca, aparece especificado que los colegiales, procedentes de las cinco diócesis gallegas, "han de ser bombres ábiles y de buena vida y costumbres y sin nota de ynfamya» (cit. por RODRíGUEZ SUÁREZ, Ma.P.: As constitucións do Dr. Cuesta ..., p.89). Por su parte, el punto $6^{\circ}$ de las constituciones elaboradas por el Arcediano de Nendos para el Colegio de San Clemente en 1635 es incluso más precisa
} 
En este sentido, la proliferación de los estatutos de limpieza de sangre que se observa para el conjunto de los dominios de la Monarquía Hispánica a partir de 1550, para acceder a las distintas instituciones de poder y a los puestos de la administración — tanto eclesiástica como civil110_, explica, en buena medida, el que las becas de los colegios universitarios gallegos fuesen a parar a manos de las clases dominantes durante los siglos XVII y XVIII ${ }^{11}$. Tal es así, que muchos colegiales se valdrán de su estancia en el colegio para asegurar sus propios intereses futuros, por lo que no es de extrañar que incluso existan lazos de parentela entre algunos de ellos, coincidiendo con el panorama descrito por R. Kagan para los colegios mayores de las universidades castellanas a la altura de $1650^{112}$.

Es precisamente entre estos colegiales compostelanos donde nos vamos a encontrar a los alumnos de procedencia nobiliaria cuyas casas han acumulado un mayor caudal simbólico y económico en el contexto del reino. Algunos de ellos llegarán a promocionarse hasta alcanzar una canonjía en la importante Catedral de Santiago, otros accederán a prebendas eclesiásticas en las otras cuatro mitras gallegas, y también los hay que harán carrera a expensas de las distintas instancias de la administración civil. Ahora bien, del mismo modo que, tal como hemos comprobado, resulta verdaderamente exagerado pensar en el colectivo estudiantil de la universidad compostelana, durante estas dos centurias, como un grupo nutrido en

en este sentido: «Statuimos quod scholastici recipiendi in boc collegio sint ligitimi et ex legitimo matrimonio nati. Chistiani veteres sine ulla macula et infectione judaerum, maurorum, confessorum, lutheranorum seu ex alia nova vel veteri secta. Veteri conversi et quod omnes sui majores semper in tali possessione extiterunt, et de conversae nunquam fuerit fama seu aliqua suspictio, nec contra eam publico vel secreto dictum; et quod eorum parentes non babuerit offitium vile aut infame jure seu reputatione in loco suae originis. Nec fuerit traditores Coronae Regiae. Neque laqueo suspenssi, nec publice puniti ab officio Sanctae Inquisitionis, nec babet aliquo judice ecclesiastico seu seculari, ita quod sit subsecua juris infamia. De quo sit deponant duo testes omni exceptione majores, redentes causam et veram rationem suae testificationis nequaquam admitantur» (cit. por GONZÁlEZ GARCÍA-PAZ, S.: O Colexio de San Clemente ..., p. 296). En relación con la significación social que tuvieron dichos expedientes de limpieza de sangre en el contexto universitario gallego de entonces, vid. las consideraciones de BARREIRO FERNÁNDEZ, X.R: Enseñanza, ilustración y política, pp. 171-173; y GASALLA REGUEIRO, P.L. y SAAVEDRA FerNÁNDEZ, P.: «La Universidad en la primera mitad del siglo XVIII ...», pp. 259-261.

110 SICROFF, A.A.: Los estatutos de limpieza de sangre. Controversias entre los siglos XV y XVII, Madrid, 1985 (París, 1979), pp.356 y ss. Sin necesidad de salir de la propia ciudad de Santiago, los expedientes de información de limpieza de sangre también fueron precisos, a partir del siglo XVII en adelante, para trabajar de médico, cirujano e incluso boticario en el Hospital Real, tal como ha señalado RODRíGUEZ GONZÁLEZ, A.: «Información de limpieza de sangre y práctica de oficio de Médicos, Cirujanos y Boticarios del Hospital Real de Santiago de Compostela (siglos XVII-XIX)», en Boletín de la Universidad Compostelana (Santiago), 73-74 (1965-66), pp. 19-47. Vid. además HERNÁNDEZ FRANCO, J.: «Cultura y representación social en la España Moderna. Aproximación a través de las pruebas de limpieza de sangre de la orden hospitalaria de San Juan de Dios", en Stvdia Historica. Historia Moderna (Salamanca), 13 (1995), pp. 214-230.

111 Vid. para los casos granadino y salmantino, las investigaciones de BARRIOS AGUILERA, M.: «Graduación y limpieza de sangre en la Universidad de Granada, 1633-1788. Materiales para su estudio", en Chronica Nova (Granada), 13 (1982-83), p. 56; y CUART MOYER, B.: Colegiales mayores y limpieza de sangre durante la Edad Moderna, Salamanca, 1981, pp. 76-81.

112 KAGAN, R.: Universidad y sociedad ..., pp. 171-172. 
exclusividad por vástagos procedentes de casas hidalgas, también lo es, igualmente, imaginarse que lo fueron los colegiales en su totalidad. De hecho, los que pueden remontar su genealogía familiar hasta los linajes nobiliarios bajomedievales son una minoría. Más bien, los expedientes de limpieza de sangre parecen destacar a aquellos cuyos ascendientes en primer y segundo grado han adquirido recientemente el reconocimiento de hidalguía, o que han ejercido de repúblicos.

Antes de adentrarnos en los resultados de nuestra pesquisa, resulta preciso hacer hincapié en una serie de consideraciones metodológicas previas.

\section{TABLA 7. EVOLUCIÓN DEL NÚMERO DE INDIVIDUOS QUE CONSIGUIERON BECA} EN LOS COLEGIOS UNIVERSITARIOS DE FONSECA Y SAN CLEMENTE.

a. Colegio de Fonseca o de Santiago el Mayor, 1580-1800.

\begin{tabular}{|l|c|c|c|}
\hline \multirow{2}{*}{ PERÍODO } & \multirow{2}{*}{$\begin{array}{c}\text { TOTAL DE INDIVIDUOS } \\
\text { QUE CONSIGUIERON BECA }\end{array}$} & $\begin{array}{c}\text { COLEGIALES DE LOS QUE SE CONSERVA } \\
\text { INFORMACIÓN GENEALÓGICA }\end{array}$ \\
\cline { 3 - 4 } & & $\mathbf{n}^{\mathbf{0}}$ & $\%$ \\
\hline $1580-1600$ & 56 & 15 & 26,78 \\
\hline $1601-25$ & 68 & 31 & 45,58 \\
\hline $1626-50$ & 55 & 26 & 47,27 \\
\hline $1651-75$ & 62 & 31 & 50,00 \\
\hline $1676-1700$ & 53 & 33 & 62,26 \\
\hline $1701-25$ & 45 & 33 & 73,33 \\
\hline $1726-50$ & 28 & 17 & 60,71 \\
\hline $1751-75$ & 27 & 16 & 59,25 \\
\hline $1776-1800$ & 34 & 21 & 61,76 \\
\hline Total & 428 & $\mathbf{2 2 3}$ & 52,10 \\
\hline
\end{tabular}

Fuente: Elaboración propia a partir de Fraguas Fraguas, 1958.

b. Colegio de San Clemente, 1626-1807.

\begin{tabular}{|l|c|c|c|}
\hline \multirow{2}{*}{ PERÍDDO } & \multirow{2}{*}{$\begin{array}{c}\text { TOTAL DE INDIVIDUOS } \\
\text { QUE CONSIGUIERON BECA }\end{array}$} & $\begin{array}{c}\text { COLEGIALES DE LOS QUE SE CONSERVA } \\
\text { INFORMACIÓN GENEALÓGICA }\end{array}$ \\
\cline { 3 - 4 } & & $\mathbf{n}^{\mathbf{o}}$ & $\%$ \\
\hline $1626-50$ & 19 & 6 & 31,57 \\
\hline $1651-75$ & 25 & 11 & 44,00 \\
\hline $1676-1700$ & 33 & 8 & 24,24 \\
\hline $1701-25$ & 21 & 5 & 23,80 \\
\hline $1726-50$ & 15 & 4 & 26,66 \\
\hline $1751-75$ & 19 & 10 & 52,63 \\
\hline $1776-1807$ & 22 & 9 & 40,90 \\
\hline Total & 154 & 53 & 34,41 \\
\hline
\end{tabular}

Fuente: Elaboración propia a partir de González García-Paz, 1934. 
En la sección Pruebas de limpieza de sangre del Archivo Histórico Universitario compostelano, recatalogada en los últimos años ${ }^{113}$, no se conserva la totalidad de los expedientes promovidos por los distintos colegiales que consiguieron una beca en alguno de estos centros académicos elitistas. Pese a que se han ido añadiendo algunos expedientes no consultados en su día por P. Pérez Costanti $^{114}$, S. González García-Paz ${ }^{115}$ y A. Fraguas Fraguas ${ }^{116}$, las series de colegiales confeccionadas por estos dos últimos autores para San Clemente y Fonseca siguen superando a los informes incluidos en los fondos que han llegado hasta nosotros. En total, S. González García-Paz localizó 154 colegiales y 21 familiares para San Clemente durante el período 1629-1807117; y a su vez, A. Fraguas Fraguas 550 colegiales y 137 familiares entre 1521 y $1840^{118}$. Es decir, un total de 704 colegiales y 158 familiares para ambos colegios, distribuidos desigualmente desde la tercera década del siglo XVI hasta la primera mitad del XIX; una cantidad bastante superior a los expedientes de limpieza de sangre actualmente conservados, y que pese a ello, el propio Fraguas Fraguas ya consideró en 1958 que se trata de relaciones no completas, cuando menos para el Colegio de Fonseca ${ }^{119}$.

Partiendo de este presupuesto inicial que nos alerta sobre el riesgo que supone el que no se hayan conservado todos los expedientes de limpieza de sangre de los colegiales que pasaron por estos cinco colegios compostelanos, hemos centrado nuestro interés en el análisis pormenorizado de los datos elaborados por González García-Paz y Fraguas Fraguas, respectivamente, para San Clemente y Fonseca, aún a sabiendas de que no se trata de las relaciones completas, pero sí más próximas a las reales que las que se pueden obtener a partir del empleo exclusivo de los expedientes de limpieza de sangre.

Condicionados por el marco cronológico de nuestra pesquisa, es decir los siglos XVII y XVIII, hemos procedido a ajustar lo mejor posible los datos de que disponemos para Fonseca. En el caso de San Clemente, los 154 colegiales localizados pasaron por dicha institución entre 1629 y 1807, por lo que no ha sido preciso acometer una selección previa en este sentido. Pero en Fonseca, el abanico cronológico resulta mucho más amplio, por lo que hemos optado por limitar nuestra reflexión a los colegiales que pasaron por esta institución entre 1600 y 1800 . A lo sumo, hemos ampliado el momento de arranque en nuestras indagaciones hasta 1580, para verificar èl grado de información genealógica que presenta la relación de Fraguas y Fraguas - básicamente fundamentada

\footnotetext{
113 A.H.U.S., F.U., S.H., Pruebas de limpieza de sangre, legs. 202-209 y 365-373.

114 Pérez Costanti, P.: Linajes galicianos, pp. 135 y ss.

115 González García-Paz, S.: Opus cit.

116 Fraguas Fraguas, A.: Opus cit.

117 GONZÁlEZ GARCíA-PAZ, S.: Opus cit., pp.135-248 y 248-252 respectivamente.

118 FraGUAS Fraguas, A.: Opus cit., pp.198 y ss. y $459-472$ respectivamente.

119 Ibidem, p. 197.
} 
en la consulta de expedientes de limpieza de sangre ${ }^{120}$-, que, como veremos, es muy modesta para antes de 1600. En definitiva, sólo hemos tomado de base para acometer nuestros cálculos, los 428 colegiales que pasaron por Fonseca entre los años 1580 y 1800 , sobre un total de 550 , prescindiendo de los familiares ${ }^{121}$. Es decir, un nada desdeñable $77,81 \%$ de todos los individuos conocidos que accedieron a una beca en dicho centro universitario a lo largo de su dilatada existencia.

Las series confeccionadas para ambos colegios evidencian además un obstáculo metodológico de difícil solución: el número total de colegiales es mayor que la información de que disponemos referida a la procedencia social de todos y cada uno de ellos; por lo que mientras que no se proceda a elaborar un estudio genealógico exhaustivo de los mismos - por otro lado, una tarea que excede con creces el marco de la presente investigación-, no se podrán dar respuestas absolutas, sino más bien parciales a la cuestión que nos ocupa.

Este imponderable es todavía mayor si cabe en el caso concreto del Colegio de San Clemente (Tabla 7.b): tan sólo disponemos de información genealógica para un modestísimo $34,41 \%$ del total de colegiales detectados por González García-Paz, lo cual se traduce en unos resultados excesivamente parciales a la hora de valorar, en conjunto, su sociología. Incluso según el agrupamiento de los distintos individuos por períodos de 25 años, sólo hay tres momentos en los que éstos representan más del 40\%: 1651-75, 1751-75 y 1776-1807, y únicamente en el segundo de ellos se llega a superar el $50 \%$. Para corregir este déficit informativo sería preciso acometer un estudio más monográfico que éste, de ahí que nos hayamos decantado por el análisis exclusivo del Colegio de Fonseca, que ofrece, sin lugar a dudas, un óptimo informativo en relación con la ascendencia familiar de los colegiales.

En total, disponemos de información genealógica suficiente referida al $52,10 \%$ de los colegiales que consiguieron una beca en dicha institución entre 1580 y 1800 (Tabla 7.a); o lo que es lo mismo, para algo más de la mitad de los 428 individuos que han sido analizados. Conviene tener en cuenta, sin embargo, que el grado de información es considerablemente mayor a partir de 1650 en

\footnotetext{
120 Para ser más exactos, a partir de los 91 expedientes de colegiales ya extractados anteriormente por Pérez Costanti en el Boletín de la Real Academia Gallega entre 1915 y 1918, más los que añadió el propio Fraguas Fraguas en 1958, aunque es muy probable que hubiesen existido algunos más, tal como nos recuerda PARDo De Guevara Y VALDÉs, E.: «Introducción» a Pérez Costanti, P.: Opus cit., nota 14, p.XIV. Además de dichos expedientes, «Moitas papeletas complementáronse gracias ás referencias que posúe no seu Arquivo Xenealóxico de Galicia, e que xenerosamente nos facilitou, o ilustre investigador de Melide don Antonio Taboada Roca» (Vid. FraGUAS FraGUAS, A.: Opus cit., p. 197).

121 Hemos prescindido, pues, de 122 individuos: 81 entre 1521 y 1579, y 37 entre 1801 y 1840. Vid. un interesante y útil cuadro sobre la evolución del número de colegiales de Fonseca entre 1550 y 1799 en Gasalla Regueiro, P.L. y SAavedra Fernández, P.: «La Universidad en la primera mitad del siglo XVIII...», p. 261.
}

Hispania, LXIII/3, núm. 215 (2003) 907-968 
adelante, pues durante la primera mitad del siglo XVII; ésta se refiere al 46,34\% de los colegiales, y llega a ser incluso mucho menor en 1580-1600 (26,78\%).

\subsection{Procedencia geográfica}

El predominio de los colegiales procedentes del ámbito rural es una constante a lo largo de las dos centurias analizadas ${ }^{122}$. En este caso, hemos decidido prescindir de la localización por diócesis que hemos aplicado para el colectivo estudiantil de origen hidalgo, ya que en las constituciones del colegio aprobadas en 1555 se había estipulado un número exacto de plazas para las cinco provincias eclesiásticas gallegas. En todo caso, conviene precisar que a Santiago le correspondía un número ligeramente mayor de colegiales que a Mondoñedo, Lugo, Ourense y Tui; y que, a veces, una plaza vacante de cualquiera de estas cuatro podía ser ocupada por un candidato procedente de otra distinta, siempre y cuando no excediese de los tres colegiales ${ }^{123}$.

La supremacía de los colegiales nacidos en parroquias rurales se halla ratificada por el hecho de que tanto sus padres/madres como sus abuelos/as paternos/as y maternos/as repiten esta misma pauta de comportamiento, llegando incluso a superar, generacionalmente, el valor alcanzado por éstos (Tabla 8). Así, tomando de referencia las cifras totales para 1580-1800, si el 64,94\% de los colegiales de Fonseca proceden del entorno rural, sus padres aumentan en tres puntos dicho porcentaje hasta situarse en el $67,72 \%$, y sus abuelos en diez

${ }^{122} \mathrm{La}$ edad media de ingreso de los colegiales, que hemos calculado a partir de los casos que ofrecen información en este sentido, es de 22,86 años, por lo tanto comprendida entre las edades mínima -16- y máxima -25- fijadas por las constituciones de 1555 (vid. RODRíGUEZ SUÁREZ, $\mathrm{M}^{\mathrm{a}}$.P.: As constitucións do Dr. Cuesta ..., p.89). Los datos, desglosados según los períodos de 25 años que hemos tomado de referencia para efectuar nuestra base de datos, son los siguientes:

\begin{tabular}{|l|c|}
\hline PERÍODO & $\begin{array}{c}\text { EDAD MEDIA DE LOS COLEGIALES AL } \\
\text { INGRESAR EN FONSECA }\end{array}$ \\
\hline $1601-25$ & 21,25 \\
\hline $1626-50$ & 23,48 \\
\hline $1651-75$ & 24,30 \\
\hline $1676-1700$ & 20,78 \\
\hline $1701-25$ & 21,83 \\
\hline $1726-50$ & 23,07 \\
\hline $1751-75$ & 24,37 \\
\hline $1776-1800$ & 23,50 \\
\hline Total & 22,86 \\
\hline
\end{tabular}

${ }^{123}$ En total, debía haber once plazas de colegiales ocupadas del siguiente modo: 5 por individuos procedentes del arzobispado de Santiago, y 2 por cada una de las restantes diócesis (Mondoñedo, Lugo, Ourense y Tui). Vid. Rodríguez SuÁrez, $\mathrm{M}^{\mathrm{a}}$.P.: As constitucións do Dr. Cuesta ..., p. 89. 
-74,57\%-. Esta alta procedencia rural no sólo deja tras de sí, en un modesto segundo lugar, a los que residen en villas y ciudades, sino que sirve para confirmar una norma que responde a dos realidades complementarias: dentro de este predominio rural evidente e incuestionable, éste resulta mayor a medida que retrocedemos en el tiempo, tal como atestiguan los datos correspondientes a los/as abuelos/as, y tiende a disminuir en sentido inverso coincidiendo con los propios colegiales.

TABLA 8: PROCEDENCIA GEOGRÁFICA DE LOS COLEGIALES DE FONSECA Y SUS PARIENTES EN PRIMER Y SEGUNDO GRADO ASCENDENTE (SÓLO A PARTIR DE LOS CASOS LOCALIZADOS).

\begin{tabular}{|l|l|c|c|c|c|c|c|}
\hline \multirow{2}{*}{ PERÍODO } & \multirow{2}{*}{$\begin{array}{l}\text { PROCEDENCIA } \\
\text { GEOGRÁFICA }\end{array}$} & \multicolumn{2}{c|}{ COLEGIALES } & \multicolumn{2}{c|}{ PADRES/MADRES } & \multicolumn{2}{c|}{ ABUELOS/AS } \\
\cline { 3 - 8 } & & $\mathrm{n}^{\circ}$ & $\%$ & $\mathrm{n}^{\circ}$ & $\%$ & $\mathrm{n}^{\circ}$ & $\%$ \\
\hline \multirow{2}{*}{$1580-1700$} & parroquias rurales & 77 & 65,81 & 124 & 62,94 & 324 & 74,31 \\
\cline { 2 - 8 } & villas y ciudades & 40 & 34,18 & 73 & 37,05 & 112 & 25,68 \\
\hline \multirow{2}{*}{$1701-1800$} & parroquias rurales & 49 & 63,63 & 90 & 73,77 & 154 & 75,12 \\
\cline { 2 - 8 } & villas y ciudades & 28 & 36,36 & 32 & 26,22 & 51 & 24,87 \\
\hline \multirow{2}{*}{ Total } & parroquias rurales & 126 & 64,94 & 214 & 67,72 & 478 & 74,57 \\
\cline { 2 - 8 } & villas y ciudades & 68 & 35,05 & 102 & 32,27 & 163 & 25,42 \\
\hline
\end{tabular}

Fuente: Elaboración propia a partir de Fraguas Fraguas, 1958.

Pese al origen rural indiscutible de estas familias, muy relacionado con el tipo de ingresos ${ }^{124}$ y el característico modelo de reproducción social puesto en funcionamiento por los segmentos más destacados de la sociedad gallega de entonces $^{125}$, existe una vocación incipiente por parte de las sucesivas generaciones por ir tomando contacto progresivamente con el entorno urbano; un proceso ciertamente necesario para acceder a algunos de los puestos de mayor responsabilidad política en el contexto del antiguo reino.

El porcentaje de colegiales procedentes de villas y ciudades es, pues, mayor en el XVIII que en el siglo anterior. Del mismo modo, la diferencia que existe entre el porcentaje de colegiales urbanos y sus abuelos también urbanos durante el XVII es menor al que podemos observar para el XVIII: si en el primero es del orden de 8,5 puntos, en el segundo se ha incrementado en tres más hasta alcanzar los 11,5. La urbanización lenta, aunque progresiva, de las familias en las que se crían los colegiales de Fonseca es, consecuentemente, una evidencia palpable para estos dos siglos modernos.

124 VILlaRes PAZ, R.: La propiedad de la tierra ..., pp. 56 y ss.

125 Presedo Garazo, A.: Dueños y señores de casas, torres y pazos ..., pp. 263 y ss. 


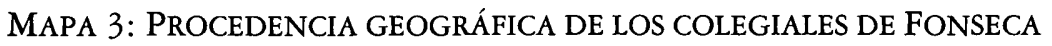

Y SUS PARIENTES EN PRIMER Y SEGUNDO GRADO EN 1580-1700, SEGÚN LAS ANTIGUAS PROVINCIAS.

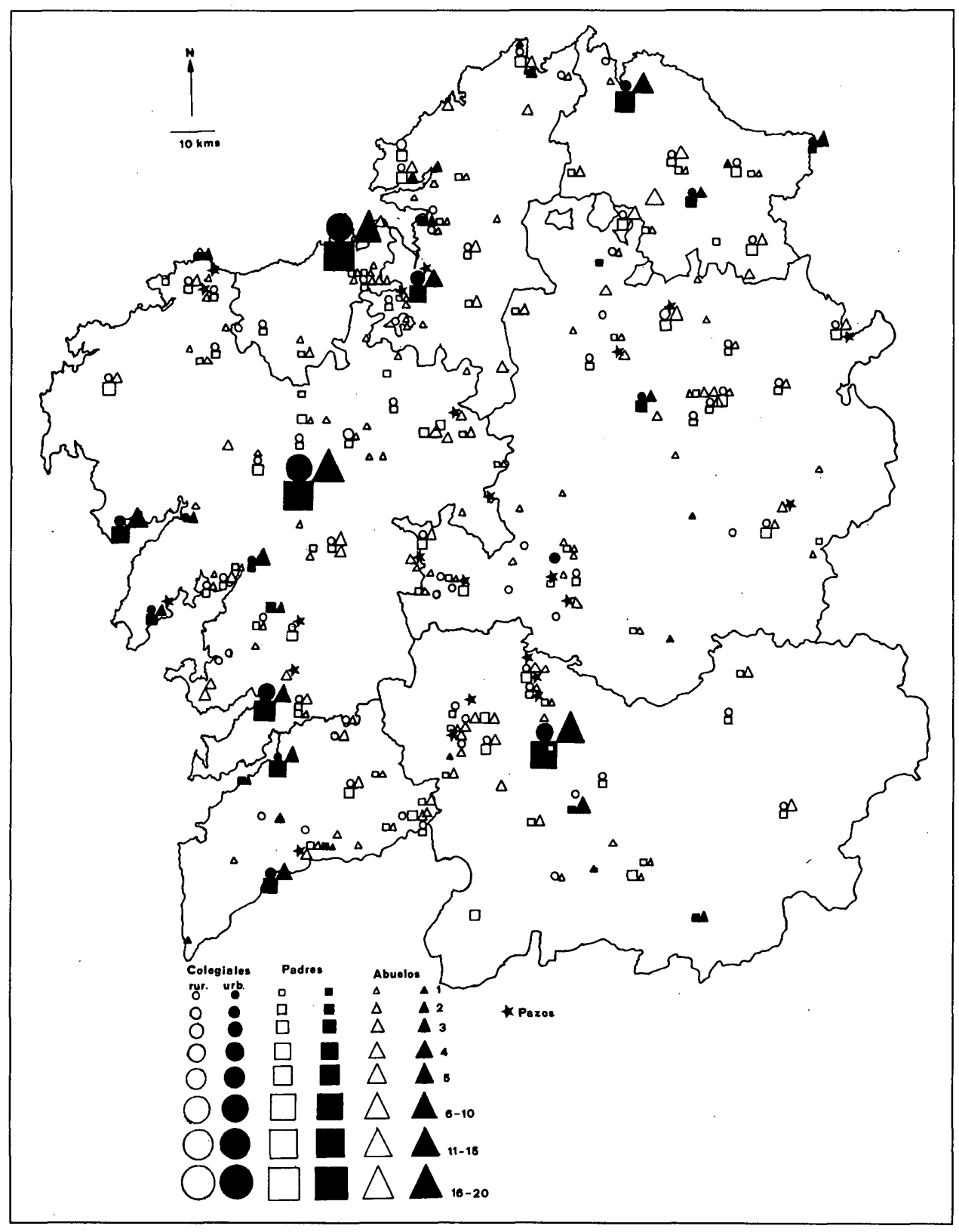

Hispania, LXIII/3, núm. 215 (2003) 907-968 
$\mathrm{Al}$ igual que sucede con los estudiantes de origen hidalgo a mediados del siglo XVII, en el caso concreto de los colegiales compostelanos también es posible verificar una destacada concentración de los mismos y su parentela en torno a algunos núcleos urbanos de la Galicia atlántica entre 1580 y 1700 (Mapa 3). En las capitales de provincia, esto es: Santiago, Coruña, Betanzos y, en menor medida, Tui, nos encontramos con las mayores concentraciones de colegiales y sus parientes de todo el reino, a las cuales debemos añadir, además, las villas de Muros, Pontevedra y Vigo. La progresiva burocratización que han experimentado tanto Santiago como Coruña, y asimismo el reclamo que siguen suponiendo el resto de núcleos urbanos a la hora de acceder a un oficio municipal, e incluso para construir una nueva residencia familiar en un entorno calificable de urbano, son dos argumentos a tener muy en cuenta a la hora de explicar esta tendencia.

El resto aparecen diseminados por buena parte del territorio comprendido por estas cuatro provincias occidentales, aunque es posible distinguir algunas zonas de máxima concentración que vienen a coincidir, en líneas generales, con lo ya señalado al referirnos al alumnado de origen hidalgo para 1647-55: la Mariña de Betanzos al norte, las jurisdicciones de Melide y Arzúa siguiendo el Camino francés, la Ría de Arousa hacia el sur, y el Val do Rosal en las proximidades con la frontera lusa, son las cuatro comarcas rurales occidentales en las que se detecta una mayor presencia de colegiales y sus parientes.

Por el contrario, la procedencia urbana en la Galicia interior y oriental es un hecho excepcional, y tan sólo merecen ser destacadas la capital orensana al sur y la villa mindoniense de Viveiro al norte. Las otras dos cabezas de provincia, es decir Lugo y Mondoñedo, apenas sí logran destacarse entre los abundantes núcleos de extracción rural. No exageraríamos, entonces, al afirmar que el origen mayoritario de los colegiales de Fonseca nacidos en esta área se halla localizado en parroquias rurales, lo cual nos pone sobre la pista de campesinos que gozan de cierto acomodo económico, profesionales que ejercen oficios jurisdiccionales, y toda suerte de hidalgos, todos ellos habitualmente emparentados entre sí a lo largo de sucesivos pactos matrimoniales.

De hecho, aparecen perfectamente destacadas tres áreas de concentración habitacional en las cuales se halla el principal número de casas grandes y pazos especificados en los expedientes de limpieza de sangre. En primer lugar, aparece en el extremo noroccidental de la antigua provincia luguesa un núcleo en torno a la comarca natural de la Terra Chá, que se desplaza en dirección sureste hasta alcanzar Castroverde. Hacia el sur, nos encontramos, en segundo lugar, en el extremo suroriental de Lugo con una concentración aún mayor que, comenzando en la comarca de Chantada, se extiende en dirección oeste para abarcar todo el Deza. Y en tercero, es preciso hacer mención al extremo noroccidental de la antigua provincia de Ourense, donde se halla, sin lugar a dudas, uno de los puntos de mayor concentración de pazos existentes en toda la geografía gallega, que discurre desde la jurisdicción de A Peroxa, ya limitando con Lugo, a través de las riberas del río Avia, hasta llegar a la provincia de Tui. 
Este panorama todavía sigue vigente durante el siglo XVIII, y sólo experimenta ligeras variaciones. En la Galicia occidental, la concentración urbana de los colegiales y su parentela en torno a las distintas capitales provinciales que vimos en la centuria precedente, se ha transformado ahora en una clara hegemonía por parte de la ciudad de Santiago y las cercanas villas de Padrón y Noia, relegando al resto de núcleos urbanos a un segundo y alejado puesto, agrupados en torno a la línea de costa. En cuanto a las comarcas rurales, las jurisdicciones de Arzúa y Melide cobran ahora un nuevo impulso. Algo similar sucede en la Galicia oriental. La ciudad de Ourense ha cedido el primer lugar que había ostentado durante el XVII en beneficio de Lugo, que aparece ahora como el principal núcleo urbano habitacional preferido por las familias de las que proceden los colegiales. El resto presenta un aspecto casi idéntico a lo que ya hemos visto: los principales puntos de procedencia se hallan en el ámbito rural, sobre todo en parroquias agrupadas en torno a las comarcas de Terra Chá-Lugo, Chantada-Deza, y Ribeiros del Miño y del Avia, si bien es cierto que con una concentración algo mayor.

\subsection{Perfil sociológico}

No todos los colegiales eran hijos de individuos que portaban el timbre «Don» (Tabla 9). En cifras absolutas, sólo un $42,60 \%$ de los 223 sujetos cotejados se hallan en esta tesitura. Es más, hasta 1650 lo habitual es que tanto el padre como la madre carezcan de dicho trato, y en caso de que lo haga alguno de los dos, lo más común es que sea la mujer y no el marido.

TABLA 9: PADRES/MADRES DE LOS COLEGIALES DE FONSECA QUE PORTAN «DON».

\begin{tabular}{|c|c|c|c|c|c|c|c|c|c|}
\hline \multirow[t]{2}{*}{ PERÍodo } & \multirow[t]{2}{*}{ COLEGIALES } & \multicolumn{2}{|c|}{$\begin{array}{l}\text { LOS } 2 \text { CÓNYUGES } \\
\text { PORTAN «DON» }\end{array}$} & \multicolumn{4}{|c|}{$\begin{array}{c}\text { SÓLO } 1 \text { CÓNYUGE PORTA } \\
\text { «DON» }\end{array}$} & \multicolumn{2}{|c|}{$\begin{array}{l}\text { NINGÚN CÓNYU- } \\
\text { GE PORTA «DON» }\end{array}$} \\
\hline & & $\mathrm{n}^{\circ}$ & $\%$ & p. & $\mathrm{m}$. & Total & $\%$ & $\mathrm{n}^{\circ}$ & $\%$ \\
\hline $1580-1600$ & 15 & 0 & 0,00 & 1 & 5 & 6 & 40,00 & 9 & 60,00 \\
\hline $1601-25$ & 31 & 4 & 12,90 & 0 & 2 & 2 & 6,45 & 25 & 80,64 \\
\hline $1626-50$ & 26 & 3 & 11,53 & 1 & 5 & 6 & 23,07 & 17 & 65,38 \\
\hline $1651-75$ & 31 & 8 & 25,80 & 1 & 8 & 9 & 29,03 & 14 & 45,16 \\
\hline $1676-1700$ & 33 & 13 & 39,39 & 0 & 12 & 12 & 36,36 & 13 & 39,39 \\
\hline $1701-25$ & 33 & 20 & 60,60 & 0 & 5 & 5 & 15,15 & 3 & 9,09 \\
\hline $1726-50$ & 17 & 15 & 88,23 & 1 & 1 & 2 & 11,76 & 0 & 0,00 \\
\hline $1751-75$ & 16 & 12 & 75,00 & 1 & 3 & 4 & 25,00 & 0 & 0,00 \\
\hline $1776-1800$ & 21 & 20 & 95,23 & 0 & 1 & 1 & 4,76 & 0 & 0,00 \\
\hline Total & 223 & 95 & 42,60 & 5 & 42 & 47 & 21,07 & 81 & 36,32 \\
\hline
\end{tabular}

Fuente: Elaboración propia a partir de Fraguas Fraguas, 1958. 
La abundancia de cónyuges femeninas que portan «Don» frente a sus homólogos masculinos es una pauta que, además de comprender todo el período, viene a incidir en el papel importante que han desempeñado las mujeres en las estrategias familiares de las casas hidalgas gallegas ${ }^{126}$. Tengamos en cuenta que la modalidad «sólo 1 cónyuge porta Don» es superior a la de «los 2 cónyuges portan Don» hasta 1675 , y que ambas opciones aún permanecen igualadas entre 1676 y 1700 . Así, durante todo el siglo XVII, e incluso desde 1580, entre los progenitores de los colegiales merecedores de dicho trato honorífico, era más frecuente que lo portasen las madres en lugar de los padres; por lo que si dicho timbre hubiese servido como indicativo de hidalguía, ésta se habría transmitido principalmente por vía femenina y no masculina. Una estrategia, por otro lado, bastante normalizada entre la nobleza provincial gallega cuando la casa está proyectando su consolidación patrimonial, y que permite una participación activa de ciertas mujeres en dicho proceso, tras adaptar la legislación sucesoria del mayorazgo a los intereses concretos que se le presentan ${ }^{127}$.

El último cuarto del siglo XVII marca un punto de inflexión. Hasta entonces, lo más habitual es que los dos progenitores no porten «Don», y que además las madres superen a los padres en caso positivo. En 1676-1700 se observa un claro equilibrio entre las tres variables que hemos establecido: un 39,39\% de los padres de los colegiales son merecedores de dicho trato, en un 36,36\% tan sólo la madre, y en un 39,39\% ninguno de los dos. Ahora bien, este equilibrio experimenta una ruptura brusca respecto a la realidad sociológica anterior a partir de 1701, muy relacionada con la endogamia social que triunfa a partir de entonces dentro de la propia institución. La modalidad «los 2 cónyuges portan Don» pasa a ser mayoritaria entre la ascendencia en primer grado de los colegiales, superando siempre el $60 \%$ del total, e irá en aumento a medida que nos aproximemos a las últimas décadas del siglo hasta alcanzar el $95 \%$. A partir de 1725 ya no habrá ningún colegial cuyos padres se puedan incluir en el sector «ningún cónyuge porta Don»; y asimismo, la modalidad «sólo 1 cónyuge porta Don» - en la cual las mujeres siempre superan a los varones- mostrará, progresivamente, valores con tendencia a la baja a medida que nos vayamos acercando a 1800 .

De todo ello es posible extraer tres conclusiones bien evidentes. En primer lugar, el timbre «Don» es aplicable a los progenitores de los colegiales de Fonseca socialmente más aventajados sin que ello tenga que ser sintomático, obligatoriamente, de pertenencia a una casa nobiliaria ${ }^{128}$. Tal es así, que hasta 1675 lo habitual es que los dos miembros de la pareja conyugal ni siquiera reciban dicho trato, incluso formando parte de la hidalguía. Además, resulta exagerado pensar que el $79,75 \%$ de los colegiales cuyos padres portaron «Don» entre 1701 y 1800

126 Presedo Garazo, A.: Os devanceiros dos pazos ..., pp. 66-68.

127 Presedo Garazo, A.: Dueños y señores de casas, torres y pazos ..., p. 313.

128 SANZ Y AYÁN, C.: art. cit.

Hispania, LXIII/3, núm. 215 (2003) 907-968 
hubiesen procedido exclusivamente del entorno hidalgo. Luego, el empleo de dicho timbre sólo nos está situando frente a individuos que gozan de una posición de evidente preeminencia social, bien sea por pertenecer al estamento noble, o bien por ejercer un oficio que conlleva prestigio social ${ }^{129}$.

En segundo lugar, la generalización del empleo del «Don» por parte de los progenitores a partir de 1676 nos está indicando que, procedan éstos o no del entorno nobiliario, su característico significado de exclusión social comienza a difuminarse a medida que recurren a su uso otros súbditos no necesariamente de origen hidalgo. La preponderancia de las mujeres sobre los varones en la modalidad «sólo 1 cónyuge porta Don» para toda la serie es una buena prueba de ello. En la medida en que los pactos matrimoniales sirven para consumar procesos de movilidad social ascendente, el casamiento con una mujer procedente de una casa hidalga, que además haya recibido una mejora vincular, puede servir para que los hijos de un letrado, de un miembro de la cúpula castrense, o incluso del propio entorno universitario, ennoblezcan su sangre ${ }^{130}$. Igualmente, esta proliferación de dicho timbre entre gentes no hidalgas a medida que avance el siglo XVIII también confirma la idea de que, en el seno de la sociedad tardofeudal gallega, los grupos socialmente emergentes imitan las prácticas y estrategias puestas en funcionamiento por los sectores sociales ya dominantes.

Y en tercer lugar, con el transcurso del tiempo se produce una evidente endogamia social por parte de las familias de los colegiales, que culmina en la centuria dieciochesca ${ }^{131}$. El hecho de que casi un $80 \%$ de los mismos porten dicho timbre en el XVIII, nos está indicando que tanto la nobleza provincial como el resto de los grupos dominantes, cuyo poder se apoya esencialmente en el servicio a la monarquía a través de la jurisprudencia y del ejército, han cerrado filas sobre sí mismos ${ }^{132}$. A partir de entonces, sólo ingresarán en el colegio de Fon-

129 Vid. en este sentido el Apéndice 3.1. De hecho, no nos encontramos ante una situación novedosa, pues tal como han ido demostrando ciertas investigaciones sobre la burguesía catalana y vasca, se produjo una aproximación continua por parte de esta clase social, y sobre todo por parte de la burguesía comercial y transportista, durante el Antiguo Régimen -aunque especialmente a lo largo del siglo XVIII-, hacia la elite nobiliaria local. Vid. una síntesis sobre dicho proceso en MOLAS RIBALTA, P.: La burguesía mercantil en la España del Antiguo Régimen, Madrid, 1985, pp. 156-161 y 226-230; y algunos casos monográficos en TORRAS I RuBÉ, J.M ${ }^{\mathrm{a}}$.: Evolució social d'una família catalá de l'Antic Règim. Els Padró d'Igualada (1642-1862), Barecelona, 1976, pp. 51 y ss.; BASURTO LARRAÑAGA, R.: Comercio y burguesía mercantil en Bilbao en la segunda mitad del siglo XVIII, Bilbao, 1983, pp. 233-263; y RoviRA GÓMEZ, S.-J.: La burguesía mercantil de Reus ennoblida durant el segle XVIII, Tarragona, 1994.

130 Proceso sobre el cual ha reflexionado, centrándose en el caso de la ciudad de Santiago, DuBERT GARCía, I.: Historia de la familia en Galicia durante la Época Moderna, 1550-1830, Sada, 1992, pp. $189-190$.

131 Tal como sucede un poco antes en los colegios mayores castellanos, para ser más exactos a la altura de 1650 . Vid. KAGAN, R.: Universidad y sociedad ..., pp. 168 y ss.

132 Vid. en este mismo sentido para el caso de Elche, BaldeQuí EsCANDELl, R. y PRADells NADAL, J.: «La familia de Don Leonardo Soler de Cornellá. Un linaje de caballeros en Elche durante el siglo XVIII", en Revista de Historia Moderna (Alicante), 11 (1992), p. 30. 
seca los vástagos procedentes de una serie de familias poderosas, en ocasiones emparentadas entre sí, cuyo objetivo fundamental consistirá en hacerse con el control de las principales instituciones de poder asentadas dentro de los límites del antiguo reino.

\section{TABLA 10: PADRES/MADRES DE LOS COLEGIALES DE FONSECA CUYA CONDICIÓN HIDALGA HA SIDO RECONOCIDA ${ }^{133}$.}

\begin{tabular}{|l|c|c|c|c|c|}
\hline PERÍODO & COLEGIALES & $\begin{array}{c}\text { LOS } 2 \text { CóNYUGES } \\
\text { PORTAN «DON» }\end{array}$ & $\begin{array}{c}\text { SÓLO } 1 \text { CÓNYUGE } \\
\text { PORTA «DON» }\end{array}$ & $\begin{array}{c}\text { NINGÚN } \\
\text { CÓNYUGE } \\
\text { PORTA «DON» }\end{array}$ & TOTAL \\
\hline $1580-1600$ & 15 & 0 & 2 & 1 & 3 \\
\hline $1601-25$ & 31 & 0 & 0 & 2 & 2 \\
\hline $1626-50$ & 26 & 1 & 1 & 6 & 8 \\
\hline $1651-75$ & 31 & 3 & 4 & 5 & 12 \\
\hline $1676-1700$ & 33 & 4 & 2 & 1 & 7 \\
\hline $1701-25$ & 33 & 8 & 2 & 0 & 10 \\
\hline $1726-50$ & 17 & 12 & 2 & 0 & 14 \\
\hline $1751-75$ & 16 & 7 & 3 & 0 & 10 \\
\hline $1776-1800$ & 21 & 9 & 1 & 0 & 10 \\
\hline Total & 223 & 44 & 17 & 15 & 76 \\
\hline
\end{tabular}

Fuente: Elaboración propia a partir de Fraguas Fraguas, 1958.

Sólo un 34,08\% de los padres de los colegiales de Fonseca forman parte de la nobleza provincial (Tabla 10). En caso de que añadamos, además, a este modesto porcentaje la totalidad de los progenitores que portan «Don», el valor experimenta un notable incremento incluso superior al doble -esto es, un $70,40 \%$ - . Dicho incremento no hace sino reforzar la hipótesis, reiteradamente señalada a lo largo de las páginas del presente trabajo, de que los resultados obtenidos exclusivamente a través del simple recuento de los individuos que portan dicho timbre, han de ser tomados con sumo cuidado ${ }^{134}$. Los diferentes

${ }^{133}$ Hacendados, hidalgos, señores y dueños de casas, pazos y torres, y emparentados con casas linajudas:

${ }^{134} \mathrm{Y}$ que, por tanto, resulta preciso acometer reconstrucciones genealógicas, que en el caso de los colegiales de Fonseca sí es posible, siguiendo la metodología de trabajo propuesta por M. Nassiet para el caso de la nobleza bretona, en la que el autor se ha decantado por representar en un mismo cuadro tanto la reproducción biológica como la reproducción social de una misma familia. Vid. NASSIET, M.: «Histoire sociale et methode lignagere. L'exemple de la petite noblesse de HauteBretagne, en Histoire, Economie et Societé (París), (1990), pp. 545-554.

Hispania, LXIII/3, núm. 215 (2003) 907-968 
testimonios incluidos en las pruebas de limpieza de sangre no dejan lugar a dudas: los progenitores que aparecen como hacendados, hidalgos, señores y dueños de casas, pazos y torres, o simplemente emparentados con casas linajudas, no son capaces de superar el $35 \%$ sobre el total de individuos que consiguieron una beca en el colegio entre 1580 y 1800.

Antes de 1625 , la modalidad «los 2 cónyuges portan Don» no cuenta con ningún caso representativo en la muestra, y aún en 1651-75 tan sólo incluye a 4 frente a los 21 que presentan las otras dos variables en conjunto. Todavía habrá que esperar hasta 1676 para que sea la opción mayoritaria, hasta 1701 para que desaparezca la variable "ningún cónyuge porta Don», y únicamente en el segundo cuarto del siglo XVIII, los padres de origen nobiliario llegan a representar el $82,35 \%$ del total.

TABLA 11: ABUELOS/AS DE LOS COLEGIALES DE FONSECA QUE PORTAN «DON»135.

\begin{tabular}{|c|c|c|c|c|c|c|c|c|c|c|}
\hline \multirow[t]{2}{*}{ PERÍODO } & \multirow{2}{*}{ COLEGIALES } & \multirow[t]{2}{*}{ ABUELOS } & \multicolumn{2}{|c|}{$\begin{array}{l}\text { LOS } 2 \text { CÓNYUGES } \\
\text { PORTAN «DON» }\end{array}$} & \multicolumn{4}{|c|}{$\begin{array}{l}\text { SÓLO } 1 \text { CÓNYUGE } \\
\text { PORTA «DON» }\end{array}$} & \multicolumn{2}{|c|}{$\begin{array}{l}\text { NINGÚN CÓNYUGE } \\
\text { PORTA «DON» }\end{array}$} \\
\hline & & & $\mathrm{n}^{\circ}$ & $\%$ & p. & $\mathrm{m}$. & Total & $\%$ & $\mathrm{n}^{\circ}$ & $\%$ \\
\hline \multirow{2}{*}{$\begin{array}{l}1580- \\
1600\end{array}$} & \multirow[t]{2}{*}{15} & Pat. & 3 & 20,00 & 0 & 2 & 2 & 13,33 & 9 & 60,00 \\
\hline & & Mat. & 2 & 13,33 & 1 & 1 & 2 & 13,33 & 10 & 66,00 \\
\hline \multirow{2}{*}{$\begin{array}{l}1601- \\
1625\end{array}$} & \multirow[t]{2}{*}{31} & Pat. & 2 & 6,45 & 0 & 1 & 1 & 3,22 & 25 & 80,64 \\
\hline & & Mat. & 2 & 6,45 & 0 & 44 & 4 & 12,90 & 22 & 70,96 \\
\hline \multirow{2}{*}{$\begin{array}{l}1626- \\
1650 \\
\end{array}$} & \multirow[t]{2}{*}{26} & Pat. & 1 & 3,84 & 1 & 2 & 3 & 11,53 & 20 & 76,92 \\
\hline & & Mat. & 1 & 3,84 & 1 & 3 & 4 & 15,83 & 16 & 61,63 \\
\hline \multirow{2}{*}{$\begin{array}{l}1651- \\
1675 \\
\end{array}$} & \multirow[t]{2}{*}{31} & Pat. & 3 & 9,67 & 1 & 6 & 7 & 22,58 & 16 & 51,61 \\
\hline & & Mat. & 5 & 16,12 & 0 & 44 & 4 & 12,90 & 13 & 41,93 \\
\hline \multirow{2}{*}{$\begin{array}{l}1676- \\
1700\end{array}$} & \multirow[t]{2}{*}{33} & Pat. & 6 & 18,18 & 0 & 7 & 7 & 21,21 & 15 & 45,45 \\
\hline & & Mat. & 4 & 12,12 & 0 & 9 & 9 & 27,27 & 14 & 42,42 \\
\hline \multirow{2}{*}{$\begin{array}{l}1701- \\
1725\end{array}$} & \multirow[t]{2}{*}{33} & Pat. & 19 & 57,57 & 3 & 3 & 6 & 18,18 & 7 & 21,21 \\
\hline & & Mat. & 20 & 60,60 & 2 & 6 & 8 & 24,24 & 2 & 6,06 \\
\hline \multirow{2}{*}{$\begin{array}{l}1726- \\
1750\end{array}$} & \multirow[t]{2}{*}{17} & Pat. & 15 & 88,23 & 0 & 1 & 1 & 5,88 & 1 & 5,88 \\
\hline & & Mat. & 15 & 88,23 & 0 & 1 & 1 & 5,88 & 1 & 5,88 \\
\hline \multirow{2}{*}{$\begin{array}{l}1751- \\
1775\end{array}$} & \multirow[t]{2}{*}{16} & Pat. & 13 & 81,25 & 0 & 1 & 1 & 6,25 & 1 & 6,25 \\
\hline & & Mat. & 13 & 81,25 & 0 & 3 & 3 & 18,75 & 0 & 0,00 \\
\hline \multirow{2}{*}{$\begin{array}{l}1776- \\
1800\end{array}$} & \multirow[t]{2}{*}{21} & Pat. & 20 & 95,23 & 0 & 0 & 0 & 0,00 & 0 & 0,00 \\
\hline & & Mat. & 16 & 76,19 & 0 & 0 & 0 & 0,00 & 0 & 0,00 \\
\hline \multirow[t]{2}{*}{ Total } & \multirow[t]{2}{*}{223} & Pat. & 82 & 36,77 & 5 & 23 & 28 & 12,55 & 94 & 42,15 \\
\hline & & Mat. & 78 & 34,97 & 4 & 31 & 35 & 15,69 & 78 & 34,97 \\
\hline
\end{tabular}

Fuente: Elaboración propia a partir de Fraguas Fraguas, 1958.

135 No se dispone de información para el $8,52 \%$ de los/as abuelos/as paternos/as, ni para el $18,38 \%$ de los/as maternos/as. 
En conclusión, los vástagos de la hidalguía oriunda no representan una mayoría a lo largo del período estudiado, pero conviven con otros colegiales cuyos padres tienen intereses e ideales socio-económicos en común. A fin de cuentas, tanto los unos como los otros están llamados a acceder a los cargos y puestos de mayor relevancia en la administración en cuestión de poco tiempo.

La información que ofrecen las pruebas de limpieza de sangre sobre la sociología de los/as abuelos/as de los colegiales confirma nuevamente lo que ya sabemos. Hasta 1650, tanto los/as paternos/as como los/as maternos/as que portan «Don» son minoritarios, independientemente de que se trate de los dos cónyuges o de uno solo (Tabla 11). A partir de entonces, los valores tienden a equilibrarse, para ser más exactos durante toda la segunda mitad del siglo XVII, si bien es cierto que en el caso de los/as abuelos/as maternos/as dicho equilibrio es más precoz que en el de los/as paternos/as; lo cual no hace sino incidir en la idea, ya señalada, de que es habitual que se premie a las mujeres con mejoras vinculares en momentos en los cuales las familias en vías de acceder a la hidalguía están acometiendo su consolidación y expansión patrimonial. En todo caso, el período de equilibrio entre las tres variables, que en el caso de los padres se sitúa en 1676-1700, se remonta ahora hasta 1650 para prolongarse hasta comienzos del XVIII. Será entonces, a lo largo de dicha centuria, cuando la modalidad «los 2 cónyuges portan Don» sea la imperante, desapareciendo la de «ningún cónyuge porta Don» a partir de 1751 para los/as abuelos/as maternos/as, y habiendo que esperar todavía hasta 1776 para el caso de los/as paternos/as.

A su vez, tan sólo un $26,45 \%$ de los/as abuelos/as paternos/as de los colegiales gozan de una condición hidalga reconocida; un porcentaje muy similar al que presentan sus homólogos maternos/as: un $25,11 \%$ sobre el total (Tabla 12). Estos han accedido a la hidalguía bastante antes que sus hijos, por lo que la modalidad «ningún cónyuge porta Don» ya ha desaparecido entre los/as maternos/as a la altura de 1676, 25 años antes de que lo haga en la siguiente generación biológica. En el caso de los paternos/as todavía será un poco más tarde: en torno a 1726. La opción de «sólo 1 cónyuge porta Don» también queda erradicada en ambos casos durante la segunda mitad del siglo XVIII: para los/as paternos/as a la altura de 1751, y para los/as maternos/as 25 años después.

En consecuencia, los colegiales de Fonseca que habían nacido y se habían criado en el seno de casas hidalgas no eran precisamente mayoritarios. Algunos de ellos, aún perteneciendo al entorno hidalgo, poseían ascendientes en primer y segundo grado que no aparecían en las pruebas de limpieza de sangre precedidos del timbre «Don»; es decir, pertenecían a familias que habían accedido al estamento noble en tiempos recientes ${ }^{136}$. Pero para todos ellos, sí parece que fueron de vital importancia los sucesivos pactos matrimoniales que habían ido diseñando

136 Vid. en relación con el ennoblecimiento de las elites urbanas y rurales en el reino de Valencia durante el siglo XVIII, Molas RibalTA, P.: «Títulos de hidalguía en el Setecientos valenciano», en VV.AA.: Hidalgos E Hidalguia dans l'Espagne des XVIe-XVIIIe siècles. Théories, pratiques et représentations, París, 1989, pp. 189-205.

Hispania, LXIII/3, núm. 215 (2003) 907-968 
tanto sus padres como sus abuelos, y que se concretizaron en casamientos sucesivos entre pequeños nobles locales y el emergente sector social de los letrados ${ }^{137}$. Esta política de reproducción social basada en alianzas endogámicas explica, por sí sola, el hecho de que a la altura de 1726 no hubiese ningún colegial cuyos padres no fuesen distinguidos con dicho trato, del mismo modo que sus abuelos/as, tanto paternos/as como maternos/as, a mediados del siglo XVIII ${ }^{138}$.

\section{TABLA 12. ABUELOS/AS DE LOS COLEGIALES DE FONSECA CUYA CONDICIÓN HIDALGA HA SIDO RECONOCIDA ${ }^{139}$.}

\begin{tabular}{|l|c|c|c|c|c|c|c|}
\hline \multirow{2}{*}{ PERÍODO } & \multirow{2}{*}{ COLEGIALES } & \multicolumn{2}{|c|}{ ABUELOS/AS PATERNOS/AS } & \multicolumn{3}{c|}{ ABUELOS/AS MATERNOS/AS } \\
\cline { 3 - 8 } & $\begin{array}{c}\text { Los 2 } \\
\text { cónyuges } \\
\text { portan } \\
\text { «Don» }\end{array}$ & $\begin{array}{c}\text { Sólo 1 } \\
\text { cónyuge } \\
\text { porta } \\
\text { «Don» }\end{array}$ & $\begin{array}{c}\text { Ningún } \\
\text { cónyuge } \\
\text { porta } \\
\text { «Don» }\end{array}$ & $\begin{array}{c}\text { Los 2 } \\
\text { cónyuges } \\
\text { portan } \\
\text { «Don» }\end{array}$ & $\begin{array}{c}\text { Sólo 1 } \\
\text { cónyuge } \\
\text { porta } \\
\text { «on» }\end{array}$ & $\begin{array}{c}\text { Ningún } \\
\text { cónyuge } \\
\text { porta } \\
\text { «Don» }\end{array}$ \\
\hline $1580-1600$ & 15 & 0 & 1 & 3 & 1 & 2 & 3 \\
\hline $1601-25$ & 31 & 0 & 1 & 1 & 0 & 0 & 2 \\
\hline $1626-50$ & 26 & 1 & 0 & 5 & 1 & 1 & 3 \\
\hline $1651-75$ & 31 & 1 & 1 & 3 & 1 & 0 & 3 \\
\hline $1676-1700$ & 33 & 0 & 0 & 3 & 2 & 1 & 0 \\
\hline $1701-25$ & 33 & 6 & 3 & 1 & 5 & 4 & 0 \\
\hline $1726-50$ & 17 & 12 & 1 & 0 & 10 & 1 & 0 \\
\hline $1751-75$ & 16 & 8 & 0 & 0 & 7 & 2 & 0 \\
\hline $1776-1800$ & 21 & 8 & 0 & 0 & 7 & 0 & 0 \\
\hline Total & 223 & 36 & 7 & 16 & 34 & 11 & 11 \\
\hline
\end{tabular}

Fuente: Elaboración propia a partir de Fraguas Fraguas, 1958.

El disponer de un origen social idóneo por formar parte de la nobleza provincial podía resultar decisivo, pero no imprescindible, para que un joven con-

137 Un rápido repaso al Apéndice 3, tanto en lo que respecta a los oficios y títulos localizados para los padres, como para los abuelos, permite disponer de una visión más concisa de esta cuestión.

138 Dinámica que incluso vemos repetirse en otras instituciones, como por ejemplo en aquellos concejos urbanos en los que fue preciso realizar una información de limpieza de sangre para acceder a un oficio municipal, pues tal como nos recuerda J. Hernández Franco para el caso de la ciudad de Murcia, entre 1752 y 1834 , «junto a aristócratas también superaron las pruebas aspirantes de raíces plebeyas y escasa trayectoria nobiliaria». Vid. HERNÁNDEZ FrANCO, J.: «Limpieza y nobleza en las ciudades de Castilla: pretensiones y consecución del estatuto por parte de Murcia (1560-1751)», en Revista de Historia Moderna (Alicante), 17 (1998-99), p. 262.

139 Hacendados, hidalgos, señores y dueños de casas, pazos y torres, y emparentados con casas linajudas.

Hispania, LXIII/3, núm. 215 (2003) 907-968 
siguiese una beca en el principal colegio universitario de la Universidad de Santiago, esto es, Fonseca. Allí dispondría de una buena oportunidad para conocer a otros compañeros, aunque no necesariamente hidalgos igual que él, con inquietudes e intereses en común, y con los que, incluso, podría empezar a tejer su particular red de influencias y amistades que finalmente habrían de revertir en beneficio de su casa de procedencia.

No es de extrañar, pues, que si un colegial había sido criado en el seno de una familia linajuda, este hecho fuese objeto de reiteración en su información de limpieza de sangre ${ }^{140}$. El expediente del colegial don Gonzalo Taboada, de Santa Baia de Losón (Diócesis de Lugo), redactado en 1604, mientras se está produciendo la incrustación de la hidalguía en el ámbito rural, puede servirnos de ejemplo ilustrativo:

«hes hijodalgo notorio por su padre e madre e abuelos, los quales an estado y estan en posesion de tales hijosdalgo notorios e como tales se les an guardado e guardan las hontras, franquezas e libertades que se guardan a los hijosdalgo, siendo libres e exentos de pechar e contribuir en los pechos e derramas en que pechan e contribuyen los pecheros e hombres de paga, aunque biben en feligresia donde ay pecho y por ser tales hijosdalgo no se les reparte ny'andan en derrama e repartimientos de los pechos e servicio real, ni otro alguno, y an sido y son libres y esentos dello por ser tales hijosdalgo notorios que an tenido e tienen sus armas y caballo y tratandose noblemente como tales hidalgos, e por tales an sido y son abidos e tenidos e reputados en la tierra e partes donde an bibido y biben y entre las personas que los conoscian y conoscen» 141 .

El solar y el linaje de procedencia, materializados en la residencia principal de la familia, generalmente ubicada en el entorno rural, eran igualmente merecedores de comentario, tal como atestigua la información referida al colegial don Sancho Figueroa Andrade, de la ciudad de Coruña (Diócesis de Santiago), acometida en 1655:

«era una muy buena casa con quartos a todos lados que todos se correspondian, y no eran muy altos ni levantados del suelo, y a la mano izquierda de la entrada una capilla junto a ella una torre nueva de canteria, fuerte y alta, tenia un escudo y en el esmaltado las armas de dicha casa que son cinco hojas de higuera y en ella unas letras abaxo del escudo que decian desta manera: Esta antiquisima torre solar de los Figueroa se reedifico el año de mill y seiscientos y veinte y dos, siendo señor della Ares Pardo de Figueroa, caballero del Orden de Santiago»142.

\footnotetext{
140 CONTRERAS CONTRERAS, J.: «Linajes y cambio social: la manipulación de la memoria», en Historia Social (Valencia), 21 (1995), pp. 105-124.

141 A.H.U.S., F.U., S.H., Pruebas de limpieza de sangre, leg. 374.

142 A.H.U.S., F.U., S.H., Pruebas de limpieza de sangre, leg. 206. 
Y que podemos ver reflejado en otros expedientes, como por ejemplo en el de don Francisco de la Torre y Soutomaior, residente en la ciudad de Santiago, redactado en 1659:

«dicha casa es una torre no muy alta por se haber bajado de pocos años aca segun me dixeron, la qual estaba cincundada de una barbacana de que oy aun hay señales y que desizo el padre de dicho don Francisco, y en dicha torre por la parte de la trabesia sobre una puerta que dixeron servia de entrada para dicha torre en tiempo antiguo y que tenia las puertas levadizas, he visto un escudo en el cual estaba dibuxado un campo y en dicho campo, una hoz y habiendo preguntado a dicho señor de la casa que armas eran aquellas dixo que eran las armas de los Prados»143.

No en vano, nos hallamos ante tres de los principales linajes galaicos que se ramificaron en distintas casas durante los siglos modernos a partir de enlaces matrimoniales, con el objeto de ampliar su poder dentro de los límites geográficos comprendidos por el antiguo reino. Su presencia temprana en el colegio universitario de Fonseca no es sino resultado de la propia lógica por la que se rigen las clases dominantes durante la Época Moderna gallega, y que depende, en gran medida, del entorno social en que haya nacido y se haya criado un individuo:

«el apellido de Prado es de mucha estimacion y (...) en toda aquella sierra las personas que los tienen son habidos y tenidos por personas principales y por los mejores caballeros della y que la casa originaria de dicho apellido es la casa de Friol»144.

\section{CONCLUSIÓN}

Durante los siglos XVII y XVIII, la Universidad de Santiago de Compostela desempeñó un papel harto importante en la formación académica de ciertos vástagos de familias nobiliarias gallegas, cuyos principales intereses socioeconómicos y políticos se dilucidaron en el ámbito regional; y para los cuales, sus ascendientes habían previsto que se llegasen a integrar en la administración, ora civil, ora eclesiástica. Luego de la actividad constitucional promovida en el seno de esta institución universitaria entre 1555 y 1588, ésta permitió que aquellos súbditos que disponían de una riqueza superior a la de la media, al margen de su procedencia estamental, pudiesen tomar contacto con los conocimientos elementales de la cultura letrada y acceder a titulaciones universitarias (bachiller, licenciado y doctor), coincidiendo con un momento en el que, precisamente, se está produciendo una demanda creciente de titulados por parte de los diferentes organismos de poder que convergen en el ámbito local.

\footnotetext{
${ }_{143}$ A.H.U.S., F.U., S.H., Pruebas de limpieza de sangre, leg. 374.

144 Ibidem.
} 
Entre 1650 y 1750 , cuando se produjo la fase de mayor expansión de la actividad fundacional por parte de los diversos sectores sociales que acabarán por conferirle un perfil ciertamente heterogéneo a dicha nobleza provincial, fueron bastantes los jefes de casa que optaron por enviar a algunos de los miembros de su prole a las aulas compostelanas, generalmente aquellos varones segundogénitos que no se iban a integrar en la milicia ni contaban con una profunda vocación religiosa, con el ánimo de recolocarlos, en un futuro no muy lejano, al servicio de algún señor -independientemente de que éste fuese laico o eclesiástico-, de algún municipio, e incluso de alguna institución monárquica — como por ejemplo la Real Audiencia de Galicia-.

A mediados del Seiscientos (1647-55), coincidiendo con el momento en que se comienza a regularizar la operación de asiento de matrículas, el porcentaje de alumnos que aparecen precedidos por el timbre «Don» en los registros de estudiantes matriculados, apenas representaban un 33,00\%, esto es: un tercio del total estudiantil. Eso quiere decir que, aún teniendo en cuenta los problemas que se pueden plantear al considerar, automáticamente, a un individuo próximo a una posición estamental aventajada cuando éste es distinguido con dicho trato, sobre todo si únicamente reducimos nuestra reflexión a este elemento, obviando la información que se desprendería de una investigación genealógica intensa - no considerada en principio entre los objetivos del presente trabajo-, el colectivo de estudiantes hidalgos en las aulas universitarias compostelanas no habría sido mayoritario. Tanto el elevado coste de manutención, como los procesos de movilidad social ascendente que están protagonizando otros grupos aventajados en el seno de la sociedad gallega, no necesariamente de origen nobiliario (como por ejemplo individuos que detentan oficios liberales, e incluso titulados universitarios), pero que pretenden ennoblecer su sangre, sólo permite que acudan a Santiago, los vástagos de aquellas casas solariegas que disponen de suficientes ingresos económicos anuales como para permitirse la posibilidad de abonar desahogadamente los gastos que se derivan de su formación académica. Se trata, en consecuencia, de un grupo selectivo dentro del propio estamento de procedencia, y asimismo dentro del propio estudiantado.

La gran mayoría se han decantado por la carrera de Cánones, hasta un $83 \%$, y en menor medida por las Artes (12\%) y la Téología (5\%), pese a lo cual nunca llegan a superan el $42 \%$ del total de alumnos que cursan los estudios canónicos a lo largo del quinquenio comprendido entre 1650 y 1655 . Tal preferencia tiene su explicación, en primer lugar, en la oferta de prebendas eclesiásticas por parte de las cinco mitras catedralicias gallegas; en segundo, en la posibilidad de acceder a unos conocimientos generales del Derecho que les permitan ejercer un cargo relacionado con la jurisprudencia; y en tercero, simplemente para tomar contacto con la cultura letrada por motivos muy diversos. De hecho, el número de hidalgos matriculados en estas carreras no deja de disminuir a medida que avanzan los sucesivos cursos de la licenciatura, por lo que resulta lógico deducir que una parte de dicho contingente tan sólo hubiese previsto estudiar los primeros cursos. 
Proceden, principalmente, de las cuatro provincias occidentales (Betanzos, Coruña, Santiago y Tui): hasta un $40 \%$ del total; y más exactamente son de extracción urbana, al ser originarios de diversas ciudades y sobre todo villas que se extienden a lo largo de un eje longitudinal que, partiendo de los emplazamientos costeros en las rías de Pontedeume y Betanzos, se desplaza hacia el sur para comprender la ciudad de Santiago y los enclaves poblacionales de las Rías Baixas, hasta llegar a la frontera con Portugal. En dicho eje atlántico, le corresponde el primer puesto a la ciudad de Santiago, y el segundo a la de Coruña, lo cual se explica por el progresivo proceso de burocratización que han experimentado dichos núcleos a lo largo del siglo XVI. Por el contrario, el alumnado de origen hidalgo que procede de las provincias interiores (también un $40 \%$ de las diócesis de Lugo y Ourense en conjunto), tiende a concentrarse en el entorno rural - fundamentalmente en las comarcas vitivinícolas de los Ribeiros del Miño y del Avia, así como en la Jurisdicción de A Peroxa-, en buena medida debido a la fuerte penetración de la hidalguía en el ámbito rural, y tan sólo destacan como núcleos urbanos de procedencia estudiantil hidalga las dos capitales de Ourense (primer puesto en la Galicia interior) y Lugo (tercero), y la villa de Monforte (segundo).

Cien años más tarde (1751-54), el perfil de este estudiantado de origen hidalgo ha experimentado algunas transformaciones. En primer lugar, el hecho de que en los libros de registro de matrícula se asiente indistintamente a todos los alumnos que abonan el importe de la misma precedidos del timbre «Don", nos está poniendo sobre la pista de que ciertos roles sociales tradicionalmente aceptados en el contexto del reino gallego han experimentado una mutación considerable, que afecta decididamente a su contenido sociológico. Por su parte, el reducido porcentaje de los expedientes personales cotejados que ofrecen suficiente información genealógica (un 17,03\% entre 1741 y 1860), indica que, si bien es cierto que se sigue constatando una mayor presencia de estudiantes universitarios hidalgos en la Galicia occidental (provincias de Betanzos y Santiago), la provincia de Lugo ocupa el segundo puesto, justo después de Santiago; al mismo tiempo que aquellos que proceden de parroquias rurales superan a los que lo hacen del entorno urbano. En su mayoría (hasta un 98\%) son hijos de individuos que portan «Don", pero este hecho ya no se corresponde, en absoluto, con una evidente filiación hidalga; al contrario, tan sólo un $10 \%$ de los mismos pueden ser asimilados a la nobleza provincial, un $8 \%$ a individuos que desempeñan oficios liberales, y un mayoritario $82 \%$ comprende situaciones indeterminadas, posiblemente a medio camino entre ambos grupos. Es más, si nos remontamos hasta la generación de sus abuelos, tan sólo un $58 \%$ reciben dicho trato. A lo cual es preciso añadir que se han decantado por un igual hacia las Leyes y Cánones $(41,46 \%)$ como por las Artes $(43,45 \%)$.

Por lo tanto, a comienzos del siglo XIX, el origen hidalgo de los alumnos universitarios cuyos expedientes hemos supervisado ya se había diluido entre una amplia serie de realidades sociales indeterminadas, para las cuales el hecho 
de ser distinguido con el timbre «Don» ya no era indicativo, necesariamente, de pertenencia alguna a la hidalguía, aunque sí de amplia capacidad adquisitiva. Ahora bien, este proceso ya era manifiesto a mediados de la centuria dieciochesca, de ahí que todos los matriculados, sin necesidad de ser hidalgos, fuesen asentados finalmente en los libros de matrículas precedidos de dicha fórmula. A su vez, este proceso se halla íntimamente relacionado con el ascenso social de ciertos pecheros que consiguieron ennoblecerse en tiempos relativamente recientes; de ahí que a mediados del siglo XVII, los individuos asentados en el registro de matrícula precedidos del timbre «Don» todavía fuesen minoritarios.

Esta situación fue más acusada, aún si cabe, entre los colegiales universitarios compostelanos. A partir de los datos procedentes de los expedientes de limpieza de sangre del Colegio Mayor de Fonseca para el período 1580-1800, podemos concluir que no fue hasta 1676-1700 cuando la variable «los 2 cónyuges portan Don», entre los ascendientes en primer y segundo grado de los colegiales — padres/madres y abuelos/as partenos/as y maternos/as-, consiguió equilibrarse con las otras dos variables analizadas, si bien es cierto que este punto de inflexión fue más contundente en el caso de los/as abuelos/as. Sin embargo, el porcentaje de colegiales cuyos padres podemos considerar nobles en sentido estricto, a partir de la información que ofrecen los diversos expedientes, apenas llega a alcanzar el $35 \%$, disminuyendo hasta el $26,46 \%$ en el caso de los/as abuelos/as paternos/as y hasta el $25,11 \%$ en el caso de los/as maternos/as. Por ello, a pesar del aumento progresivo en la utilización del timbre «Don» entre los progenitores de los colegiales, hecho que será mayoritario a mediados del siglo XVIII, el porcentaje de los mismos que podemos considerar de origen nobiliario seguirá siendo minoritario hasta el segundo cuarto la centuria dieciochesca, cuando menos a tenor de la información subministrada por los expedientes de limpieza de sangre.

Los ascendientes de la mayor parte de estos individuos proceden -al igual que el conjunto estudiantil- de la Galicia occidental, y sobre todo de núcleos urbanos; mientras que aquellos que lo hacen de las áreas interior y oriental, acostumbran a hacerlo del entorno rural, en el que, además, es notoria la presencia de casas grandes hidalgas, y también de las capitales de provincia (principalmente Ourense entre 1580 y 1700 , y Lugo entre 1701 y 1800). A su vez, es frecuente que tanto sus padres como sus abuelos hayan ejercido algún oficio jurisdiccional antes de 1675, y algún cargo en la milicia entes de 1725 .

Por lo tanto, el período de formación que pasaron los colegiales de Fonseca en dicha institución, nacidos en el seno de una casa hidalga, generalmente de origen rural, fue decisivo para que dichos vástagos tomasen contacto con otros hijos de letrados, titulados universitarios y de cargos militares, que no procedían, al igual que ellos, del entorno sociocultural hidalgo. Pero está lo suficientemente claro que tanto unos como otros poseían intereses en común. De ahí que a lo largo del siglo XVIII, este colegio mayor haya experimentado un proceso de endogamia social selectiva, lo cual explica que se produzcan alianzas matrimo- 
niales entre familias cuyos vástagos habían accedido a una beca en dicha institución. A lo cual debemos añadir que a partir de 1726, tanto los padres como las madres de los colegiales poseen el tratamiento distinguido del «Don», sin que ello tenga que implicar obligatoriamente una filiación nobiliaria.

Ahora bien, entre 1726 y 1800 , el 62,96\% de los colegiales que pasaron por Fonseca sí procedieron de familias hidalgas; lo cual viene a confirmar que la ideología nobiliaria, y sobre todo, el vivir noblemente, sigue identificándose como un referente lo suficientemente significativo de éxito social en la Galicia del Antiguo Régimen, aún a pesar de la transformación que han experimentado los roles sociales tradicionalmente aceptados. 
APÉNDICE 1. EVOLUCIÓN DE LA MATRÍCULA DE LOS ESTUDIANTES DE ORIGEN HIDALGO EN LA UNIVERSIDAD DE SANTIAGO DE COMPOSTELA, POR CARRERAS Y CURSOS, EN 1647-55 (SEGÚN EL TOTAL DE MATRICULADOS QUE PORTAN «DON»).

\begin{tabular}{|c|c|c|c|c|c|}
\hline \multirow{2}{*}{$\begin{array}{c}\text { AÑO } \\
\text { ACADÉMICO }\end{array}$} & \multirow[t]{2}{*}{ CARRERA } & \multirow[t]{2}{*}{ CURSO } & \multirow{2}{*}{$\begin{array}{l}\text { ALUMNOS MATRICULADOS } \\
\text { QUE PORTAN «DON» }\end{array}$} & \multicolumn{2}{|c|}{$\begin{array}{l}\text { TOTAL POR AÑOS ACA- } \\
\text { DÉMICOS Y CARRERAS }\end{array}$} \\
\hline & & & & $\mathrm{n}^{\mathrm{o}}$ & $\%$ \\
\hline \multirow[t]{13}{*}{$1647-48$} & \multirow[t]{3}{*}{ Artes } & $1^{\circ}$ & 2 & & \\
\hline & & $2^{\circ}$ & 2 & & \\
\hline & & $3^{\circ}$ & 1 & 5 & 7,24 \\
\hline & \multirow[t]{4}{*}{ Teología } & $1^{\circ}$ & 2 & & \\
\hline & & $2^{\circ}$ & 1 & & \\
\hline & & $3^{\circ}$ & 0 & & \\
\hline & & $4^{\circ}$ & 0 & 3 & 4,34 \\
\hline & \multirow[t]{5}{*}{ Cánones } & $1^{\circ}$ & 13 & & \\
\hline & & $2^{\circ}$ & 22 & & \\
\hline & & $3^{\circ}$ & 12 & & \\
\hline & & $4^{\circ}$ & 8 & & \\
\hline & & $5^{\circ}$ & 5 & 60 & 86,95 \\
\hline & $\begin{array}{l}\text { No espe- } \\
\text { cificados }\end{array}$ & & 1 & 1 & 1,44 \\
\hline \multirow[t]{12}{*}{$1648-49$} & \multirow[t]{3}{*}{ Artes } & $1^{0}$ & 3 & & \\
\hline & & $2^{\circ}$ & 0 & & \\
\hline & & $3^{\circ}$ & 2 & 5 & 5,68 \\
\hline & \multirow[t]{4}{*}{ Teología } & $1^{\circ}$ & 1 & & \\
\hline & & $2^{\circ}$ & 0 & & \\
\hline & & $3^{\circ}$ & 0 & & \\
\hline & & $4^{0}$ & 1 & 2 & 2,27 \\
\hline & \multirow[t]{5}{*}{ Cánones } & $1^{\circ}$ & 24 & & \\
\hline & & $2^{\circ}$ & 16 & & \\
\hline & & $3^{\circ}$ & 20 & & \\
\hline & & $4^{\circ}$ & 10 & & \\
\hline & & $5^{\circ}$ & 10 & 80 & 90,90 \\
\hline \multirow[t]{9}{*}{$1649-50$} & \multirow[t]{3}{*}{ Artes } & $1^{\circ}$ & 8 & & \\
\hline & & $2^{\circ}$ & 1 & & \\
\hline & & $3^{\circ}$ & 0 & 9 & 10,34 \\
\hline & \multirow[t]{4}{*}{ Teología } & $1^{\circ}$ & 1 & & \\
\hline & & $2^{\circ}$ & 0 & & \\
\hline & & $3^{\circ}$ & 1 & & \\
\hline & & $4^{\circ}$ & 0 & 2 & 2,29 \\
\hline & \multirow[t]{2}{*}{ Cánones } & $1^{\circ}$ & 29 & & \\
\hline & & $2^{\circ}$ & 13 & & \\
\hline
\end{tabular}

Hispania, LXIII/3, núm. 215 (2003) 907-968 


\begin{tabular}{|c|c|c|c|c|c|}
\hline \multirow{2}{*}{$\begin{array}{c}\text { AÑo } \\
\text { ACADÉMICO }\end{array}$} & \multirow[t]{2}{*}{ CARRERA } & \multirow[t]{2}{*}{ CURSO } & \multirow{2}{*}{$\begin{array}{l}\text { ALUMNOS MATRICULADOS } \\
\text { QUE PORTAN «DON» }\end{array}$} & \multicolumn{2}{|c|}{$\begin{array}{l}\text { TOTAL POR AÑOS ACA- } \\
\text { DÉMICOS Y CARRERAS }\end{array}$} \\
\hline & & & & $\mathrm{n}^{\mathrm{o}}$ & $\%$ \\
\hline & & $3^{\circ}$ & 15 & . & \\
\hline & & $4^{\circ}$ & 8 & & \\
\hline & & $5^{\circ}$ & 7 & 72 & 87,75 \\
\hline & Medicina & $1^{\circ}$ & 1 & 1 & 1,14 \\
\hline & $\begin{array}{l}\text { No espe- } \\
\text { cificados }\end{array}$ & & 3 & 3 & 3,44 \\
\hline \multirow[t]{12}{*}{$1650-51$} & \multirow[t]{3}{*}{ Artes } & $1^{\circ}$ & 23 & & \\
\hline & & $2^{\circ}$ & 2 & & \\
\hline & & $3^{\circ}$ & 2 & 27 & 23,27 \\
\hline & \multirow[t]{4}{*}{ Teología } & $1^{\circ}$ & 2 & & \\
\hline & & $2^{\circ}$ & 1 & & \\
\hline & & $3^{\circ}$ & 2 & & \\
\hline & & $4^{\circ}$ & 1 & 6 & 5,17 \\
\hline & \multirow[t]{5}{*}{ Cánones } & $1^{\circ}$ & 22 & & \\
\hline & & $2^{\circ}$ & 21 & & \\
\hline & & $3^{\circ}$ & 12 & & \\
\hline & & $4^{\circ}$ & 16 & & \\
\hline & & $5^{\circ}$ & 12 & 83 & 71,55 \\
\hline \multirow[t]{12}{*}{$1651-52$} & \multirow[t]{3}{*}{ Artes } & $1^{\circ}$ & 10 & & \\
\hline & & $2^{\circ}$ & 10 & & \\
\hline & & $3^{\circ}$ & 4 & 24 & 19,83 \\
\hline & \multirow[t]{4}{*}{ Teología } & $1^{\circ}$ & 1 & & \\
\hline & & $2^{\circ}$ & 2 & & \\
\hline & & $3^{\circ}$ & 1 & & \\
\hline & & $4^{\circ}$ & 1 & 5 & 4,13 \\
\hline & \multirow[t]{5}{*}{ Cánones } & $1^{\circ}$ & 30 & & \\
\hline & & $2^{\circ}$ & 18 & & \\
\hline & & $3^{\circ}$ & 19 & & \\
\hline & & $4^{\circ}$ & 13 & & \\
\hline & & $5^{\circ}$ & 12 & 92 & 76,03 \\
\hline \multirow[t]{10}{*}{$1652-53$} & \multirow[t]{3}{*}{ Artes } & $1^{\circ}$ & 8 & & \\
\hline & & $2^{\circ}$ & 6 & & \\
\hline & & $3^{\circ}$ & 4 & 18 & 16,07 \\
\hline & \multirow[t]{4}{*}{ Teología } & $1^{\circ}$ & 2 & & \\
\hline & & $2^{\circ}$ & 0 & & \\
\hline & & $3^{\circ}$ & 2 & & \\
\hline & & $4^{\circ}$ & 1 & 5 & 4,46 \\
\hline & \multirow[t]{3}{*}{ Cánones } & $1^{\circ}$ & 24 & & \\
\hline & & $2^{\circ}$ & 26 & & \\
\hline & & $3^{\circ}$ & 16 & & \\
\hline
\end{tabular}




\begin{tabular}{|c|c|c|c|c|c|}
\hline \multirow{2}{*}{$\begin{array}{c}\text { AÑo } \\
\text { ACADÉMICO }\end{array}$} & \multirow[t]{2}{*}{ CARRERA } & \multirow[t]{2}{*}{ CuRso } & \multirow{2}{*}{$\begin{array}{l}\text { ALUMNOS MATRICULADOS } \\
\text { QUE PORTAN «DON» }\end{array}$} & \multicolumn{2}{|c|}{$\begin{array}{l}\text { TOTAL POR AÑOS ACA- } \\
\text { DÉMICOS Y CARRERAS }\end{array}$} \\
\hline & & & & $\mathrm{n}^{\circ}$ & $\%$ \\
\hline \multirow[t]{2}{*}{$1652-53$} & & $4^{\circ}$ & 13 & & \\
\hline & & $5^{\circ}$ & 10 & 89 & 79,46 \\
\hline \multirow[t]{12}{*}{$1653-54$} & \multirow[t]{3}{*}{ Artes } & $1^{\circ}$ & 7 & & \\
\hline & & $2^{\circ}$ & 5 & . & \\
\hline & & $3^{\circ}$ & 2 & 14 & 12,96 \\
\hline & \multirow[t]{4}{*}{ Teología } & $1^{\circ}$ & 1 & & \\
\hline & & $2^{\circ}$ & 1 & & \\
\hline & & $3^{\circ}$ & 1 & & \\
\hline & & $4^{\circ}$ & 2 & 5 & 4,62 \\
\hline & \multirow[t]{5}{*}{ Cánones } & $1^{\circ}$ & 22 & & \\
\hline & & $2^{\circ}$ & 19 & & \\
\hline & & $3^{\circ}$ & 23 & & \\
\hline & & $4^{\circ}$ & 14 & & \\
\hline & & $5^{\circ}$ & 11 & 89 & 82,42 \\
\hline \multirow[t]{12}{*}{$1654-55$} & \multirow[t]{3}{*}{ Artes } & $1^{\circ}$ & 10 & & \\
\hline & & $2^{\circ}$ & 3 & & \\
\hline & & $3^{\circ}$ & 3 & 16 & 15,09 \\
\hline & \multirow[t]{4}{*}{ Teología } & $1^{\circ}$ & 1 & & \\
\hline & & $2^{\circ}$ & 0 & & \\
\hline & & $3^{\circ}$ & 2 & & \\
\hline & & $4^{\circ}$ & 0 & 3 & 2,83 \\
\hline & \multirow[t]{5}{*}{ Cánones } & $1^{\circ}$ & 24 & & \\
\hline & & $2^{\circ}$ & 16 & & \\
\hline & & $3^{\circ}$ & 13 & & \\
\hline & & $4^{\circ}$ & 21 & & \\
\hline & & $5^{\circ}$ & 13 & 87 & 82,07 \\
\hline \multirow[t]{12}{*}{$1655-56$} & \multirow[t]{3}{*}{ Artes } & $1^{\circ}$ & 5 & & \\
\hline & & $2^{\circ}$ & 2 & & \\
\hline & & $3^{\circ}$ & 1 & 8 & 8,42 \\
\hline & \multirow[t]{4}{*}{ Teología } & $1^{\circ}$ & 2 & & \\
\hline & & $2^{\circ}$ & 1 & & \\
\hline & & $3^{\circ}$ & 0 & & \\
\hline & & $4^{\circ}$ & 0 & 3 & 3,15 \\
\hline & \multirow[t]{5}{*}{ Cánones } & $1^{\circ}$ & 24 & & \\
\hline & & $2^{\circ}$ & 21 & & \\
\hline & & $3^{\circ}$ & 19 & & \\
\hline & & $4^{\circ}$ & 6 & & \\
\hline & & $5^{\circ}$ & 10 & 80 & 84,21 \\
\hline
\end{tabular}

Fuente: Elaboración propia a partir de A.H.U.S., S.H., lib. A.229, Libro de matrículas de 1647-61.

Hispania, LXIII/3, núm. 215 (2003) 907-968 
APÉDICE 2. DATOS SOCIOLÓGICOS PROCEDENTES DE LOS 50 EXPEDIENTES REVISADOS PARA EL PERÍODO 1816-60.

2.1. Expedientes que incluyen copia de partida de bautismo.

\begin{tabular}{|c|c|c|}
\hline \multicolumn{3}{|c|}{$\begin{array}{l}\text { a. Fecha de nacimiento de los alumnos cuyos expedientes } \\
\text { incluyen copia de partida de bautismo: }\end{array}$} \\
\hline \multirow[t]{2}{*}{ DÉCADA } & \multicolumn{2}{|c|}{ ALUMNOS } \\
\hline & $\mathrm{n}^{\mathrm{o}}$ & $\%$ \\
\hline $1801-10$ & 5 & 10 \\
\hline $1811-20$ & 12 & 24 \\
\hline $1821-30$ & 10 & 20 \\
\hline $1831-41$ & 10 & 20 \\
\hline Total & 37 & 74 \\
\hline \multicolumn{3}{|c|}{$\begin{array}{l}\text { b. Primera referencia cronológica de los alumnos cuyos expedientes } \\
\text { no incluyen copia de partida de bautismo: }\end{array}$} \\
\hline \multirow[t]{2}{*}{ DÉCADA } & \multicolumn{2}{|c|}{ ALUMNOS } \\
\hline & $\mathrm{n}^{\circ}$ & $\%$ \\
\hline $1811-20$ & 3 & 6 \\
\hline $1821-30$ & 8 & 16 \\
\hline $1831-40$ & 2 & 4 \\
\hline Total & 13 & 26 \\
\hline
\end{tabular}

Fuente: Elaboración propia a partir de A.H.U.S., F.U., E.P., legs.1310 a 1312, 1329 a 1332, 1349 a $1352,1373,1374,1378$ a 1380,1408 a 1412 , y 1434 a 1441.

\subsection{Procedencia geográfica.}

\begin{tabular}{|l|c|}
\hline \multicolumn{2}{|c|}{ a. Según la provincia } \\
\hline Betanzos & 10 \\
\hline Coruña & 1 \\
\hline Lugo & 12 \\
\hline Mondoñedo & 2 \\
\hline Ourense & 6 \\
\hline Santiago & 15 \\
\hline Tui & 4 \\
\hline Total & 50 \\
\hline \multicolumn{2}{|c|}{ b. Según la diócesis } \\
\hline Lugo & 12 \\
\hline Mondoñedo & 3 \\
\hline
\end{tabular}

Hispania, LXIII/3, núm. 215 (2003) 907-968 


\begin{tabular}{|l|c|}
\hline Ourense & 6 \\
\hline Santiago & 25 \\
\hline Tui & 4 \\
\hline Total & 50 \\
\hline \multicolumn{1}{|c|}{ c. Según se trate de ámbito rural o urbano } \\
\hline Parroquias rurales & 24 \\
\hline Villas y ciudades & 26 \\
\hline Total & 50 \\
\hline
\end{tabular}

Fuente: Elaboración propia a partir de A.H.U.S., F.U., E.P., legs.1310 a 1312,1329 a 1332,1349 a $1352,1373,1374,1378$ a 1380,1408 a 1412 , y 1434 a 1441.

\subsection{Información sobre el origen social.}

\begin{tabular}{|l|c|c|}
\hline VARIABLES POSIBLES & $\mathrm{n}^{\circ}$ & $\%$ \\
\hline $\begin{array}{l}\text { a. Estudiantes que tienen otros hermanos cursando estudios } \\
\text { universitarios }\end{array}$ & 19 & 38 \\
\hline b. Estudiantes que ostentan un título nobiliario & 1 & 2 \\
\hline c. Sociología de los padres & $\mathrm{n}^{\circ}$ & $\%$ \\
\hline - Padre y madre que portan «Don» & 41 & 82 \\
\hline - Id. y además son dueños de casas y/o pazos & 4 & 8 \\
\hline - Id.y además el padre ejerce una profesión liberal & 4 & 8 \\
\hline - Sin información específica & 1 & 2 \\
\hline d. Sociología de los abuelos & $\mathbf{n}^{\circ}$ & $\%$ \\
\hline - Paternos y maternos que portan «Don» & 29 & 58 \\
\hline - Sólo paternos o sólo maternos que portan «Don» & 4 & 8 \\
\hline $\begin{array}{l}\text { - Paternos y/o maternos que hayan sido dueños de casas y/o pa- } \\
\text { zos }\end{array}$ & 1 & 2 \\
\hline $\begin{array}{l}\text { - Algún abuelo paterno y/o materno que, además de portar } \\
\text { «Don», haya ejercido una profesión liberal }\end{array}$ & 6 & 12 \\
\hline - Sin información específica & 10 & 20 \\
\hline
\end{tabular}

Fuente: Elaboración propia a partir de A.H.U.S., F.U., E.P., legs.1310 a 1312, 1329 a 1332, 1349 a $1352,1373,1374,1378$ a 1380,1408 a 1412, y 1434 a 1441. 


\section{APÉNDICE 3. OFICIOS Y TÍTULOS LOCALIZADOS DE LOS PADRES Y LOS ABUELOS DE LOS COLEGIALES DE FONSECA (1580-1800).}

\subsection{Oficios y títulos de los padres.}

\begin{tabular}{|c|c|c|c|c|c|c|c|c|c|}
\hline OFICIOS Y TÍTULOS & $\begin{array}{l}1598 \\
1600\end{array}$ & $\begin{array}{l}1601- \\
1625\end{array}$ & $\begin{array}{l}1626- \\
1650\end{array}$ & $\begin{array}{l}1651- \\
1675\end{array}$ & $\begin{array}{l}1676- \\
1700\end{array}$ & $\begin{array}{l}1701- \\
1725\end{array}$ & $\begin{array}{l}1726- \\
1750\end{array}$ & $\begin{array}{l}1751- \\
1775\end{array}$ & $\begin{array}{l}1776- \\
1800\end{array}$ \\
\hline & $\mathrm{n}^{\circ}$ & $\mathrm{n}^{\circ}$ & $\mathrm{n}^{0}$ & $n^{\circ}$ & $\mathrm{n}^{0}$ & $\mathrm{n}^{0}$ & $\mathrm{n}^{\circ}$ & $\mathrm{n}^{0}$ & $\mathrm{n}^{\mathrm{o}}$ \\
\hline $\begin{array}{l}\text { 1. Oficios jurisdiccio- } \\
\text { nales: } \\
\text { - merino, juez, alcalde }\end{array}$ & 2 & - & 2 & - & - & 5 & 1 & 2 & - \\
\hline - regidor & - & 1 & 3 & 3 & - & 4 & 2 & 3 & 1 \\
\hline - escribano & - & 2 & 4 & 1 & - & - & - & - & - \\
\hline $\begin{array}{l}\text { - oidor de la Real } \\
\text { Audiencia }\end{array}$ & - & - & - & - & - & - & - & 1 & - \\
\hline $\begin{array}{l}\text { 2. Títulos académicos: } \\
\text { bachiller, licenciado } \\
\text { y doctor }\end{array}$ & 2 & - & 2 & 2 & - & 1 & - & 1 & - \\
\hline $\begin{array}{l}\text { 3. Cargos en la milicia: } \\
\text { - maestro de campo }\end{array}$ & - & - & - & - & - & 1 & - & - & - \\
\hline - teniente & - & - & - & - & - & - & - & 1 & - \\
\hline - capitán & - & 1 & 2 & 4 & 3 & 2 & - & - & - \\
\hline $\begin{array}{l}\text { - oficial de la Real } \\
\text { Armada }\end{array}$ & - & - & - & - & - & - & - & - & 1 \\
\hline $\begin{array}{l}\text { 4. Oficios administra- } \\
\text { tivos: } \\
\text { - secretario }\end{array}$ & 1 & - & - & - & 1 & - & - & - & _ \\
\hline $\begin{array}{l}\text { 5. Cargos en el Santo } \\
\text { Oficio }\end{array}$ & - & - & 5 & 1 & 2 & 2 & - & - & 1 \\
\hline $\begin{array}{l}\text { 6. Otros casos: } \\
\text { - mercader }\end{array}$ & - & - & - & 1 & - & - & - & - & - \\
\hline - piloto & - & - & - & 1 & - & - & - & - & - \\
\hline - médico & - & - & - & - & 1 & - & - & - & - \\
\hline $\begin{array}{l}\text { 7. Sin ningún oficio ni } \\
\text { título específicos }\end{array}$ & 8 & 26 & 11 & 11 & 20 & 12 & 3 & 4. & 10 \\
\hline
\end{tabular}

Fuente: Elaboración propia a partir de Fraguas Fraguas, 1958. 
3.2. Oficios y títulos de los abuelos paternos (p.) y maternos (m.).

\begin{tabular}{|c|c|c|c|c|c|c|c|c|c|c|c|c|c|c|c|c|c|c|}
\hline \multirow[t]{3}{*}{$\begin{array}{l}\text { OFICIOS Y } \\
\text { TÍ́TULOS }\end{array}$} & \multicolumn{2}{|c|}{$\begin{array}{l}1598- \\
1600\end{array}$} & \multicolumn{2}{|c|}{$\begin{array}{l}1601- \\
1625\end{array}$} & \multicolumn{2}{|c|}{$\begin{array}{c}1626- \\
1650\end{array}$} & \multicolumn{2}{|c|}{$\begin{array}{l}1651- \\
1675\end{array}$} & \multicolumn{2}{|c|}{$\begin{array}{l}1676- \\
1700\end{array}$} & \multicolumn{2}{|c|}{$\begin{array}{l}1701- \\
1725\end{array}$} & \multicolumn{2}{|c|}{$\begin{array}{l}1726- \\
1750\end{array}$} & \multicolumn{2}{|c|}{$\begin{array}{l}1751- \\
1775\end{array}$} & \multicolumn{2}{|c|}{$\begin{array}{l}1776- \\
1800\end{array}$} \\
\hline & p. & $\mathrm{m}$. & p. & $\mathrm{m}$. & p. & $\mathrm{m}$. & p. & m. & p. & $\mathrm{m}$. & p. & m. & p. & $\mathrm{m}$. & p. & m. & p. & m. \\
\hline & $n^{\circ}$ & $n^{\circ}$ & $\mathrm{n}^{\circ}$ & $n^{\circ}$ & $\mathrm{n}^{\circ}$ & $n^{\circ}$ & $\mathrm{n}^{\circ}$ & $n^{\circ}$ & $\mathrm{n}^{\circ}$ & $\mathrm{n}^{\circ}$ & $\mathrm{n}^{\circ}$ & $\mathrm{n}^{\circ}$ & $n^{\circ}$ & $n^{\circ}$ & $\mathrm{n}^{\circ}$ & $\mathrm{n}^{\circ}$ & $n^{\circ}$ & $\mathrm{n}^{\circ}$ \\
\hline $\begin{array}{l}\text { 1. Oficios ju- } \\
\text { risdiccionales: } \\
\text { - merino, } \\
\text { juez, alcalde }\end{array}$ & 1 & 1 & 1 & 1 & - & _- & - & - & - & _- & 1 & 2 & _- & _- & _- & - & - & _- \\
\hline - regidor & - & - & - & 1 & 1 & 1 & 1 & 1 & - & - & 2 & 2 & 1 & - & - & - & - & 1 \\
\hline - escribano & - & 1 & - & 3 & 1 & 2 & 2 & 1 & - & - & - & - & - & - & - & 1 & - & - \\
\hline - procurador & - & - & - & - & - & - & - & - & - & - & 1 & - & - & - & - & - & - & - \\
\hline $\begin{array}{l}\text { 2. Títulos } \\
\text { académicos: } \\
\text { bachiller, } \\
\text { licenciado y } \\
\text { doctor }\end{array}$ & - & 1 & 1 & 2 & 3 & - & 3 & 2 & - & - & - & 1 & - & - & - & - & - & - \\
\hline $\begin{array}{l}\text { 3. Cargos en } \\
\text { la milicia: } \\
\text { - alférez }\end{array}$ & - & - & - & - & - & - & - & - & - & 1 & 1 & - & - & - & - & - & - & - \\
\hline - cabo & - & - & - & - & - & - & - & - & 1 & - & - & - & - & - & - & - & - & - \\
\hline - capitán & - & - & - & - & - & 3 & 1 & - & 2 & 1 & 2 & - & - & - & - & - & - & - \\
\hline $\begin{array}{l}\text { 4. Oficios } \\
\text { administrati- } \\
\text { vos: } \\
\text { - secretario }\end{array}$ & - & 1 & - & - & - & - & - & - & - & 1 & $\therefore$ & - & - & - & - & - & - & - \\
\hline $\begin{array}{l}\text { 5. Cargos en } \\
\text { el Santo Oficio }\end{array}$ & - & 1 & 1 & 2 & 3 & - & 3 & 2 & - & - & - & 1 & - & - & - & - & - & - \\
\hline $\begin{array}{l}\text { 6. Otros } \\
\text { casos: } \\
- \text { mercader }\end{array}$ & - & - & - & 1 & - & - & - & - & - & - & - & - & _- & - & _- & - & _- & _ \\
\hline - piloto & - & - & - & - & - & - & 1 & - & - & - & - & - & - & - & - & - & - & - \\
\hline $\begin{array}{l}\text { 7. Sin ningún } \\
\text { oficio ni título } \\
\text { especificados }\end{array}$ & 9 & 3 & 25 & 19 & 11 & 13 & 14 & 14 & 24 & 21 & 18 & 15 & 3 & 5 & 7 & 7 & 12 & 8 \\
\hline
\end{tabular}

Fuente: Elaboración propia a partir de Fraguas Fraguas, 1958. 